\title{
FORMAÇÃO DE PREÇOS DE AÇÚCAR E ÁLCOOL COMBUSTIVEL ANIDRO E HIDRATADO NO ESTADO DE SÃO PAULO
}

\author{
CINTHIA CABRAL DA COSTA \\ Engenheiro Agrônomo
}

Orientador: Profa Dra HELOÍSA LEE BURNQUIST

Dissertação apresentada à Escola
Superior de Agricultura "Luiz de
Queiroz", Universidade de São
Paulo, para obtenção do título de
Mestre em Ciências, Área de
Concentração: Economia Aplicada.

PIRACICABA

Estado de São Paulo - Brasil

Dezembro de 2000 
Dados Internacionais de Catalogação na Publicação (CIP)

DIVISĀO DE BIBLIOTECA E DOCUMENTAÇĀO - Campus "Luiz de Oueiroz"/USP

Costa, Cinthia Cabral da

Formaçāo de preços de açúcar e álcool combustivel anidro e hidratado no estado de São Paulo / Cinthia Cabral da Costa. - - Piracicaba, 2000.

$104 \mathrm{p}$.

Dissertaçāo (mestrado) - - Escola Superior de Agricultura Luiz de Queiroz, 2000.

Bibliografia.

1. Açúcar 2. Álcool hidratado 3. Álcool motor 4. Comercialização 5. Mercado 6. Pós-desregulamentaçāo 7. Preço I. Título

CDD $338.4 \$ 6641$ 


\section{ERRATA}

\begin{tabular}{|c|c|c|c|c|}
\hline Página & Parágrafo & Linha & Onde se lê & Que se leia \\
\hline 10 & 2 & 1 & $\begin{array}{l}\text {... do funcionamento do setor } \\
\text { sucroalcooleiro. }\end{array}$ & $\begin{array}{l}\text {... do funcionamento da comercialização } \\
\text { do setor sucroalcooleiro. }\end{array}$ \\
\hline 12 & 2 & 2 & ... que o mercado interno... & $\begin{array}{l}\text {... que a comercialização no mercado } \\
\text { interno... }\end{array}$ \\
\hline 14 & Figura 2.6 & legenda & $\begin{array}{l}\text { anidro (US\$/L) } \\
\text { hidratado (US } \$ / \mathrm{L})\end{array}$ & $\begin{array}{l}\text { anidro }\left(\mathrm{US} \$ / \mathrm{m}^{3}\right) \\
\text { hidratado }\left(\mathrm{US} \$ / \mathrm{m}^{3}\right)\end{array}$ \\
\hline 25 & 4 & 3 & ... o produtor é o mesmo. & $\begin{array}{l}\text {... o produtor é, predominantemente, } 0 \\
\text { mesmo. }\end{array}$ \\
\hline 49 & 1 & 1 & Na Tabela 4.4 foi... & $\begin{array}{l}\text { Nos resultados apresentados na Tabela } \\
4.4 \text { foi... }\end{array}$ \\
\hline
\end{tabular}

Dedico ao meu pai GERALDO, com toda

minha gratidão, amor e admiração, e também à minha mãe ANDRÉA e à GINA. Ao FREDERICO, ofereço com todo amor. 


\section{Agradecimentos especiais:}

À "todo mundo do céu" por sempre estarem comigo em toda minha vida. Aos meus pais e ao Frederico.

À Escola Superior de Agricultura "Luiz de Queiroz" e à CNPQ, pela oportunidade de realizar este curso.

À orientadora e amiga Heloísa Lee Burnquist, muito obrigada pelo incentivo e atenção nesse trabalho, pela orientação durante $\mathrm{o}$ mestrado $\mathrm{e}$ pelo respeito $\mathrm{e}$ compreensão comigo.

Ao Departamento de Economia, Administração e Sociologia, e à colaboração dos professores Geraldo Sant'ana de Camargo Barros, Miriam Rumenos Piedade Bacchi, Zilda Paes de Barros Mattos e José Vicente Caixeta Filho. À todos os meus professores deste curso de mestrado, pela minha formação.

À Maielli e Pedro pela paciência conosco e amizade, e a todos os demais funcionários do Depertamento de Economia e do CEPEA. Aos bibliotecários Ligiane, Luciane e Álvaro.

Ao Robson, Marta, Marcos, Margarido, Raquel Caruso e Magri, pelas conversas e ajudas na realização deste trabalho.

Aos professores da Universidade Federal de Viçosa por parte da minha formação, especialmente aos professores Danilo e Armando, pelo incentivo por este curso e ao professor Casali, pelos ensinamentos em pesquisa.

Às amigas Cristiane e Valeriana, pelas horas deliciosas de conversa e companhia em todos os momentos, inclusive de estudo. $\grave{A}$ todos os demais colegas do curso de Economia Aplicada, principalmente àqueles que se transformaram em amigos, pelo incentivo, solidariedade e convivência.

Aos demais amigos que continuam presentes, e todos os amigos conquistados durante o mestrado, que com certeza foram e são muito importantes. Ao Aderbal e demais amigos da Vila; à Maria Tereza e à Viviane, pela agradável convivência neste período. 
Página

LISTA DE FIGURAS V

LISTA DE TABELAS VI

RESUMO VIII

SUMMARY $\mathbf{X}$

1. INTRODUÇÃO 1

1.1 APRESENTAÇÃo 1

1.2 OBJetivos 4

2. REVISÃO BIBLIOGRÁFICA 5

2.1 O SETOR SUCROALCOOLEIRO NO ESTADO DE SÃo PAULO 5

2.1.1 Importância 5

2.1.2 Sistemas de comercialização

2.2 TRABALHOS EMPÍRICOS VOLTADOS PARA O SETOR SUCROALCOOLEIRO BRASILEIRO12

2.3 METODOLOGIAS UTILIZADAS EM ESTUDOS SIMILARES

3. METODOLOGIA 21

3.1 MODELOS ECONÔMICOS 21

3.1.1 Modelo de Gardner (1975) 22

3.1.2 Modelo de Heien (1980) 23

3.1.2 Modelo de Barros (1990) 23

3.2 MODELO ECONÔMICO PROPOSTO 24

3.2.1 Mercado de açúcar cristal e açúcar refinado 26

3.2.2 Mercado de álcool combustivel anidro 31

3.2.3 Mercado de álcool combustível hidratado 32 
3.3 MATERIAL E MÉTODO 33

3.3.1 Testes econométricos 34

3.3.1.1 Teste de estacionariedade 34

3.3.1.2 Teste de co-integração 37

3.3.1.3 Teste do sentido de causalidade 38

3.3.1.4 Modelo de correção de erro e co-integração 40

3.3.2 Fonte de dados 42

4. RESULTADOS E DISCUSSÃO 45

4.1 MERCADOS DE AÇÚCAR CRISTAL E DE AÇÚCAR REFINADO 47

4.1.1 Testes de raiz unitária 47

4.1.2 Testes de co-integração 52

4.1.3 Testes de causalidade de Granger 55

4.1.4 Equações de formação de preços com termo de correção de erro 59

4.2 MERCADo DE ÁlCOOL COMBUSTível ANIDRO 66

4.2.1 Testes de raiz unitária 66

4.2.2 Testes de co-integração 69

4.2.3 Testes de causalidade de Granger 71

4.2.4 Equações de formação de preços com termo de correção de erro 73

4.3 MeRCADo de ÁlCOOL HidRATAdo 76

4.3.1 Testes de raiz unitária 76

4.3.2 Testes de co-integração 79

4.3.3 Testes de causalidade de Granger 81

4.3.4 Equações de formação de preços com termo de correção de erro 83

5. CONCLUSÕES 86

\section{REFERÊNCIAS BIBLIOGRÁFICAS}

APÊNDICE 1 - ESTATÍSTICAS DO TESTE DE RAIZ UNITÁRIA E DE COINTEGRAÇÃO 96

APÊNDICE 2 - RESULTADOS DA ANÁLISE DE MULTICOLINEARIDADE 99 


\section{LISTA DE FIGURAS}

Página

Figura 2.1 Produção de aÇúcar no Estado de São Paulo e no Brasil, Safras $1989 / 1990$ A $1999 / 2000$

FIGURA 2.2 CONSUMO FINAL DE ENERGIA (\%) NO BRASIL, NOS ANOS DE 1970 E 1998 7

Figura 2.3 Produção de ÁlCoOl anidro no Estado de São PaUlo e no Brasil, SAFRAS 1991/1992 A 1999/2000

Figura 2.4 Produção de ÁlCOOl hidratado no Estado de São PaUlo e no Brasil, SAFRAS 1991/1992 A 1999/2000

FIGURA 2.5 ESQUEMA SIMPLIFICADO DA COMERCIALIZAÇ̃̃o DE AÇÚCAR E ÁLCOOL COMBUSTIVEL 10

FIGURA 2.6 PREÇOS AO NÍVEL DE PRODUTOR DE AÇÚCAR CRISTAL, ÁLCOOL ANIDRO E HIDRATADO PARA O PERÍODO NO QUAL SEUS PREÇOS ENCONTRAM-SE DESREGULAMENTADOS PELO GOVERNO

FIGURA 2.7 PREÇOS DE ATR PARA PRODUÇÃO DE AÇÚCAR CRISTAL, ÁlCOOL ANIDRO E HIDRATADO NO PERÍODO QUE SEUS PREÇOS ENCONTRAM-SE DESREGULAMENTADOS PELO GOVERNO 


\section{LISTA DE TABELAS}

Página

TABELA 4.1 - VARIÁVEIS UTILIZADAS NA PESQUISA ___ 46

TABELA 4.2 - TESTE DE ESTACIONARIEDADE EM MODELO COM CONSTANTE $(\alpha)$ E TENDÊNCIA $(\mathrm{T})$, ESTATÍSTICA $\tau_{\tau}$ 48

TABELA 4.3 - TESTE DE ESTACIONARIEDADE EM MODELO COM CONSTANTE $(\alpha)$, ESTATÍSTICA $\tau_{\mu}$ 49

TABELA 4.4 - TESTE DE ESTACIONARIEDADE EM MODELO SEM CONSTANTE E TENDÊNCIA, ESTATÍSTICA $\tau$ 50

TABELA 4.5 - TESTE DE RAIZ UNITÁRIA EM MODELO SEM CONSTANTE E TENDÊNCIA, ESTATÍSTICA $\tau$ 51

TABELA 4.6 - CORRELAÇÕES CRUZADAS ENTRE AS VARIÁVEIS UTILIZANDO 12 DEFASAGENS PARA AS VARIÁVEIS 56

TABELA 4.7 - RESUltado do TESTE DE CAUSALIDADE DE GRANGER COM TERMO DE CORREÇÃO DE ERRO, AO NÍVEL DE SIGNICÂNCIA DE 10\% 59

TABELA 4.8 - EsTIMATIVAS DE FORMAÇÃo DOS PREÇOS NOS NÍVEIS DE PRODUTOR, ATACADo E VAREJo do MERCAdo de AÇÚCAR CRISTAL No ESTAdo DE SÃo PaUlo de ACORDO COM UM SISTEMA DE EQUAÇÕES SIMULTÂNEAS; PERÍODO: ABRIL DE 1997 A MAIO DE 2000

TABELA 4.9 - ESTIMATIVAS DE FORMAÇÃO DOS PREÇOS NOS NÍVEIS DE PRODUTOR E VAREJO DO MERCADO DE AÇÚCAR REFINADO No EsTADO DE SÃo PAULO DE ACORdO COM UM SISTEMA DE EQUAÇÕES SIMULTÂNEAS; PERÍODO: ABRIL DE 1997 A MAIO DE 2000

TABELA 4.10 - TESTE DE ESTACIONARIEDADE EM MODELO COM CONSTANTE $(\alpha)$ E TENDÊNCIA $(\boldsymbol{T})$, ESTATÍSTICA $\tau_{\tau}$

TABELA 4.11 - TeSte DE ESTACIONARIEDAdE EM MODELo COM CONSTANTE $(\alpha)$, ESTATÍSTICA $\tau_{\mu}$ 
TABELA 4.12 - TESTE DE ESTACIONARIEDADE EM MODELO SEM CONSTANTE E TENDÊNCIA, ESTATÍSTICA $\tau$

TABELA 4.13 - TESTE DE RAIZ UNITÁRIA EM MODELO SEM CONSTANTE E TENDÊNCIA, ESTATÍSTICA $\tau$

TABELA 4.14 - CORRELAÇÕES CRUZADAS ENTRE AS VARIÁVEIS UTILIZANDO 7 DEFASAGENS PARA AS VARIÁVEIS

TABELA 4.15 - RESUltADO DO TESTE DE CAUSALIDADE DE GRANGER COM TERMO DE CORREÇÃO DE ERRO

TABELA 4.16 - ESTIMATIVAS DE FORMAÇÃO DOS PREÇOS NOS NÍVEIS DE PRODUTOR E VAREJO DO MERCADO DE ÁLCOOL ANIDRO NO ESTADO DE SÃo PAULO DE ACORDO COM UM SISTEMA DE EQUAÇÕES SIMULTÂNEAS; PERÍODO: MAIO DE 1998 A JULHO DE 2000

TABELA 4.17 - TESTE DE ESTACIONARIEDADE EM MODELO COM CONSTANTE $(\alpha)$ E TENDÊNCIA $(\boldsymbol{T})$, ESTATÍSTICA $\tau_{\tau}$ 77

TABELA 4.18 - TESTE DE ESTACIONARIEDADE EM MODELO COM CONSTANTE $(\alpha)$, ESTATÍSTICA $\tau_{\mu}$

TABELA 4.19 - TESTE DE ESTACIONARIEDADE EM MODELO SEM CONSTANTE E TENDÊNCIA, ESTATÍSTICA $\tau$

TABELA 4.20 - TESTE DE RAIZ UNITÁRIA EM MODELO' SEM CONSTANTE E TENDÊNCIA, ESTATÍSTICA $\tau$

TABELA 4.21 - CORRELAÇÕES CRUZADAS ENTRE AS VARIÁVEIS UTILIZANDO 4 DEFASAGENS PARA AS VARIÁVEIS

TABEla 4.22 - RESUltado Do TESTE DE CAUSAlIDADE DE GRANGER COM TERMO DE CORREÇÃO DE ERRO

TABELA 4.23 - ESTIMATIVAS DE FORMAÇÃO DOS PREÇOS NOS NÍVEIS DE PRODUTOR E VAREJo do MERCADo DE ÁlCOOL HIDRATADO NO ESTADO DE SÃo PAULO DE ACORDO COM UM SISTEMA DE EQUAÇÕES SIMULTÂNEAS; PERÍODO: FEVEREIRO DE 1999 A JULHO DE 2000 


\title{
FORMAÇÃO DE PREÇOS DE AÇÚCAR E ÁLCOOL COMBUSTÍVEL ANIDRO E
} HIDRATADO NO ESTADO DE SÃO PAULO

\author{
Autora: CINTHIA CABRAL DA COSTA \\ Orientadora: $\operatorname{Prof}^{\mathrm{a}} \operatorname{Dr}^{\mathrm{a}}$ HELOÍSA LEE BURNQUIST
}

\section{RESUMO}

Este trabalho analisou o comportamento dos preços dos principais produtos do setor sucroalcooleiro - açúcar, álcool anidro e hidratado - no mercado do Estado de São Paulo, compreendendo o período de pós-desregulamentação desses produtos.

Para isto foi estimado um modelo econômico que considera relações de desequilíbrio no curto prazo, de forma que os preços se ajustam por excesso de demanda nos níveis do produtor e atacado e, no varejo, por ajustamentos parciais do preço esperado.

A presente pesquisa apresenta, a princípio, uma análise das séries temporais utilizadas no estudo, com o uso de teste de raiz unitária de Dickey-Fuller, testes de cointegração de Engle e Granger e a estimação dos modelos propostos para a formação de preços, incorporando o termo correção de erro. Dessa forma, as estimativas obtidas se mostraram estáveis.

Os sinais das estimativas dos coeficientes referentes ao modelo proposto para os mercados dos produtos finais do setor sucroalcooleiro apresentaram-se, em sua maioria, de acordo com o esperado. O curto período dos dados utilizados para estudo e a ausência dos preços no atacado dos mercados de álcool combustível foram os principais problemas diagnosticados na estimativa do modelo econômico. Contrário ao previsto no modelo do mercado de açúcar cristal, observou-se sinal positivo da variável preço no varejo na formação do preço no atacado. 
Portanto, verificou-se que os níveis do produtor e do atacado determinam as alterações iniciais nos preços de açúcar e álcool combustível e, os preços no varejo sofrem ajustamentos parciais em relação àqueles níveis de mercado mais concentrados. Assim, a formação dos preços desses produtos pode ser expressa por relações de desequilíbrio no curto prazo. 


\title{
SUGAR AND FUEL HYDRATED AND ANHYDROUS ETHANOL PRICE \\ FORMATION PROCESS IN SÃO PAULO STATE
}

\author{
Author: CINTHIA CABRAL DA COSTA \\ Adviser: Prof ${ }^{\mathrm{a}} \mathrm{Dr}^{\mathrm{a}}$ HELOÍSA LEE BURNQUIST
}

\section{SUMMARY}

An analysis of the price behavior of the sugarcane sector's final products, such as sugar and fuel ethanol, was conducted in this work for São Paulo State, considering the post-market deregulation period.

For that purpose an economic model that considers short run disequilibrium relations was estimated. The model assumes that price adjust by excess demand ant producer and wholesale market levels and by partial adjustments to the expected price at the retail level.

The research first presents a time series analysis of the data time series used for the study employing Dickey-Fuller unit root tests, followed by an Engle and Granger cointegration text, and finally, an error-correction model was estimated. These assured the stability of the estimates obtained.

The estimated coefficients of the econometric model used to represent the price formation process in the sugarcane final products' markets presented the expected signs in most of the cases. The short period of available data series, due to the implementation of market deregulation relatively recent period together with the unavailable data for wholesale fuel ethanol were considered as major problems for the econometric estimation. Contrary to what was expected, however, in the crystal sugar market, a positive sign for the retail price estimated coefficient was obtained. 
The results indicated that in general, price changes are transmitted between the different market levels, starting at the producer and wholesale level in the sugar and fuel ethanol markets. In addition, retail prices present partial adjustment with respect to the most concentrated market levels. Therefore, short run disequilibrium relations seem to explain the price formation process for these products. 


\section{INTRODUÇÃO}

\subsection{Apresentação}

O presente estudo esteve voltado para identificação e análise do processo de formação de preços, através dos canais de comercialização, dos principais produtos finais do setor sucroalcooleiro - açúcar e álcool combustível anidro e hidratado - no âmbito do mercado do Estado de São Paulo. A análise compreendeu o período pósdesregulamentação desses mercados, a fim de verificar o comportamento do setor num contexto de livre mercado.

O estudo foi restrito ao mercado do Estado de São Paulo tanto do açúcar quanto do álcool combustível, tendo em vista que este estado é auto-suficiente com relação a esses produtos. Na realidade, São Paulo é responsável pelo maior volume de produção nacional, englobando cerca de $60 \%$ do total de açúcar e $70 \%$ do total de álcool combustível produzido pelo país na safra de 1999/00 (Burnquist, 1999). Considera-se plausível afirmar que São Paulo não importa esses produtos de outros estados, tendo em vista não apenas a dimensão da sua produção, como também os custos relativos a frete e incidência diferenciados de impostos indiretos, como o ICMS, cujas alíquotas são mais elevadas para negociações interestaduais, relativamente às incidentes sobre negociações intra-estaduais.

A forma como a relação entre os preços de produtos agroindustriais é estabelecida, nos diferentes níveis de comercialização, tem sido preocupação constante 
tanto de produtores quanto de agentes de comercialização no atacado e varejo. A maneira pela qual a transmissão de choques de preços se processa entre os diferentes níveis de mercado constitui-se em informação de extrema relevância não apenas para esses agentes do mercado, como também para os formuladores de política setorial.

Essa questão tem-se tornado particularmente relevante para o setor sucroalcooleiro, mediante a redução progressiva da ingerência governamental e o forte estímulo à gestão da comercialização dos produtos pelo setor privado, processo que se consolidou no final da década de 90 . Isso tem motivado o desenvolvimento de um número crescente de estudos voltados à análise do desempenho do setor e à identificação dos mecanismos que determinam o funcionamento desse mercado. Essas análises buscam prover informações úteis para que a reestruturação do mercado seja conduzida de forma eficiente.

Do ponto de vista conceitual, o preço em um mercado de produtos agroindustriais é indicador das intenções de compra e venda do produto, sendo transmitido por ocasião da realização do consumo, da produção, da formação e do carregamento de estoques do produto. A metodologia utilizada no presente trabalho permitiu caracterizar a dinâmica de formação dos preços, proporcionando informações importantes para caracterizar a forma de atuação dos agentes nos mercados.

Teoricamente, sabe-se que a estrutura de um mercado tem grande influência na determinação dos preços. Além disso, os preços estão sujeitos a choques de oferta e, ou, demanda nos diferentes níveis de mercado. Esses fatores determinam a forma e intensidade de transmissão de preços entre os diferentes níveis de mercado (Burnquist, 1986).

A identificação quanto à forma pela qual os preços são transmitidos, seja em termos de direção, seja em termos de intensidade entre os diferentes níveis de mercado, 
tem-se apresentado como informação fundamental, tanto para confirmar as pressuposições teóricas quanto à estrutura de um mercado, como também para captar a forma de resposta dos preços áos aspectos conjunturais de natureza diversa.

No que se refere ao aspecto da causalidade entre preços, a hipótese geral implícita na condução do presente trabalho é de que esta estaria predominantemente relacionada à estrutura do mercado, ao longo do período da análise. Assim, pressupõe-se uma relação causal do nível de mercado mais concentrado para o nível menos concentrado. Em muitos mercados agrícolas, o segmento produtivo é geralmente mais pulverizado e opera em condições de mercado relativamente mais competitivas do que os níveis de atacado e varejo. No entanto, uma hipótese a ser testada no presente estudo é que o mesmo não se aplica para o caso do setor sucroalcooleiro, sendo essa característica fundamental para determinar o sentido de causalidade dos preços.

Quanto ao açúcar, esta análise enfocou os mecanismos envolvidos na formação e transmissão dos preços entre os níveis do produtor, do atacado e do varejo de açúcar cristal. Além disso, são considerados o nível do produtor e do varejo de açúcar refinado. Com relação ao álcool, a análise considerou apenas os níveis de produção e varejo, em razão de restrições quanto à disponibilidade de uma série de dados relativa aos valores negociados entre as distribuidoras de combustível (segmento atacadista) e os postos de combustível (varejo).

O presente trabalho foi dividido em cinco tópicos. Neste primeiro, após uma apresentação, são descritos os objetivos do estudo. No segundo tópico, vêm uma revisão da caracterização do setor sucroalcooleiro paulista, destacando a importância do setor, assim como o sistema de comercialização vigente; uma revisão dos estudos relacionados ao setor sucroalcooleiro após a desregulamentação e de trabalhos enfocando o comportamento dos preços de açúcar e álcool; e, finalmente, uma revisão das metodologias adotadas para estudo desta natureza envolvendo outros produtos. A 
descrição da metodologia (referenciais teórico e empírico) encontra-se no terceiro tópico. No quarto tópico, apresentam-se os resultados do trabalho e a respectiva discussão. No quinto tópico, sintetizam-se as conclusões e sugestões.

\subsection{Objetivos}

O objetivo geral do presente trabalho foi analisar aspectos relativos ao processo de formação de preço de açúcar e álcool combustível anidro e hidratado no Estado de São Paulo, compreendendo o período de pós-desregulamentação.

Especificamente, procurou determinar o sentido de causalidade dos preços de açúcar e álcool entre os diferentes níveis de mercado. Procurou-se, então, avaliar o comportamento do setor de comercialização de açúcar e álcool, no tocante as pressuposições adotadas no modelo econômico teórico de formação desses preços. 


\section{REVISÃO BIBLIOGRÁFICA}

A revisão bibliográfica foi estruturada de forma a apresentar, primeiramente, um panorama do setor sucroalcooleiro, enfatizando-se a importância do Estado de São Paulo na produção desse setor, assim como o sistema de comercialização vigente. Numa segunda etapa, foram apresentados estudos recentes sobre o comportamento do setor sucroalcooleiro em face do processo de desregulamentação. Finalmente, numa terceira parte, foram citados modelos econômicos e, principalmente, procedimentos econométricos utilizados nos trabalhos revistos, cujos objetivos foram similares aos do presente estudo.

\subsection{0 setor sucroalcooleiro no Estado de São Paulo}

\subsubsection{Importância}

A relevância de estudar o funcionamento do setor sucroalcooleiro de São Paulo tem residido na representatividade do estado no tocante à produção, tanto no contexto do mercado doméstico como do mercado internacional. A produção de açúcar e álcool no Brasil torna o país auto-suficiente com relação a esses produtos.

No caso do açúcar, o Brasil vem-se destacando como o maior produtor e exportador mundial, sendo um dos países mais competitivos no mercado mundial. Tal competitividade não resulta da intervenção governamental, mas das condições de 
produção, organização e tecnologia do setor. A participação do Estado de São Paulo na produção nacional, desde meados da década de 20 , expandiu-se rapidamente, tendo assumido papel de destaque na produção nacional ${ }^{1}$ (Figura 2.1). Essa importância relativa como maior produtor de açúcar vem sendo mantida por várias décadas, com ressalva de que, ao longo das últimas safras, a produção de açúcar em São Paulo compreendeu um percentual pouco inferior a $60 \%$ do total nacional (Burnquist, 1999).

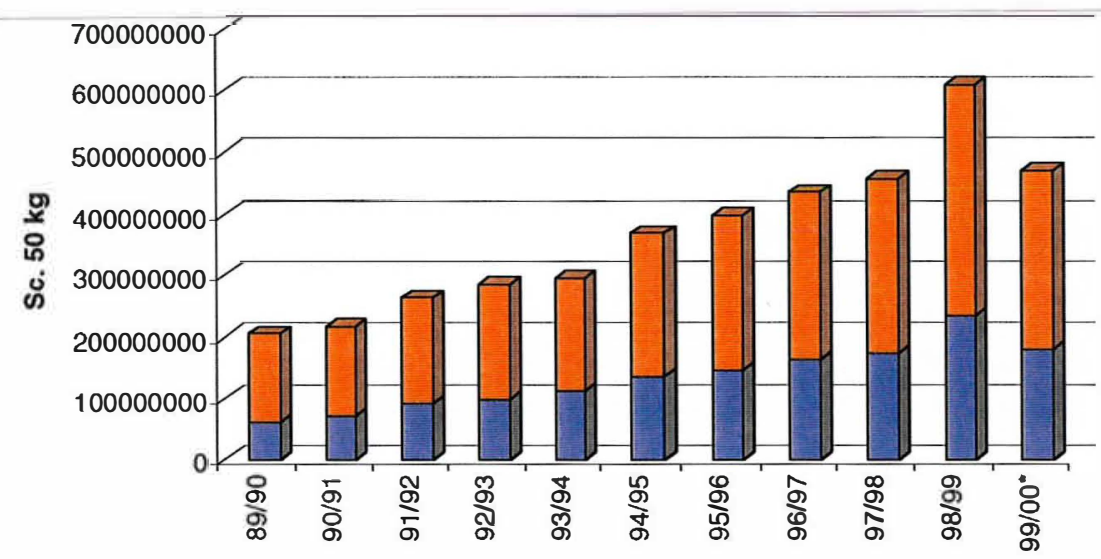

São Paulo $\square$ Brasil

Figura 2.1 Produção de aÇúCar no Estado de São Paulo e no Brasil, Safras 1989/1990 A 1999/2000

Fonte: FNP Consultoria, 2000.

Com relação ao consumo de açúcar cristal para consumo direto (venda no varejo), dado sobre o qual não foi possível identificar informações quanto ao volume exato absorvido pelo estado, considerou-se válido ilustrar a importância relativa do volume absorvido pelo mercado de São Paulo de forma indireta, utilizando-se uma estimativa do consumo anual "per capita" para o país e o tamanho da população do estado, segundo estimativa do Instituto (1996).

1 "Nessa época, o estado já era considerado um centro açucareiro, por manter o oligopsônio na comercialização do açúcar nordestino e o oligopólio na comercialização do açúcar refinado" Burnquist (1995), "O mercado de açúcar e a formação de preços" (mimeo). 
Segundo Carvalho (2000), estima-se que o consumo brasileiro "per capita" anual de açúcar é da ordem de 50,6 kg, com uma distribuição de cerca de $61,5 \%$ do volume consumido no país, sendo de uso direto. Essa estimativa resultaria em um volume consumido pelo estado de, aproximadamente, 1,6 milhão de toneladas, representando cerca de $45,7 \%$ do total produzido no estado, no ano de $1991^{2}$. Carvalho (2000) descreveu ainda que, do total de açúcar destinado ao consumo direto, $34 \%$ do consumo foi de açúcar refinado e $66 \%$, principalmente, do tipo cristal.

A produção de álcool, por sua vez, começou a ser incentivada em 1975, em face da crise do petróleo. Atualmente, o país é o maior produtor de etanol do mundo, tendo sido, em 1998, responsável por aproximadamente 58\% da produção mundial total, proporcionando certa independência energética. A importância do álcool como fonte de energia no Brasil é ilustrada na Figura 2.2.

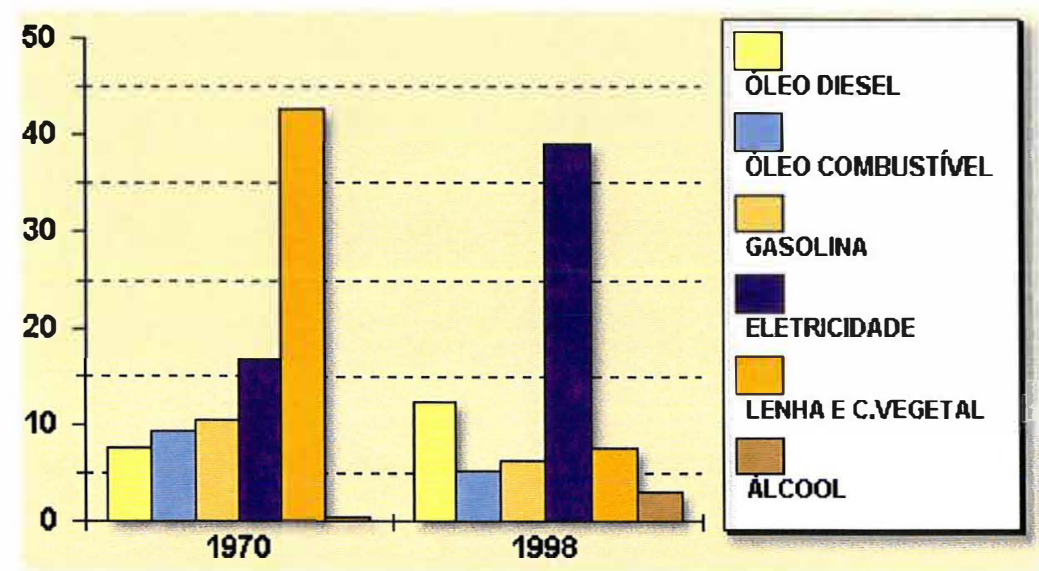

Figura 2.2 CONSUMO FINAL DE ENERGIA (\%) NO BRASIL, NOS ANOS DE 1970 E 1998 Fonte: Cooperativa, 2000.

\footnotetext{
${ }^{2}$ Foi estabelecido o ano de 1991, porque foi o último ano de censo demográfico realizado.
} 
Segundo a União da Agroindústria Canavieira do Estado de São Paulo UNICA (2000b), o setor sucroalcooleiro do Estado de São Paulo é responsável por 63\% (9,4 bilhões de litros) da produção nacional de álcool, totalizando 15,0 bilhões de litros. Nas Figuras 2.3 e 2.4, tem-se a evolução recente da produção de álcool anidro e hidratado, respectivamente, no Estado de São Paulo e no Brasil. Observa-se, nessas figuras, que o álcool anidro vem tendo produção crescente. Segundo Burnquist (1999), esse aumento pode ser associado, por um lado, a perspectivas de retomada de crescimento na economia brasileira e, por outro lado, ao estímulo proporcionado pelas medidas governamentais para aumentar o percentual de mistura de álcool na gasolina (primeiramente, de 22 para $24 \%$; e a divulgação, no mês de junho/99, de um possível incremento adicional para $26 \%$ ).

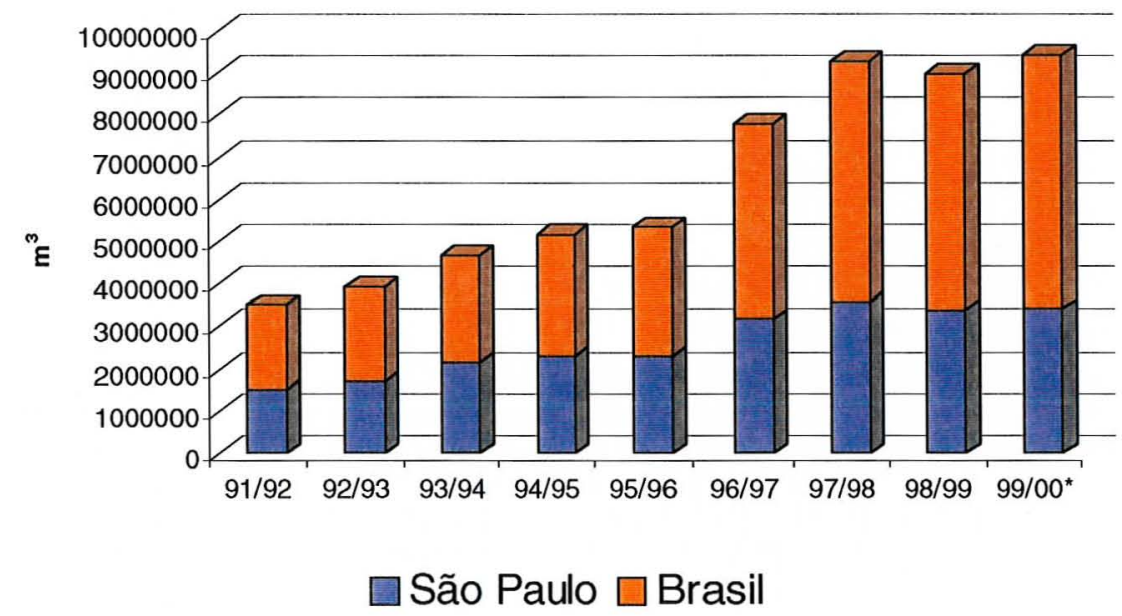

Figura 2.3 Produção de ÁlCoOl anidro no Estado de São PaUlo E no Brasil, SAFRAS 1991/1992 A 1999/2000

Fonte: FNP Consultoria, 2000. 


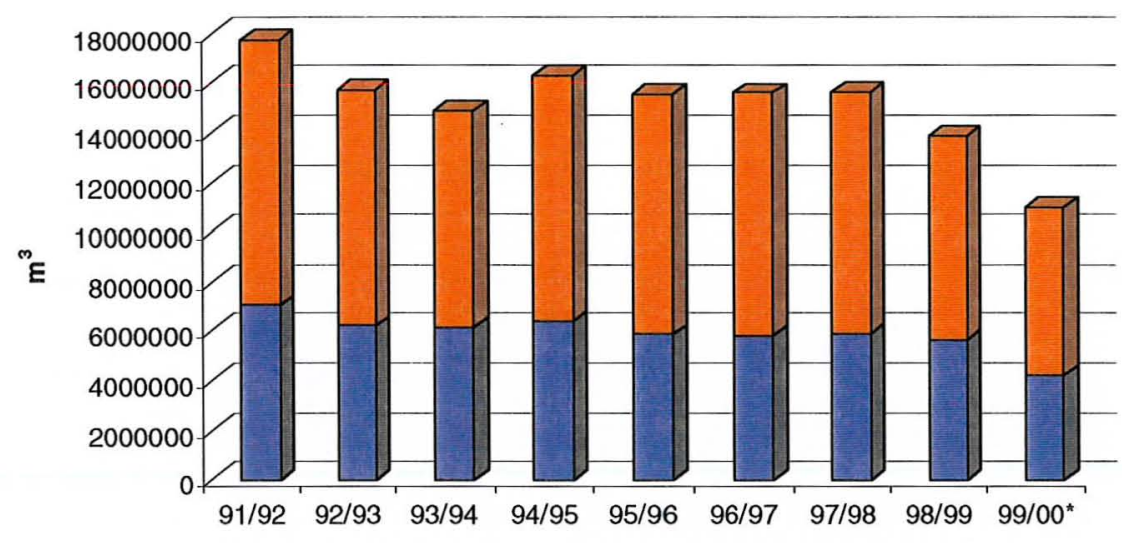

São Paulo $\square$ Brasil

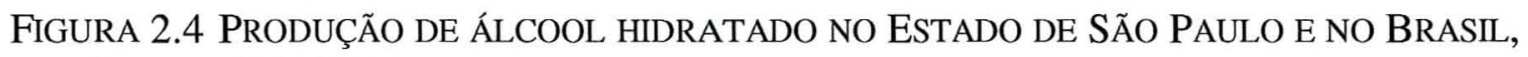
SAFRAS 1991/1992 A 1999/2000

Fonte: FNP Consultoria, 2000.

No que se refere ao consumo de álcool hidratado, apesar de a produção de veículos a álcool ter sofrido forte redução nos últimos anos, segundo a Associação Nacional dos Fabricantes de Veículos Automotivos (Anfavea), a produção de veículos a álcool passou de cerca de mil unidades em 1997 e 1998 para um número pouco superior a 11 mil unidades em 1999.

Tem-se ainda que 40\% (1,5 milhão de veículos) da frota de carro a álcool do país (3,8 milhões de veículos) circula em São Paulo, com um consumo de 61\% (5,6 bilhões de litros) da produção. O restante, que se constitui num volume de 3,8 bilhões de litros, é exportado para outros estados (União, 2000a).

\subsubsection{Sistemas de comercialização}

Nos sistemas de comercialização de açúcar e de álcool, a instituição que representa o nível do produtor (usinas e destilarias) é comum em ambos os mercados, 
uma vez que se têm usinas acompanhadas de destilaria anexa. No Estado de São Paulo há 135 unidades produtoras, das quais 34 comercializam em conjunto, através da associação em cooperativa (Copersucar). A comercialização do açúcar é feita em sacas de $50 \mathrm{~kg}$ e a do álcool, em volume, não existindo um padrão estabelecido quanto ao tamanho do lote. Os demais níveis de mercado têm sido distintos para o açúcar e para o álcool.

A seguir tem-se uma representação esquemática simplificada do funcionamento do setor sucroalcooleiro:

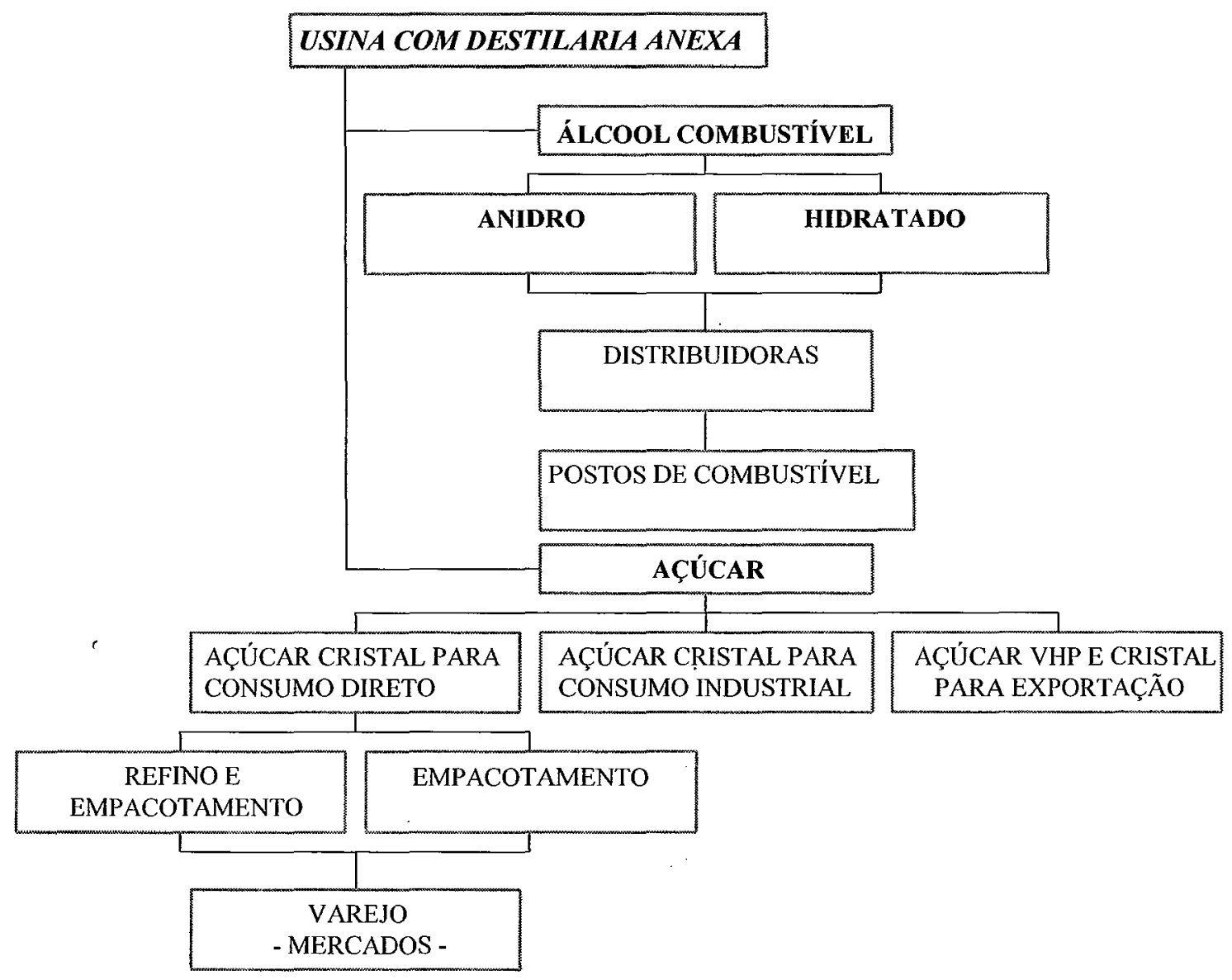

Figura 2.5 ESQUEMA SIMPLIFICADO DA COMERCIALIZAÇÃo DE AÇÚCAR E ÁlCOOL COMBUSTIVEL

Fonte: Elaboração do autor. 
Os agentes intermediários no sistema de comercialização do açúcar cristal, por limitação de dados disponíveis relativos a preços, estão restritos ao atacado na presente pesquisa, sendo esse nível o que realiza o serviço de empacotamento do açúcar em embalagens de $5 \mathrm{~kg}$ para a venda no varejo. Ao longo dos últimos anos, o papel desempenhado pelo segmento produtor tem se alterado, o qual vem absorvendo, progressivamente, as funções dos atacadistas. Existe dominância crescente de empresas/usinas integradas que não apenas produzem o açúcar, como também realizam os serviços de empacotamento. A forma pela qual as vendas têm sido comumente efetivadas, ou seja, na condição Posto-Veículo-Usina (PVU), torna os serviços de transporte e distribuição uma incumbência assumida pelo varejo.

No Estado de São Paulo, estima-se que o número de empacotadoras fica em pouco mais de 10 unidades, tendo como base o acompanhamento de mercado conduzido pelo Centro de Estudos Avançados em Economia Aplicada _ CEPEA/ESALQ/USP.

Com relação ao açúcar refinado, que é produzido a partir do açúcar cristal, temse um número aproximado de cinco refinadoras no Estado de São Paulo, segundo estimativas também formadas a partir do acompanhamento de mercado pelo CEPEA.

Ao contrário do atacado, o mercado varejista do açúcar cristal e do refinado é muito pulverizado, constituído de pequenos armazéns até hipermercados.

O mercado do álcool (anidro e hidratado) é estruturado de forma que o segmento produtor vende o combustível às distribuidoras, das quais seis se destacam: BR, Ipiranga, Shell, Texaco, Esso e Agip. Há ainda no estado diversas pequenas e médias distribuidoras, que, de acordo com dados da Agência Nacional de Petróleo ANP (2000) referente ao período de maio/98 a dezembro/99, atualmente são por volta de 150. Segundo Pinazza e Alimandro (2000), os distribuidores tendem a responder com preços de acordo com as condições imediatas de oferta e demanda do produto. $\mathrm{O}$ 
segmento de venda para o consumo final da produção são os postos de combustíveis, que compõem o segmento varejista nesse mercado, os quais podem ser contabilizados em torno de 10 mil unidades.

Como observação adicional sobre a comercialização nesses mercados, sabe-se que o mercado interno do açúcar (desde 1995) e, também do álcool anidro, a partir de abril de 2000, tem sido transacionado nos mercados de futuro e opções da Bolsa de Mercadorias e Futuros - BM\&F, refletindo as expectativas do mercado.

\subsection{Trabalhos empíricos voltados para o setor sucroalcooleiro brasileiro}

A intervenção estatal no mercado sucroalcooleiro deu-se de forma continuada desde a criação do IAA (Instituto do Açúcar e do Álcool) em 1933, que administrava todas as etapas das produções agrícola e industrial do setor, definia os volumes destinados aos mercados interno e externo e fixava preços da matéria-prima e dos produtos finais.

O setor sucroalcooleiro teve grande expansão com o desenvolvimento do programa de utilização do álcool como combustível alternativo da gasolina, iniciado em meados da década de 70. Entretanto, a intervenção do Estado também foi intensificada. Conforme citado por Lima e Sampaio (1997), muitos trabalhos têm analisado essa intervenção. Barros (1996), ao avaliar as políticas públicas anteriormente adotadas para o setor sucroalcooleiro, apontou algumas deficiências, como o controle de preços, utilizando o setor como parte das políticas antiinflacionárias do governo.

Analisando a evolução da agroindústria canavieira do Brasil de 1975 a 1995, Shikida e Bacha (1999) constataram grandes diferenças tecnológicas entre as duas 
regiões produtoras: Centro-Sul e Norte-Nordeste, e as justificaram pela subvenção do Estado através do subsídio.

Aparentemente, ineficiências associadas ao processo de intervenção promoveram a separação do Estado das atividades do setor, iniciando com a extinção do IAA em 1990. A partir de então, o setor buscou progressos tecnológicos, de forma a produzir eficientemente e concorrer num mercado não mais regulamentado. Trabalhos como os de Eid (1996), Eid et al. (1998), Rodrigues (1998), Vian et al. (1997) e Correia (1996), dentre outros, evidenciaram essa tendência do setor em aumentar a competitividade pela modernização do complexo tanto no nível tecnológico como no organizacional. Nas usinas e destilarias, a tendência de redução dos custos e aumento da competitividade tem sido por meio da utilização econômica dos subprodutos do processo de produção de açúcar e álcool, principalmente de bagaço de cana, e também da associação dos produtores em cooperativas. Alteraram-se também as relações contratuais da cadeia sucroalcooleira, conforme descrito por Moraes (1998), desenvolvendo um modelo de remuneração da cana-de-açúcar pela quantidade de Açúcar Total Recuperável (ATR).

Com a desregulamentação do setor, os preços dos produtos passaram a ser determinados de acordo com as regras de livre mercado. Segundo Bacchi e Maistro (1999), análises que possam identificar o comportamento desses preços podem auxiliar a tomada de decisão dos agentes desses mercados. Nesse sentido, essas autoras analisaram o preço do açúcar cristal em sacas de $50 \mathrm{~kg}$ e o cristal empacotado vendido no atacado no período de abril/97 a outubro/99. Observaram que o preço do açúcar cristal empacotado manteve-se, em média, 23\% acima do preço praticado na saca, apresentando comportamento sazonal muito semelhante entre eles. Acrescentaram ainda que, como o açúcar cristal empacotado tem representado só uma parte do total do açúcar cristal produzido, espera-se efeito causal mais forte do preço do açúcar cristal (saca de $50 \mathrm{~kg}$ ) para o preço do açúcar cristal empacotado do que o inverso. 
A formação do preço do açúcar no mercado doméstico foi estudado por Lima e Sampaio (1997), utilizando uma função de transferência de preços (modelo ARMAX), em que o preço doméstico foi relacionado à sua memória auto-regressiva e ao preço internacional do açúcar, compreendendo o período de 1980 a 1995. Esses autores concluíram que a formação dos preços domésticos do açúcar depende, principalmente, da memória auto-regressiva e que a transmissão de preços do mercado externo para o mercado doméstico não é significativa. Entretanto, ressalta-se que o estudo foi realizado com séries de preços relativas ao período em que prevaleceu o intervencionismo estatal.

Na Figura 2.6, observa-se a evolução dos preços do álcool, juntamente com a do açúcar para o produtor, praticados no Estado de São Paulo, tomando-se os períodos a partir da liberalização dos preços de cada um dos produtos. Os preços do açúcar deixaram de ser tabelados no mercado interno no início dos anos 90, com cotas de exportação liberadas a partir da safra 1997/98. O álcool anidro teve seus preços liberados em maio de 1998 e os de álcool hidratado, em janeiro de 1999.

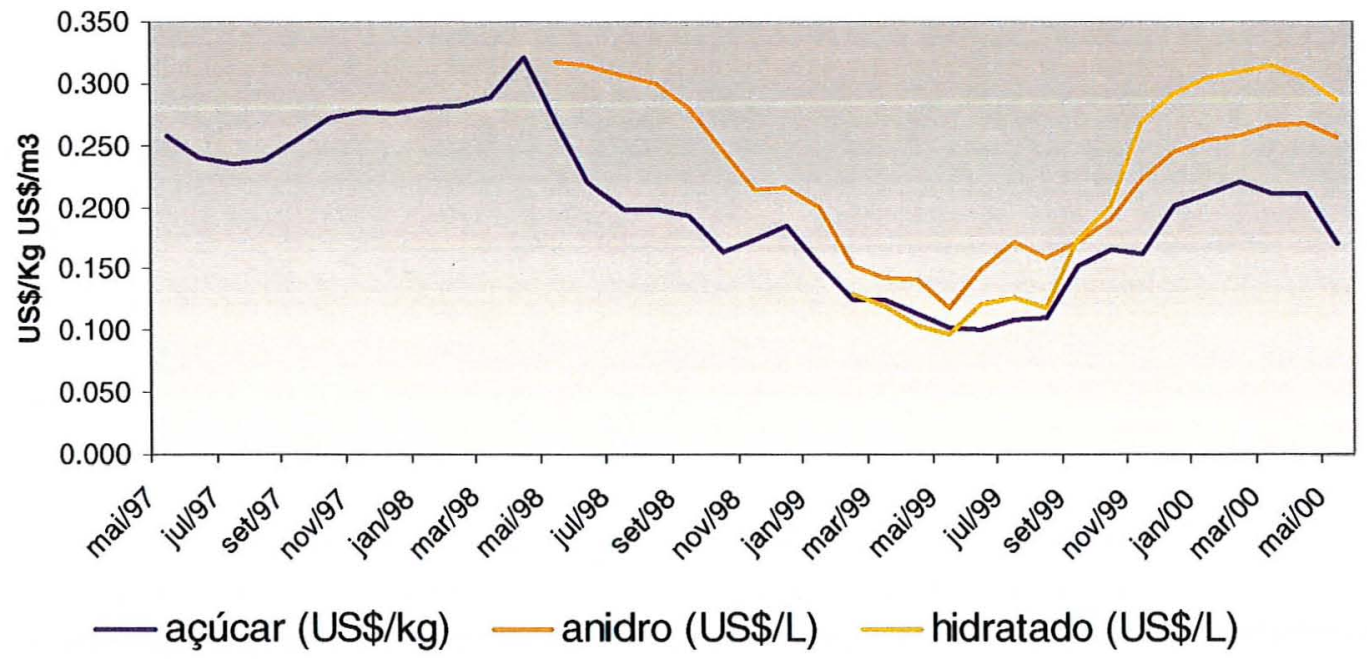

Figura 2.6 PReÇOS Ao NÍVEl DE PRODUTOR DE AÇÚCAR CRISTAL, ÁlCOOL ANIDRO E HIDRATADO PARA O PERÍODO NO QUAL SEUS PREÇOS ENCONTRAM-SE DESREGULAMENTADOS PELO GOVERNO

Fonte: Centro, 2000. 
Apesar de estarem plotados num mesmo gráfico, não há paridade técnica entre um quilo de açúcar, um litro de álcool anidro e um litro de álcool hidratado. Portanto, uma comparação dos seus preços, conforme visualizado na Figura 2.6, não é aconselhável. Para proceder a tal comparação, deve-se utilizar a paridade técnica entre esses produtos, a qual utiliza o conceito de ATR (Açúcar Total Recuperável). O ATR é uma medida que informa a quantidade de sacarose que pode ser transformada em açúcar e, ou, álcool, relacionando as produções de açúcar e álcool. Segundo Conselho (1999), tem-se a seguinte relação entre os produtos:

$1 \mathrm{~kg}$ ATR $=1,0495 \mathrm{~kg}$ açúcar $=1,81691$ álcool anidro = 1,7409 $\mathrm{l}$ álcool hidratado.

Assim, a paridade técnica é de 0,5776 tonelada de açúcar para cada $1 \mathrm{~m}^{3} \mathrm{de}$ álcool anidro e de 0,6028 tonelada de açúcar para cada $1 \mathrm{~m}^{3}$ de álcool hidratado. $\mathrm{Na}$ Figura 2.7, mostra-se a relação de preço (em US\$) de um ATR para produzir açúcar e álcool anidro ou hidratado.

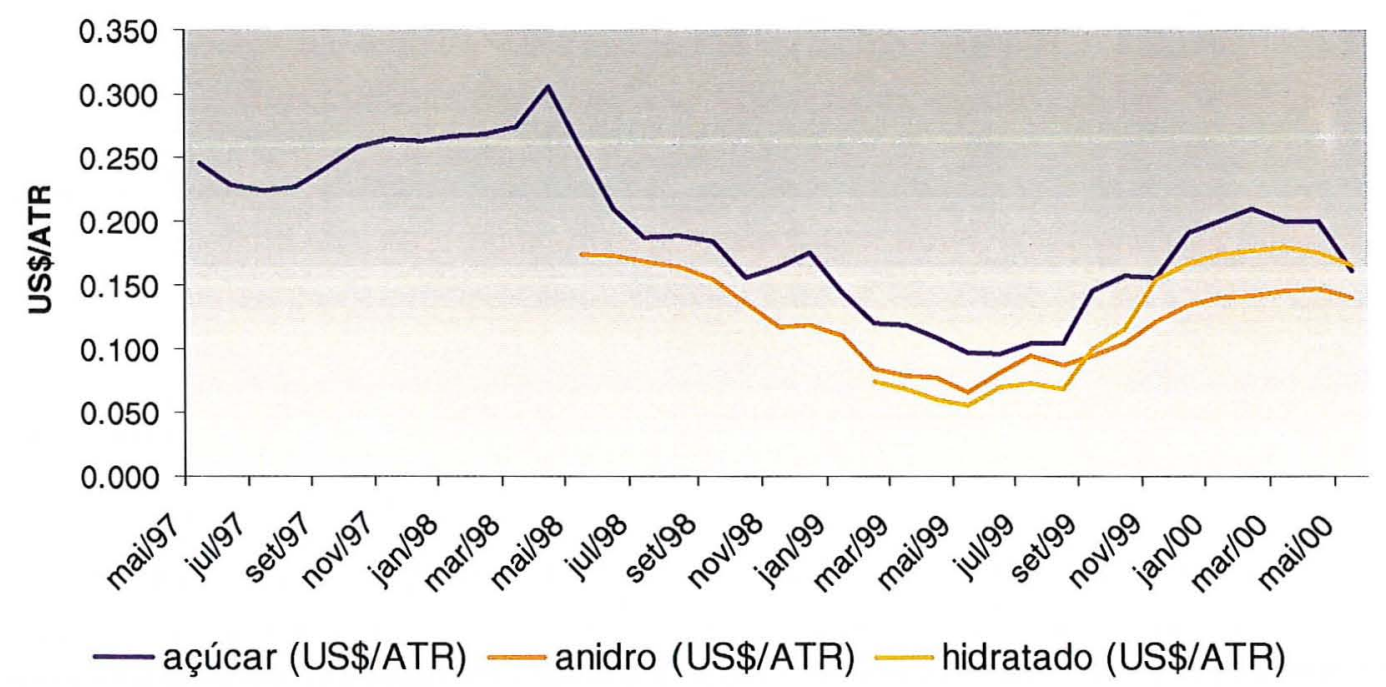

Figura 2.7 Preços de ATR Para PRODUÇÃo de AÇÚCAR CRISTAL, ÁlCOOL ANIDRO E HIDRATADO NO PERÍODO QUE SEUS PREÇOS ENCONTRAM-SE DESREGULAMENTADOS PELO GOVERNO 
Como demonstrado anteriormente nos gráficos de produção de açúcar e álcool no Estado de São Paulo (Figuras 2.1, 2.3 e 2.4) observou-se tendência de aumento da produção paulista de açúcar nas últimas safras (foi descrito até a safra de 1999), o que não estava sendo acompanhado pela produção de álcool.

Conforme destacado em relatório do USDA, citado por Burnquist (1999), os fatores que determinaram a reversão da produção de álcool (particularmente o hidratado) em açúcar pelo setor sucroalcooleiro brasileiro e, particularmente, pelo paulista compreenderam basicamente: i) a existência de estoques de álcool muito elevados no início da safra, que criaram expectativas de um contexto instável e desfavorável à produção de álcool; ii) uma demanda firme pelo açúcar brasileiro no mercado internacional, que foi atendida, a despeito do baixo nível de preços que prevaleceu; iii) a necessidade dos produtores de gerar fluxo de caixa por meio de contratos de exportação que proporcionam financiamento antecipado; iv) a recuperação dos preços no mercado doméstico, que teve início em agosto, tendo se acentuado em setembro em face da expectativa de escassez relativa do produto; e v) o clima seco durante o período de colheita na região Centro-Sul, favorecendo a concentração de açúcar na cana.

Entretanto, como pode ser observado no último mês do gráfico da Figura 2.7 e conforme indicação até outubro de 2000 , o preço em ATR de álcool hidratado ultrapassou o de açúcar, mudando a tendência que havia sido observada. Dados de outubro da UNICA evidenciaram que o "mix" de produção está se concretizando em $55 \%$ para o álcool e $45 \%$ para o açúcar, ou seja, uma produção mais alcooleira.

Stalder e Burnquist (1996), estudando o comportamento das margens de comercialização do açúcar e do álcool na usina ou destilaria em relação ao produtor de cana-de-açúcar, verificaram que as margens têm se mantido no patamar de $40 \%$ e $50 \%$, respectivamente. 
Sobre o álcool anidro e o álcool hidratado não há estudos específicos a respeito da formação de preços. Utilizando preços dos produtos do setor sucroalcooleiro no período de 1980 a 1995, Dias e Sordi (1999) determinaram uma função de demanda para o mercado de álcool hidratado no Brasil, concluindo que uma curva de demanda do tipo linear foi a que melhor se adequou aos dados.

Assim, verificou-se que há poucos trabalhos enfocando especificamente o comportamento dos preços no mercado sucroalcooleiro num contexto de liberalização dos preços de seus produtos. A análise apresentada no presente trabalho veio suprir tal deficiência, fornecendo aos agentes desses mercados informações úteis para a comercialização de seus produtos.

\subsection{Metodologias utilizadas em estudos similares}

Existem vários trabalhos cujo objetivo é o comportamento dos preços de produtos, principalmente, agrícolas. Assim, realiza-se a seguir uma revisão das metodologias utilizadas nesses estudos, com o propósito de identificar procedimentos teóricos e empíricos possíveis de serem empregados para propósitos semelhantes ao do presente trabalho.

Utilizando um modelo de equilíbrio estático baseado na pressuposição de equilíbrio instantâneo de oferta e procura no varejo, atacado e produtor, vários autores estudaram o comportamento dos preços de produtos agrícolas, tomando como base o modelo de Gardner (1975). Outros utilizaram o modelo desenvolvido por Heien (1980), o qual consideróu desequilíbrio na determinação de preços e margens no varejo, atacado e produtor. O modelo teórico desenvolvido por Barros (1990) foi também utilizado por diversos autores, principalmente em estudos de preços de produtos hortifrutícolas. 
Para determinação do sentido de causa-efeito e da elasticidade de transmissão entre preços, o método de Sims foi o mais utilizado em estudos no Brasil. Burnquist (1986), Bliska (1989), Aguiar (1990), Alves (1996), Felippi e Waquil (1999), Santos e Fett (1999) e Barros e Mafioletti (1999), dentre outros, estudaram a causalidade e a intensidade da transmissão de preços entre níveis de mercado de vários produtos agrícolas, utilizando o método proposto por Sims (1972).

A causalidade entre preços interno e externo também foi estudada por Carvalho et al. (1983) para o mercado de algodão e também por Aguiar (1990) para o mercado de soja. Almeida e Mesquita (1995) estudaram a relação de causalidade entre preços externos e quantidades exportadas de café do Brasil no mercado internacional. Bacchi (1995) testou a relação causal entre preços de bovino, suíno e frango no Estado de São Paulo, enquanto Zen (1997), a fim de testar a integração do mercado de carne bovina entre as regiões produtoras no Estado de São Paulo, assim como os demais autores acima mencionados, utilizou a metodologia de Sims.

Outras metodologias podem ainda ser encontradas para análise de causalidade, bem como de transmissão de preços. Na análise da transmissão de preços mensais entre os mercados externo e interno, Aguiar (1995) utilizou o modelo de Mundlak-Larson. Margarido et al. (1999) utilizaram a metodologia de séries temporais desenvolvida por Box, Jenkins e Reinsel (1994): modelos Auto-Regressivos Integrados de Médias Móveis (ARIMA), e de função de transferência para analisar a elasticidade de transmissão da cotação mensal do grão de soja na Bolsa de Chicago (CBOT) e do preço CIF do porto de Rotterdam para os preços FOB Brasil e Argentina entre outubro de 1990 e outubro de 1998. Utilizando-se essa mesma metodologia, a transmissão de preços internacionais de suco de laranja para preços ao produtor de laranja no Estado de São Paulo foi analisada por Margarido (1994). 
Analisando a transmissão de preços entre os três segmentos da cadeia produtiva da pecuária de corte brasileira - cria, recria e engorda - Bacchi (1999) empregou a análise de Auto-Regressão Vetorial (VAR).

Bittencourt (1995) utilizou também o modelo VAR, analisando a formação de preços no mercado de frango de São Paulo.

Lamounier e Bressan (1999) testaram as relações de causalidade entre preços agrícolas agregados e níveis gerais de preços na economia brasileira, no período compreendido entre julho de 1994 e maio de 1998. Para tal, esses autores utilizaram o teste de causalidade de Granger e a metodologia proposta por Fuller (1976), para o estudo da estacionariedade das séries estudadas.

Utilizando ainda o teste de causalidade de Granger, alguns outros autores estudaram relações entre variáveis diversas. Willett, Hansmire e Bernard (1997) analisaram a causalidade e assimetria dos preços no comportamento do mercado de maçã, utilizando os preços estacionários, uma vez que possuíam raiz unitária. Uri (1999) estudou a relação causal de preços de energia e utilização de conservação de terras cultivadas nos Estados Unidos, também com as variáveis estacionárias. Saatcioglu e Starks (1998) utilizaram o teste de causalidade para estudar a relação entre preço e volume do estoque no conjunto dos mercados na América Latina. Strauss (1999) estudou a relação entre preços de não-comercializáveis e taxa de câmbio real, utilizando essa mesma metodologia. Pesonen (1999), trabalhando com as variáveis estacionárias, calculou a relação causal entre estoques de mercados emergentes da Ásia e da Rússia pelo teste de Granger. Khalafalla e Webb (2000), estudando a relação entre exportação e crescimento econômico na Malásia, utilizaram o teste de causalidade de Granger.

Maia et al. (1999) obtiveram a elasticidade de transmissão de preços por meio de duas metodologias distintas e as compararam do ponto de vista de resultados. A 
primeira metodologia foi usualmente usada com procedimentos de modelos de defasagens distribuídas, utilizando-se a metodologia de Granger (1969); a segunda seguiu o procedimento dos modelos de séries temporais de Box-Jenkins, com o uso de uma função de transferência. Esses autores concluíram que os resultados indicaram sinais coincidentes em ambas as metodologias, entretanto com magnitudes diferentes. Comentaram também que, levando em consideração a simplicidade de procedimento no uso da metodologia de Box-Jenkins e o tratamento dado aos resíduos, tornando-os ruídos brancos, este modelo ganhou destaque e confiança na estimação de elasticidade de transmissão de preços entre níveis de mercado. Entretanto, Maia et al. (1999) não estudaram a estacionariedade das variáveis utilizadas no modelo de Granger, conforme foi realizado nos trabalhos anteriormente descritos.

No presente trabalho, utilizou-se, para análise de causalidade entre os níveis de mercado, o método proposto por Granger, com as séries estacionárias. 


\section{METODOLOGIA}

Este capítulo está dividindo em duas partes. A primeira aborda, brevemente, características de alguns modelos teóricos utilizados para estudos de formação de preços, sendo, então, proposto um modelo econômico para a formação dos preços de açúcar e álcool, com base naqueles modelos. A segunda parte apresenta os métodos econométricos a serem aplicados nos dados para se alcançarem os objetivos previamente estabelecidos, visando a um melhor entendimento do funcionamento dos mercados de açúcar e álcool, assim como aos dados a serem utilizados e sua origem.

Segundo Aguiar (1990), o referencial teórico consiste em encontrar relações que se repetem sistematicamente, dadas as mesmas condições. $\mathrm{E}$ a preocupação empírica consiste em mensurar, através dos procedimentos econométricos, essas relações e testar as hipóteses formuladas pela teoria.

\subsection{Modelos econômicos}

Neste item, expõem-se, de forma resumida, os modelos teóricos de formação de preços e margens de comercialização que procuram explicar a formação dos preços em diferentes níveis de mercado. São enfatizados os pressupostos e as implicações dos modelos teóricos, bem como as relações entre esses modelos. 


\subsubsection{Modelo de Gardner (1975)}

O modelo de Gardner é de natureza estático-comparativa, examinando-se as conseqüências do equilíbrio competitivo nos mercados de produto e de fatores sobre a relação entre os preços de alimentos ao varejo e ao produtor. $\mathrm{O}$ modelo considera que $\mathrm{o}$ equilíbrio é alcançado instantaneamente. Prevê, ainda, equilíbrio instantâneo nos três mercados considerados (do produto final, da matéria-prima agrícola e do agregado de insumos de comercialização), considerando-se os níveis de produtor e varejo.

Gardner relatou o comportamento dos mercados diante de alterações na demanda (varejo), na oferta agrícola ou na oferta dos insumos de comercialização, demonstrando que:

- aumentos na demanda primária reduzirão a margem relativa de comercialização, desde que a elasticidade-preço da oferta do insumo de comercialização seja maior que a das matérias-primas agrícolas;

- aumentos na oferta de produtos agrícolas elevarão a margem relativa de comercialização;

- aumentos na oferta de insumos de comercialização farão com que se reduza a margem de comercialização;

- a demanda por produtos agrícolas será, em geral, menos elástica em nível do produtor do que em nível de varejo; e

- a elasticidade de transmissão de preços tenderá a ser negativa para choques oriundos da oferta de insumo de comercialização e positiva e inferior ou igual a 1 para variações na oferta e demanda primárias. 


\subsubsection{Modelo de Heien (1980)}

Este modelo se diferencia do de Gardner, por pressupor que o equilíbrio instantâneo entre oferta e demanda nos níveis de varejo, atacado e produtor se aplica apenas no longo-prazo. Portanto, este é um modelo dinâmico, mais adequado para análises de curto-prazo, que permite investigar o que ocorre entre duas situações de equilíbrio.

O modelo teórico de determinação de preços e margens desenvolvido por Heien engloba os níveis de varejo, de atacado e de produtor, especificando equações de ajustamento de preços, seguindo o comportamento dos excessos de demanda e diferenciando-se do modelo anterior, também por excluir o mercado de insumos de comercialização.

Esse autor observou ainda em seu modelo que, no varejo, existe um número grande de produtos 'comercializados pelos supermercados, o que torna inviável aos agentes de comercialização o acompanhamento de todos os produtos. Assim, ele relatou que uma teoria operacionalmente mais realista é aquela que considera que o comerciante aplica um markup sobre o preço de compra, a fïm de obter o preço de venda. Essa regra de markup é consistente em situações em que se tem retornos constantes a escala e tecnologia fixas, o que seria o caso de curto prazo.

\subsubsection{Modelo de Barros (1990)}

O modelo econômico desenvolvido por Barros baseia-se fundamentalmente em Heien, mas com algumas características próprias. Neste modelo, o ajustamento de preços no atacado ocorre instantaneamente, por admitir baixo custo de mudança de preço, maior acesso à informação e freqüência de transações e pela possibilidade de perdas significativas em caso de não se efetuar a transação. As variações de preços 
iniciam-se nesse nível, ajustando seu preço por excesso de demanda. As mudanças de preço para os produtores se processam por meio de ajustes parciais. O varejo utilizaria uma política de markup sobre os custos e também ajustes parciais, atingindo um preçometa.

Segundo Aguiar (1993), prevalecendo o modelo de Barros, tanto choques de oferta agrícola como choques de demanda levariam a alterações iniciais no preço do atacado, nível que mais rapidamente se informaria sobre o choque e que teria condições de alterar os termos de troca.

\subsection{Modelo econômico proposto}

O modelo econômico proposto a seguir representa o mercado de açúcar e de álcool combustível no Estado de São Paulo, baseando-se nos modelos de Heien (1980) e de Barros (1990), dado que esses modelos consideram relações de desequilíbrio no curto prazo. Para compor a estrutura do mercado de açúcar, considerou-se a inter-relação entre o produtor de açúcar cristal (açúcar em sacas de $50 \mathrm{~kg}$ ), a empacotadora de açúcar cristal em pacotes de $5 \mathrm{~kg}$ e o varejo deste açúcar, assim como o produtor de açúcar refinado, que é também o empacotador de pacotes de $1 \mathrm{~kg}$, e o varejo de açúcar refinado. A empacotadora é representada no presente modelo como o atacadista do açúcar cristal. Essa atividade está, entretanto, sendo cada vez mais incorporada pelos próprios produtores.

Nos mercados de álcool anidro e hidratado, consideraram-se apenas os níveis de produção e varejo para caracterizar a estrutura do mercado, como mencionado anteriormente, em razão de restrições quanto à disponibilidade de dados relativos aos valores negociados entre as distribuidoras e os postos de combustível. 
As principais hipóteses do modelo proposto para a análise conduzida foram:

1. Nos níveis de produtor e de atacado dos mercados de açúcar e de álcool, os preços se ajustam continuamente de acordo com o excesso de demanda, identificando-se mais diretamente a descrição segundo o modelo de Heien (1980), e diferenciando-se daquele proposto por Barros (1990), à medida em que este considerou mudanças de preços por ajustes parciais no segmento de produção ${ }^{3}$. De fato, as unidades produtoras são em pequeno número, conforme descrição no item 2.1.2, o que indica que os produtores de açúcar e de álcool têm acesso suficiente a informações de mercado que possibilitam alterações na oferta.

2. As mudanças de preços no varejo se dão por ajustes parciais até atingirem o preço de equilíbrio.

3. A produção de açúcar e de álcool combustível anidro e hidratado, principais produtos do setor sucroalcooleiro, estão interligadas, uma vez que esses produtos têm o agente de produção comum, ou seja, o produtor é o mesmo (usinas com destilaria anexa). Assim, no nível do produtor, os preços de açúcar e de álcool anidro e hidratado estão relacionados da seguinte forma: aumento no preço de um desses produtos leva a um crescimento na oferta, reduzindo a oferta dos outros dois produtos.

Os ajustamentos parciais e por excesso de demanda são formas de se admitir a existência de desequilíbrio nos mercados de curto prazo, conforme proposto por Heien (1980) e Barros (1990).

\footnotetext{
${ }^{3}$ O segmento de produção no modelo proposto por Barros (1990) é muito pulverizado, o que é uma característica comum nos mercados de produtos agrícolas. Entretanto, não se observa essa característica nos mercados dos produtos finais do setor sucroalcooleiro.
} 


\subsubsection{Mercado de açúcar cristal e açúcar refinado}

No varejo, o setor de açúcar cristal (e também o de refinado) opera de acordo com uma função de produção do tipo Leontief:

$$
V=\min \left\{\frac{A}{b_{1}}, \frac{Z_{1}}{b_{2}}\right\}
$$

em que $V$ é a quantidade de açúcar cristal no varejo, $\boldsymbol{A}$ é a quantidade de açúcar cristal no atacado, $\boldsymbol{Z}_{\boldsymbol{l}}$ é a quantidade de insumo do varejo e $\boldsymbol{b}_{\boldsymbol{1}}$ e $\boldsymbol{b}_{2}$ são os coeficientes técnicos da produção, $\operatorname{com} \boldsymbol{b}_{1}$ e $\boldsymbol{b}_{2}>0$.

O ajuste do preço do açúcar cristal no varejo se dá por ajustes parciais até atingir o preço de equilíbrio, como descrito por Barros (1990), considerando-se que as transações nesse nível de mercado são descentralizadas:

$$
v_{t}-v_{t-1}=\alpha\left(v_{t}^{*}-v_{t-1}\right)^{4}
$$

em que $v$ é o preço no varejo de açúcar cristal e $\alpha$ é a taxa de velocidade de ajustamento desse preço. Assim, para determinar o preço esperado do açúcar cristal no varejo, somase ao preço de atacado o preço dos insumos de comercialização:

$$
v_{t}^{*}=b_{1} a_{t}+b_{2} z_{1, t}
$$

sendo $\boldsymbol{a}$ o preço no atacado e $z_{l}$ o preço do insumo de comercialização no varejo.

$$
\begin{aligned}
& \text { Substituindo a equação (2) na equação (1) e rearranjando os termos, often-se } \\
& v_{t}=(1-\alpha) v_{t-1}+\alpha b_{1} a_{t}+\alpha b_{2} z_{1, t}
\end{aligned}
$$

\footnotetext{
${ }^{4}$ Os subscritos "t" e "t-1" indicam tempo, em que "t-1" é o período defasado em relação ao período "t".
} 
Considera-se, ainda, que a demanda por açúcar cristal no varejo é uma função linear do próprio preço no varejo:

$V_{t}^{D}=\theta_{0}+\theta_{1} v_{t}$

esperando que a função de demanda seja negativamente inclinada, tem-se $\theta_{1}<0$.

O modelo analítico pressupõe que o segmento varejista de açúcar refinado pode ser representado de forma semelhante ao descrito para o açúcar cristal ${ }^{5}$.

No modelo proposto, considera-se que o preço de açúcar cristal no atacado se ajusta por desequilíbrio entre oferta e demanda, sendo representado por excesso de demanda pelo produto, ou seja:

$$
a_{t}-a_{t-1}=\delta\left(A_{t}^{D}-A_{t}^{S}\right)
$$

em que $\boldsymbol{A}$ representa a quantidade de açúcar cristal no atacado, $\boldsymbol{a}$ é o preço de açúcar cristal no atacado e $\delta$ é a taxa de velocidade de ajustamento do preço, por excesso de demanda, no atacado.

A demanda por açúcar cristal no atacado $\left(A^{D}\right)$ é obtida pela conversão da demanda por açúcar cristal no varejo $\left(V^{D}\right)$ do período anterior:

$$
A_{t}^{D}=b_{1} V_{t-1}^{D}
$$

em que $V^{D}$ é descrita na equação (4) e $\boldsymbol{b}_{\boldsymbol{l}}>0$, pressupondo-se que aumento da demanda no varejo eleva a demanda no atacado no período seguinte, a fim de repor os estoques nesse nível.

\footnotetext{
${ }^{5}$ Dessa forma, a variável $v$ também indica o preço no varejo de açúcar refinado e $z_{l}$, o insumo de comercialização no varejo de açúcar refinado.
} 
As relações de oferta ao atacado são expressas de forma a indicar que os preços no nível do produtor e do atacado se formam simultaneamente, ambos representados por excesso de demanda. A oferta de açúcar cristal no atacado $\left(A^{S}\right)$ é uma função do preço ao produtor (pac) e do preço do açúcar cristal empacotado (a) no período anterior:

$A_{t}^{S}=\varpi_{0} p a c_{t}+\varpi_{1} a_{t-1}$

em que se espera que: $\varpi_{0}<0$, indicando que redução no preço ao produtor favorece a compra de açúcar cristal no atacado e que $\varpi_{I}>0$, pressupondo que o aumento dos preços no período anterior estimula o incremento da oferta de açúcar cristal.

Considerando, portanto, a substituição das equações (6) e (7) na equação (5), tem-se que o preço de açúcar cristal no atacado é formado segundo um processo indicado da seguinte forma:

$$
a_{t}=\delta b_{1} \theta_{0}+\delta b_{1} \theta_{1} v_{t-1}-\delta \varpi_{0} p_{a c}+\left(1-\delta \varpi_{1}\right) a_{t-1}
$$

No nível do produtor de açúcar cristal, a oferta total do produtor $\left(\boldsymbol{P} A C^{S}\right)$ no modelo adotado para a análise de formação do preço de açúcar cristal é uma função dos preços de álcool anidro (pi) e hidratado ( $\boldsymbol{p h}$ ), tendo em conta que estes são ofertados pelo produtor em substituição ao açúcar, e também do preço internacional do açúcar exportado (ni). Portanto, a oferta de açúcar cristal pelo produtor pode ser assim expressa:

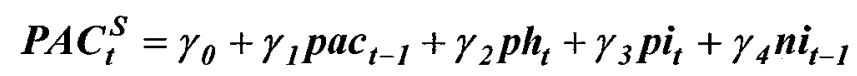

Pressupõe-se que o preço do produtor de açúcar no período anterior afeta positivamente sua oferta $\left(\gamma_{1}>0\right)$; o preço de álcool anidro e hidratado apresenta relação negativa com a oferta de açúcar, conforme descrito na hipótese 3, tendo-se $\gamma_{2}$ e $\gamma_{3}<0$; e que o aumento nas exportações no período anterior, que poderia ser provocado, a princípio, por 
elevação do preço internacional, reduz a oferta de açúcar cristal no mercado doméstico $\left(\gamma_{4}<0\right)$.

A demanda de açúcar $\left(\boldsymbol{P} \boldsymbol{A} \boldsymbol{C}^{\boldsymbol{D}}\right)$ é função dos preços dos demandantes diretos desse produto no período anterior, quais sejam, dos preços no produtor de refinado $(r)$, do atacado do cristal (a) e dos produtos industriais finais que demandam o açúcar cristal como insumo de produção $\left(z_{4}\right)$ :

$P A C_{t}^{D}=\beta_{1} z_{4, t-1}+\beta_{2} a_{t-1}+\beta_{3} r_{t-1}$

em que se espera que a demanda por açúcar refinado no produtor, por açúcar cristal no atacado e pelos produtos industriais finais que utilizam o açúcar cristal como insumo de produção aumente ao haver redução nos seus preços, ou seja, $\beta_{1}, \beta_{2}$ e $\beta_{3}<0$. Assim, no próximo período, a demanda pelo açúcar cristal no produtor aumenta, a fim de se reporem os estoques desses produtos.

Como a representação do ajustamento do preço no produtor pode ser feita por excesso de demanda:

$$
\operatorname{pac}_{t}-\text { pac }_{t-1}=\varsigma\left(P A C_{t}^{D}-P A C_{t}^{S}\right)
$$

em que $\varsigma$ é a taxa de velocidade de ajustamento do preço, por excesso de demanda, no nível do produtor de açúcar cristal.

Incorporando em (11) as equações (9) e (10) e arranjando os termos, obtém-se:

$$
\text { pac }_{t}=-\varsigma \gamma_{0}+\varsigma \beta_{1} z_{4, t-1}+\varsigma \beta_{2} a_{t-1}+\varsigma \beta_{3} r_{t-1}-\varsigma \gamma_{2} p h_{t}-\varsigma \gamma_{3} p i_{t}-\varsigma \gamma_{4} n i_{t-1}+\left(1-\varsigma \gamma_{1}\right) p a c_{t-1}
$$

Com relação ao produtor de açúcar refinado, o ajustamento por excesso de demanda também se justifica, uma vez que os produtores desse açúcar praticamente 
assumem o papel da empacotadora e comercializam, de maneira geral, diretamente com o segmento varejista:

$$
\boldsymbol{r}_{t}-\boldsymbol{r}_{t-1}=\lambda\left(\boldsymbol{R}_{t}^{D}-\boldsymbol{R}_{t}^{S}\right)
$$

em que $\boldsymbol{R}$ é a quantidade de açúcar refinado no nível do produtor desse açúcar, $\boldsymbol{r}$ é o preço do produtor de açúcar refinado e $\lambda$ é a taxa de velocidade de ajustamento do preço, por excesso de demanda, no nível do produtor de açúcar refinado.

A demanda do produtor de refinado $\left(\boldsymbol{R}^{D}\right)$ é obtida pela conversão da demanda do varejo $\left(\boldsymbol{V}^{D}\right)$ no período anterior:

$$
R_{t}^{D}=b_{1} V_{t-1}^{D}
$$

em que $\boldsymbol{V}^{\boldsymbol{D}}$ é definida também na equação (4), mas referente ao açúcar refinado, e $\boldsymbol{b}_{\boldsymbol{l}}>0$, esperando-se que o aumento da demanda no varejo eleve a demanda do produtor no período seguinte, a fim de se reporem os estoques nesse nível.

A oferta do produtor de refinado $\left(\boldsymbol{R}^{S}\right)$ é função do preço do produtor de açúcar cristal (pac) e do seu próprio preço $(\boldsymbol{r})$ no período anterior:

$$
R_{t}^{S}=\phi_{0} \operatorname{pac}_{t}+\phi_{1} r_{t-1}
$$

pressupondo-se que a redução no preço ao produtor favoreça a compra de açúcar cristal no atacado $\left(\phi_{0}<0\right)$ e que a elevação do preço no período anterior estimule o aumento da oferta de açúcar cristal $\left(\phi_{1}>0\right)$.

Dessa forma, considera-se que o preço ao produtor de açúcar refinado se forma da seguinte maneira:

$$
r_{t}=\lambda b_{1} \theta_{0}+\lambda b_{1} \theta_{1} v_{t-1}-\lambda \phi_{0} p a c_{t}+\left(1-\lambda \phi_{1}\right) r_{t-1}
$$




\subsubsection{Mercado de álcool combustível anidro}

Segundo o ajustamento de preço por excesso de demanda proposto por Heien (1980) para o nível do produtor, tem-se para o produtor de álcool anidro

$$
p i_{t}-p i_{t-1}=\vartheta\left(P I_{t}^{D}-P I_{t}^{S}\right)
$$

em que $\boldsymbol{P I}$ é a quantidade de álcool anidro no nível do produtor, $p \boldsymbol{i}$ representa o preço do produtor de álcool anidro e $\vartheta$ é a taxa de velocidade de ajustamento do preço, por excesso de demanda, no nível do produtor de álcool anidro.

Pressupõe-se que

$$
\boldsymbol{P I} I_{t}^{S}=\psi_{0}+\psi_{1} p i_{t-1}+\psi_{2} \mathrm{pac}_{t}+\psi_{3} p \boldsymbol{h}_{t}
$$

em que se espera que o preço do produtor de álcool anidro no período anterior afete positivamente sua oferta $\left(\psi_{l}>0\right)$; e que o preço de açúcar cristal e de álcool hidratado tenha relação contrária à do preço de açúcar, conforme descrito na hipótese 3 , tendo-se $\psi_{2}$ e $\psi_{3}<0$.

$$
P I_{t}^{D}=\pi_{1} v i_{t-1}
$$

em que vi é o preço de álcool anidro no varejo, e esperando que a função de demanda seja negativamente inclinada, a redução do preço no varejo aumente a demanda neste nível, elevando por sua vez, a demanda do atacado no período seguinte, a fim de se reporem os estoques nesse nível $\left(\pi_{1}<0\right)$.

Substituindo as equações (18) e (19) em (17), pode-se expressar a equação referente à formação dos preços de álcool anidro, no nível do produtor, da seguinte forma:

$$
p i_{t}=-\vartheta \psi_{0}+\vartheta \pi_{1} v i_{t-1}-\vartheta \psi_{2} p a c_{t}-\vartheta \psi_{3} p h_{t}+\left(1-\vartheta \psi_{1}\right) p i_{t-1}
$$


Acredita-se que o preço de varejo de álcool anidro é formado principalmente em função do preço no atacado. Entretanto, como esses preços não foram utilizados neste estudo, considerou-se apenas que há relação positiva entre os preços do produtor e os preços do varejo. Pelo fato de ser utilizado juntamente com a gasolina e utilizar o preço desta como indicador do preço no varejo de álcool anidro, tem-se que outras variáveis formadoras do preço da gasolina também devem estar positivamente relacionadas na sua formação.

\subsubsection{Mercado de álcool combustível hidratado}

O ajustamento de preço por excesso de demanda proposto por Heien (1980) para o nível do produtor é igualmente indicado para a formação do preço no nível do produtor de álcool hidratado, ou seja:

$$
p h_{t}-p h_{t-1}=\xi\left(P H_{t}^{D}-P H_{t}^{S}\right)
$$

em que $\boldsymbol{P H}$ é a quantidade de álcool hidratado no nível do produtor, $\boldsymbol{p h}$ representa o preço do produtor de álcool hidratado e $\xi$ é a taxa de velocidade de ajustamento do preço, por excesso de demanda, no nível do produtor de álcool anidro. maneira:

A função de oferta do produtor de álcool hidratado é expressa da seguinte

$$
P H_{t}^{S}=\omega_{0}+\omega_{1} p h_{t-1}+\omega_{2} p a c_{t}+\omega_{3} p i_{t}
$$

em que se espera que o preço do produtor de álcool hidratado no período anterior afete positivamente sua oferta $\left(\omega_{1}>0\right)$ e que o preço de açúcar cristal e de álcool anidro tenha relação contrária ao preço de açúcar, conforme descrito na hipótese $3\left(\omega_{2}\right.$ e $\left.\omega_{3}<0\right)$.

A demanda do produtor de álcool hidratado é função dos preços do demandante; no caso, dos preços do varejo: 
$P H_{t}^{D}=\sigma_{1} v h_{t-1}$

em que $\boldsymbol{v} \boldsymbol{h}$ é o preço de álcool hidratado no varejo, e espera-se que a redução do preço no varejo aumente sua demanda, elevando a demanda no atacado no período seguinte, a fim de se reporem os estoques nesse nível $\left(\sigma_{1}<0\right)$.

Substituindo na equação (21) as equações (22) e (23), pode-se expressar a equação referente à formação dos preços de álcool hidratado, no nível do produtor, da seguinte forma:

$$
p h_{t}=-\xi \omega_{0}+\xi \sigma_{1} v h_{t-1}-\xi \omega_{2} p a c_{t}-\xi \omega_{3} p i_{t}+\left(1-\xi \omega_{1}\right) p h_{t-1}
$$

O preço de varejo de álcool hidratado é formado, principalmente, em função do preço no atacado, mas, como esses preços não foram utilizados neste estudo, considerouse apenas que há relação positiva entre os preços do produtor e os preços do varejo.

As equações (3), (8), (12), (16), (20) e (24), além das relações entre preços no varejo de álcool anidro e hidratado, foram estimadas para se confirmar as relações estabelecidas na formação do preço de açúcar cristal, açúcar refinado, álcool anidro e álcool hidratado.

\subsection{Material e método}

As análises serão feitas, considerando-se dados de preços mensais relativos ao período pós-desregulamentação para cada um dos produtos: açúcar, álcool anidro e álcool hidratado, a partir de abril de 1997, maio de 1998 e fevereiro de 1999, respectivamente. $\mathrm{O}$ mercado de açúcar deixou de ser regulamentado pelo governo federal no início da década de 90 , entretanto este estudo considerou o período após abril de 1997, em razão de mudança na padronização da metodologia utilizada para o cálculo 
dos preços após essa dada pela fonte fornecedora dos dados utilizados (CEPEA/ESALQ/USP).

A análise empírica dividiu-se na aplicação dos seguintes testes: teste de raiz unitária, para averiguar a estacionariedade das séries temporais; teste de co-integração, a fim de se verificar a existência de relação estável de longo prazo entre as variáveis integradas de mesma ordem; teste de causalidade de Granger, para investigar as possíveis relações causais entre as variáveis; e, finalmente, estimaram-se os coefícientes das equações de formação de preço propostas no tópico anterior, verificando as pressuposições utilizadas no modelo.

\subsubsection{Testes econométricos}

\subsubsection{Teste de estacionariedade}

De modo geral, trabalhos empíricos utilizando dados de séries temporais não mais pressupõem estacionariedade dessas séries. Numa regressão, quando se analisam dados não-estacionários sem alguma transformação deles, a relação entre as variáveis

obtida pelo alto valor do coeficiente de determinação $\left(R^{2}\right)$ pode ser, na verdade, uma relação espúria (Gujarati, 1995).

Segundo Gujarati (1995), um processo estatístico é considerado estacionário se suas médias e variâncias são constantes ao longo do tempo e o valor da covariância entre dois períodos de tempo depende somente do intervalo de tempo e não do tempo para o qual a covariância é computada. Assim, uma série é considerada não-estacionária se possuir tendência estocástica. Portanto, a estacionariedade das variáveis consideradas no estudo deve ser previamente verificada, a fim de que as séries relacionadas no modelo estejam corretamente especificadas. 
Um teste de estacionariedade que tem sido, em período recente, utilizado com freqüência é conhecido como teste de raiz unitária, conforme descrito nos parágrafos subseqüentes.

Considera-se que uma série gerada por um processo auto-regressivo de primeira ordem $[\mathrm{AR}(1)]$ pode ser representada por

$$
Y_{t}=\theta Y_{t-1}+e_{t}
$$

A equação (25) pode ser modificada para realizar o teste de raiz unitária, da seguinte forma:

$$
\Delta Y_{t}=(\theta-1) Y_{t-1}+e_{t}
$$

Pelo teste de Dickey-Fuller, sendo $\theta$ estatisticamente igual a 1 (raiz unitária) em (25) ou $\theta-1=0$ na equação (26), tem-se, então, uma série não-estacionária, já que estacionariedade requer que $\theta-1<0$ e $\theta \in(-1,1)$.

Assumindo que a série é gerada por um processo auto-regressivo de ordem $\boldsymbol{p}$ $[\operatorname{AR}(p)]$, tem-se, para fins de teste da estacionariedade da série, o seguinte modelo modificado para testar a hipótese de nulidade:

$$
\Delta Y_{t}=\alpha+\beta_{1} T+\eta Y_{t-1}+\sum_{i=1}^{p-I} \theta_{i} \Delta Y_{t-i}+e_{t}
$$

Sendo

$$
\eta=\sum_{i=1}^{p} \theta_{i}-1 ; \mathrm{e}
$$

$\boldsymbol{T}=$ tendência determinística do modelo.

$\mathrm{O}$ valor de $\boldsymbol{p}$ deve ser tal que torne a série dos resíduos $\left(\boldsymbol{e}_{t}\right)$ uma série "ruído branco" (série estacionária). Um procedimento que tem sido muito utilizado para 
determinação do valor de $p$ é o critério de Akaike (AIC) e Schwarz (SC) ${ }^{6}$.

Para a análise do processo $\mathrm{AR}(\boldsymbol{p})$, utiliza-se o teste de Dickey-Fuller Aumentado (DFA). O teste aplica-se à equação (27), baseado na hipótese nula Ho: $\eta=0$, que é uma generalização do que se observa no teste para a equação (25). O teste consiste na utilização das estatísticas $\tau_{\beta \tau}$ e $\tau_{\alpha \mu}$, que avaliam, respectivamente, a significância das variáveis constante $(\alpha)$ e tendência $(\beta)$ do modelo. Assim, são utilizadas as estatísticas $\tau_{\tau}, \tau_{\mu}$ e $\tau$, as quais consideram os modelos para análise de estacionariedade com constante e tendência, apenas com constante e sem constante e tendência, respectivamente, caso esses termos sejam não-significativos.

O procedimento para detectar raiz unitária consiste na análise quanto à significância estatística do coeficiente $\eta$. Se o valor calculado for, em módulo, menor que o valor crítico observado no teste de Dickey-Fuller, a um dado nível de significância, não se rejeita a hipótese nula (não se rejeita a hipótese de raiz unitária).

Nesse caso, aplica-se mais uma diferença e testa-se novamente a hipótese nula. Caso a série seja estacionária na primeira diferença, ela é representada por I(1), ou seja, integrada de ordem 1 . Tal fato caracteriza a série com raiz unitária.

Caso a série não apresente estacionariedade na primeira diferença, ela é novamente diferenciada, repetindo o processo anteriormente citado até que o teste se apresente significativo. $\mathrm{O}$ número de diferenças aplicadas para tornar o coeficiente $\eta$

\footnotetext{
${ }^{6}$ Os critérios de AIC e SC consistem no seguinte:

$A I C=\ln \sigma^{2}+\frac{2}{N}$ (número de parâmetros) e $S C=\ln \sigma^{2}+\frac{\ln N}{N}$ (número de parâmetros), sendo $\sigma^{2}$ a soma dos quadrados dos resíduos estimados do processo auto-regressivo de ordem $\boldsymbol{p}$ dividida pelo número de observações $(N)$. O modelo mais adequado é aquele que apresentar o menor valor para os critérios AIC e SC. Maiores detalhes podem ser encontrados em Lütkepohl (1993).
} 
significativo determina a ordem de integração da série $\mathrm{I}(\mathrm{d})$, em que d é o número de diferenças aplicadas à série.

Entretanto, com essa transformação das séries, perdem-se as suas informações de longo prazo. Assim, a diferenciação dos dados pode levar a sérios problemas de especificação quando não se consideram tais informações. O conceito de co-integração descrito a seguir pode ser empregado para solucionar esse problema. Uma vez que duas ou mais variáveis são co-integradas, o termo de correção de erro estimado neste teste recupera as informações de longo prazo entre as variáveis.

\subsubsection{Teste de co-integração}

Conforme descrito por Lütkepohl (1993), muitas variáveis econômicas têm relação de equilíbrio de longo prazo. Esse mesmo autor definiu o processo de cointegração da maneira descrita no parágrafo subseqüente.

Dado um processo k-dimensional $\mathrm{y}_{\mathrm{t}}$ integrado de ordem $\mathrm{d}, \mathrm{y}_{\mathrm{t}} \sim \mathrm{I}(\mathrm{d})$, se $\Delta^{\mathrm{d}} \mathrm{y}_{\mathrm{t}}$ é estacionário e $\Delta^{\mathrm{d}-\mathrm{l}} \mathrm{y}_{\mathrm{t}}$ não é estacionário ${ }^{7}$. O processo $\mathrm{y}_{\mathrm{t}} \mathrm{I}(\mathrm{d})$ é chamado de co-integrado se há combinação linear c' $y_{t}$, a qual é integrada de ordem menor do que d.

Conforme o método descrito por Engle e Granger (1987) para verificar a presença de co-integração, supondo o vetor $y_{t}$ com duas variáveis integradas de ordem 1 , testar co-integração entre aquelas variáveis significa testar $\boldsymbol{u}_{\boldsymbol{t}}$ de uma equação de cointegração da fórmula

$$
y_{1 t}=\theta+\lambda y_{2 t}+u_{t}
$$

\footnotetext{
${ }^{7}$ Esta condição é similar à ordem de diferenciação das séries para se tornarem estacionárias, conforme definido no item anterior.
} 
é estacionária, ou seja, aplica-se o teste de estacionariedade descrito anteriormente para $u_{t}=y_{1 t}-\theta-\lambda y_{2 t}$. Se $\boldsymbol{u}_{t}$ for I(0), yt I(1) é co-integrado, e $\boldsymbol{u}_{t}$ é o termo de correção de erro, que recupera as informações de longo prazo perdidas na diferenciação das séries.

\subsubsection{Teste do sentido de causalidade}

A análise quanto ao sentido de causalidade entre as séries de preços será conduzida, empregando-se o procedimento estatístico apresentado por Granger (1969). A essência do conceito de Granger para o teste do sentido de causalidade é de que uma variável $P_{1}$ causa a variável $P_{2}$, se a inclusão dos valores defasados da variável $P_{1}$ contribui para explicar a variável $P_{2}$. Assim, a causalidade refere-se à capacidade de previsibilidade de uma variável a partir da outra.

A seguir, apresentam-se as duas equações necessárias para o teste de causalidade entre dois níveis de mercado, que podem ser estimadas por MQO:

$$
\begin{aligned}
& \ln P_{1, t}=\beta_{0}+\sum_{i=1}^{n} \beta_{1, i} \ln P_{2,(t-i)}+\sum_{k=1}^{m} \beta_{2, k} \ln P_{1,(t-k)}+\mu_{t} \\
& \ln P_{2, t}=\alpha_{0}+\sum_{k=1}^{m} \alpha_{l, k} \ln P_{l,(t-k)}+\sum_{i=1}^{n} \alpha_{2, i} \ln P_{2,(t-i)}+v_{t}
\end{aligned}
$$

sendo

$P_{l, t}=$ preço no mercado 1 , no período t;

$P_{2, t}=$ preço no mercado 2 , no período t;

$\beta_{0}, \beta_{1, i}, \beta_{2, k}=$ parâmetros estimados na equação (29);

$\alpha_{0}, \alpha_{1, k}, \alpha_{2, i}=$ parâmetros estimados na equação (30);

$i, k=$ números de defasagens dos preços nos níveis de mercado 1 e 2 , respectivamente; $\mathrm{e}$ $\mu_{t}, v_{t}=$ erros aleatórios. 
As hipóteses a serem testadas são de que os coeficientes dos valores passados da variável exógena das equações (29) e (30) são iguais a zero, ou seja:

$$
\begin{array}{ll}
\beta_{1,1}=\beta_{1,2}=\ldots=\beta_{1, n}=0 \quad(\text { na equação } 29) ; \mathrm{e} \\
\alpha_{1,1}=\alpha_{1,2}=\ldots=\alpha_{1, m}=0 \quad(\text { na equação } 30) .
\end{array}
$$

O sentido de causalidade será verificado pelo teste $\mathrm{F}$, considerando-se os graus de liberdade adequados. Se as hipóteses dessas duas equações forem rejeitadas, ter-se-á relação bi-causal; se ambas não forem rejeitadas, ter-se-á ausência de causalidade; se a hipótese de uma das equações for rejeitada e a outra não, a causalidade será unidirecional no sentido da variável exógena para a variável dependente da equação para a qual a hipótese nula é rejeitada.

Ao se estimarem as equações (29) e (30) para realizar o teste de causalidade, alguns cuidados devem ser tomados. Um deles é a definição do número de defasagens ( $n$ e $m$ ) que devem ser usadas nessas equações.

O número de defasagens da variável dependente é determinado com base nos resultados dos testes de AIC-Akaike e SC-Schwarz, já descritos na metodologia do teste de raiz unitária. Esses testes não são específicos para a definição do número de defasagens a serem utilizadas em testes de causalidade. No entanto, eles podem ser utilizados para proporcionar orientação sobre a duração do efeito de perturbações sofridas pelas próprias séries em tempo passado. Para a variável explicativa, o número de defasagens a ser considerado no modelo de causalidade pode ser função das defasagens dessa variável, que apresenta correlação cruzada significativa com o termo não-defasado da variável dependente.

Segundo Hoffman (1998), a análise de correlação procura determinar o grau de relacionamento linear entre duas variáveis, ou seja, procura-se medir a covariabilidade entre elas. 
As equações (29) e (30), descritas para o procedimento do teste de causalidade, apresentam as variáveis em nível. Entretanto, se elas possuírem raiz unitária, as variáveis devem ser aplicadas na primeira diferença. Lütkepohl (1993) e Sims, Stock e Watson (1990) descreveram que o teste de causalidade de Granger no contexto de um sistema integrado e co-integrado pode ser conduzido como nos sistemas em nível. Entretanto, a interpretação do sentido causal é referente ao curto prazo.

Sendo co-integradas as variáveis relacionadas para testar causalidade, deve-se também incorporar o termo de correção de erro às equações, para evitar problemas de especificação do modelo. De acordo com o teorema desenvolvido por Sims, Stock e Watson (1990), a significância do coeficiente estimado para esse termo deve ser testada (assim como as outras restrições de não-causalidade de Granger), comportando-se como um teste de coeficientes sobre média zero em regressores estacionários. Esse coeficiente, por sua vez, determina a relação de longo prazo entre as variáveis.

\subsubsection{Modelo de correção de erro e co-integração}

Se as séries de preços utilizadas no presente estudo forem não-estacionárias, os modelos de formação de preços formulados no item 3.2 devem ser estabelecidos na primeira diferença, a fim de se terem estimadores efícientes e não-viesados. Dessa forma, a análise de transmissão de preços fica prejudicada ${ }^{8}$, uma vez que as variáveis

\footnotetext{
${ }^{8}$ O modelo de transmissão de preços estabelecido por Nerlove (1958) descreveu que o ajuste dos preços ocorre da seguinte maneira:

$$
Y_{t}^{*}=\alpha X_{t}+u_{t}
$$
}

em que $X_{t}$ e $\boldsymbol{Y}_{t}$ são os preços correspondentes em dois níveis do mercado considerado, e o modelo a seguir se refere à formação do preço $Y_{i}$ :

$$
\boldsymbol{Y}_{t}-\boldsymbol{Y}_{t-1}=\delta\left(\boldsymbol{Y}_{t}^{*}-\boldsymbol{Y}_{t-1}\right)
$$

com $0<\delta<1$, em que $\delta$ representa a velocidade de ajustamento.

Assim, a elasticidade de curto prazo é igual a $E_{C P}=\frac{\partial Y_{t}}{\partial X_{t}} \frac{X_{t}}{Y_{t}}=\alpha \delta \frac{X_{t}}{Y_{t}}$

enquanto a elasticidade de longo prazo é representada por $E_{L P}=\frac{\partial Y_{t}^{*}}{\partial X_{t}} \frac{X_{t}}{Y_{t}^{*}}=\alpha \frac{X_{i}}{Y_{t}^{*}}$ 
representam a taxa de crescimento dos preços e não mais os preços propriamente ditos. Entretanto, podem-se verificar algumas das relações que foram pressupostas nesses modelos e obter inferências relacionadas ao mercado.

Ao estabelecer os modelos propostos, se as séries forem I (1) e a relação de longo prazo entre as variáveis existe, os parâmetros estimados com as variáveis na primeira diferença são também viesados. A inclusão de um componente que recupera esse desvio da trajetória de longo prazo das variáveis, denominado termo de correção de erro, já descrito para o teste de causalidade, soluciona esse problema. O termo de correção de erro consiste no resíduo da regressão da equação de co-integração e é incluído como variável determinística na estimação do modelo econométrico principal, dando origem ao chamado modelo com correção de erro.

Lütkepohl (1993) descreveu um modelo com correção de erro da seguinte maneira: "suponha, por exemplo, que $y_{1 t}$ representa o preço de uma commodity em um mercado particular e $y_{2 t}$ é o preço correspondente da mesma commodity em outro mercado. Assume-se, entretanto, que a relação de equilíbrio entre as duas variáveis é dado por $y_{1 t}=y_{2 t}$ e que a mudança em $y_{1 t}$ depende do desvio do equilíbrio no período $\mathrm{t}-1$, ou seja:

$$
\Delta y_{1 t}=h_{1}\left(y_{1, t-1}-y_{2, t-1}\right)+u_{1 t}
$$

Uma relação similar pode ser mantida para $y_{2 t}$, ou seja:

$$
\Delta y_{2 t}=h_{1}\left(y_{1, t-1}-y_{2, t-1}\right)+u_{2 t}
$$

Num modelo de correção de erro mais geral, o $\Delta y_{i t}$ pode depender também de mudanças prévias em ambas as variáveis, como no seguinte modelo:

$$
\begin{aligned}
& \Delta y_{1 t}=h_{1}\left(y_{1, t-1}-y_{2, t-1}\right)+f_{11,1} \Delta y_{1, t-1}+f_{12,1} \Delta y_{2, t-1}+u_{1 t} \\
& \Delta y_{2 t}=h_{2}\left(y_{1, t-1}-y_{2, t-1}\right)+f_{21,1} \Delta y_{1, t-1}+f_{22,1} \Delta y_{2, t-1}+u_{2 t}
\end{aligned}
$$


Para verificar a relação entre o modelo de correção de erro e o conceito de cointegração, suponha que $\boldsymbol{y}_{1 t}$ e $\boldsymbol{y}_{2 t}$ são ambas variáveis I(1). Nesse caso, todos os termos em (33) e (34) envolvem $\Delta y_{i t}$ estacionários. Assim, também $\boldsymbol{u}_{1 t}$ e $\boldsymbol{u}_{2 t}$ são erros ruídos brancos, os quais são também estacionários. Desde que um termo não-estacionário não possa ser envolvido no processo,

$$
h_{i}\left(y_{1, t-1}-\gamma y_{2, t-1}\right)=\Delta y_{i t}-f_{i 1,1} \Delta y_{1, t-1}-f_{i 2,1} \Delta y_{2, t-1}-u_{i t}
$$

deve também ser estacionário. Portanto, se $\boldsymbol{h}_{1} \neq 0$ ou $\boldsymbol{h}_{2} \neq 0, \boldsymbol{y}_{\boldsymbol{t}}-\boldsymbol{y}_{2 t}$ é estacionário e, então, representa uma relação de co-integração".

Uma vez ajustado um modelo com correção de erro, é importante também analisar a presença de autocorrelação entre os resíduos nas equações estimadas, utilizando-se o teste desenvolvido por Box e Pierce ${ }^{9}$ (Gujarati, 1995). A existência de correlação de resíduo faz com que seja violada uma das pressuposições básicas para a utilização de análise de regressão. Portanto, nos demais modelos descritos para testar a presença de raiz unitária, co-integração e teste de causalidade, a presença de autocorrelação de resíduos também deve ser verificada.

\subsubsection{Fonte de dados}

Com a finalidade de analisar a formação de preços no mercado de açúcar e álcool no Estado de São Paulo no período de pós-desregulamentação desses produtos, foram utilizadas 13 séries econômicas com dados de médias mensais em moeda nacional (real).

\footnotetext{
${ }^{9}$ No teste desenvolvido por Box e Pierce, a hipótese de nulidade representa a ausência de autocorrelação entre os resíduos e é verificada pelo teste $\mathrm{Q}$, definido como $Q=n \sum_{k=1}^{m} \hat{\rho}_{k}{ }^{2}$.

Sendo $\hat{\rho}$ a autocorrelação de resíduos, $n$ o número de amostras e $m$ o número de defasagens considerado para a variável.
} 
Para as variáveis incluídas na formação de preços do mercado de açúcar, as séries de preços (em kg) compreenderam o período de abril de 1997 a maio de 2000 . Os preços de açúcar cristal na prodúção é no atacado, assim como os preços ao produtor de açúcar refinado, foram calculados a partir dos indicadores de preços levantados e divulgados pelo CEPEA/ESALQ/USP (Centro, 2000). O mercado de açúcar deixou de ser regulamentado pelo governo federal no início da década de 90. Entretanto, este estudo considerou somente o período após abril de 1997, em razão da padronização da metodologia utilizada para o cálculo dos preços nesse período pelo CEPEA.

A série de preços de açúcar refinado no varejo foi calculada a partir do índice de preços de açúcar que compõe o Índice de Preços ao Consumidor - IPC, publicado pelo DIEESE em seu informativo mensal. Os preços de açúcar cristal no varejo foram obtidos também pelo DIEESE, na tabela de preços dos produtos da cesta básica do município de São Paulo.

Foram também levantados os preços internacionais do açúcar demerara no mercado "spot", utilizando-se preços de Nova York. Estes preços foram convertidos em moeda nacional, pois os produtores recebem seu pagamento em real e não em dólar. Para tanto, os preços em dólar foram multiplicados pela média mensal da taxa câmbio.

O preço de transporte, calculado pelo Índice Nacional de Preços ao Consumidor - INPC - IBGE/SNIPC (Instituto, 2000), foi utilizado como "proxy" para preço de insumo de comercialização no varejo. Como "proxy" para a relação do preço de açúcar cristal ao produtor e as indústrias consumidoras desse açúcar, foi utilizado o índice de preços de bebidas não-alcoólicas da Fundação Getúlio Vargas (FGV) - Conjuntura Econômica (CE). Acredita-se que a maior parte dos produtos incluidos como bebida não-alcoólica utiliza o açúcar como insumo de produção. Apenas os refrigerantes consomem $38 \%$ do consumo industrial de açúcar, segundo Carvalho (2000). 
Para o mercado do álcool anidro, utilizaram-se médias mensais em litros dos preços ao produtor e ao varejo, compreendendo o período de maio de 1998 a julho de 2000. Para o preço do álcool anidro no varejo foi utilizada como "proxy" a variável preço da gasolina. $\mathrm{O}$ álcool combustível anidro é vendido para o varejo como aditivo da gasolina, e por isso não se tem um índice de preço específico para esse produto no varejo. Nesse mesmo período foi também utilizada, como uma das séries indicadoras da formação do preço de gasolina, a série de preços de petróleo (óleo cru) expressos em US\$/ barril, a qual é divulgada na revista Conjuntura Econômica. Essa série foi transformada em moeda nacional, multiplicando-se seus preços pela média mensal da taxa de câmbio. Os preços de varejo para o álcool hidratado e para a gasolina foram calculados a partir do Índice de Preços ao Consumidor (Índice, 2000).

Os preços do álcool anidro e hidratado ao produtor foram calculados também a partir dos indicadores de preços levantados e divulgados pelo CEPEA/ESALQ/USP. Entretanto, para essas séries referentes ao período de abril de 1997 a abril de 1998, período para o qual o modelo referente ao estudo do mercado de açúcar exige, foi calculado com base nos preços de varejo desses produtos, considerando-se margem fixa e igual à margem calculada para maio de $1998^{10}$.

As séries de preços nominais ${ }^{11}$ foram empregadas na forma de logaritmo natural $(\mathrm{ln})$, a fim de se obter um melhor ajustamento dos modelos.

Este trabalho teve ênfase maior no estudo do mercado do açúcar, em razão de limitação na disponibilidade de preços no mercado de álcool e de seu curto período de desregulamentação. Não existe, por exemplo, uma fonte oficial de dados relativos ao setor atacadista desse produto.

\footnotetext{
${ }^{10}$ Margem de maio de 1998 = (preço de varejo de maio/98) - (preço do produtor de maio/98).

11 Segundo Pino e Rocha (1994), "se a taxa de inflação for semelhante de mês a mês no período considerado, o modelo com a série, previamente transformada na primeira diferença, deflacionada é aproximadamente equivalente ao modelo com esta série sem deflação", o que pode ser considerado no período deste estudo, no caso de se utilizarem as variáveis na primeira diferença.
} 


\section{RESULTADOS E DISCUSSÃO}

Este tópico está dividido em três partes, sendo em cada uma delas as séries de preços primeiramente estudadas quanto à sua estacionariedade e a possíveis relações de co-integração, tendo-se identificado, a seguir, relações de causalidade entre elas e, finalmente, estimados e analisados os coeficientes das equações de formação dos preços descritos no tópico anterior. A primeira parte trata dos resultados do processo de formação de preço nos níveis de mercado de açúcar. A segunda e a terceira abordam os respectivos resultados das relações de preços ao produtor e de preços no varejo para álcool anidro e hidratado ${ }^{12}$.

Um modelo econômico foi proposto e estimado para expressar a formação de preços no mercado do açúcar e nos mercados de álcool anidro e hidratado. O mercado de álcool anidro é muito complexo, uma vez que esse produto é consumido juntamente com a gasolina. A inexistência de estatísticas relativas aos preços atacadistas do mercado de álcool limitou esta análise. No mercado de álcool hidratado, também a ausência dos preços no atacado e o período relativamente limitado dos dados (mercado desregulamentado a partir de fevereiro de 1999 e dados estudados até julho de 2000) restringiram a análise dos resultados.

Na Tabela 4.1 apresenta-se a relação das variáveis utilizadas e suas respectivas descrições.

\footnotetext{
${ }^{12}$ Os níveis de mercado foram estabelecidos em função da disponibilidade dos dados.
} 
Tabela 4.1 - Variáveis utilizadas na pesquisa

\begin{tabular}{llc}
\hline Variáveis & \multicolumn{1}{c}{ Descrição } & $\begin{array}{c}\text { Indicações das variáveis } \\
\text { no Modelo Econômico }\end{array}$ \\
\hline lppac & Logaritmo do preço no produtor de açúcar cristal & pac \\
lpaac & Logaritmo do preço no atacado de açúcar cristal & $\mathrm{a}$ \\
lpvac & Logaritmo do preço no varejo de açúcar cristal & $\mathrm{v}$ \\
lppar & Logaritmo do preço no produtor de açúcar refinado & $\mathrm{r}$ \\
lpvar & Logaritmo do preço no varejo de açúcar refinado & $\mathrm{v}$ \\
lpni & Logaritmo do preço internacional de açúcar & $\mathrm{ni}$ \\
lpph & Logaritmo do preço no produtor de álcool hidratado & $\mathrm{ph}$ \\
lpvh & Logaritmo do preço no varejo de álcool hidratado & $\mathrm{vh}$ \\
lppi & Logaritmo do preço no produtor de álcool anidro & $\mathrm{pi}$ \\
lpvi & $\begin{array}{l}\text { Logaritmo do preço no varejo de álcool anidro (indicado } \\
\text { como preço ao varejo da gasolina) }\end{array}$ & $\mathrm{vi}$ \\
lppetro & Logaritmo do preço do petróleo & \\
lpb & Logaritmo do preço de bebidas não-alcoólicas (índice) & - \\
lptr & Logaritmo do preço de transporte (índice) & $\mathrm{z}_{4}$ \\
\hline
\end{tabular}

Conforme descrito no modelo econômico, os preços ao produtor de açúcar, álcool anidro e hidratado são relacionados. Essa relação se estabelece no preço observado desses produtos, não levando em consideração a questão da paridade técnica (descrita no tópico 2, item 2.2) entre os preços dos produtos do setor sucroalcooleiro. A paridade técnica não influencia o processo de formação de preços desses mercados, porque a relação técnica entre os preços desses produtos é uma constante. 


\subsection{Mercados de açúcar cristal e de açúcar refinado}

Conforme descrito no tópico 3, o modelo econômico de formação de preços do mercado de açúcar foi desenvolvido, considerando-se cinco equações comportamentais, a serem estimadas para confirmação das pressuposições teóricas da formação de preços nos diferentes níveis do mercado de açúcar.

\subsubsection{Testes de raiz unitária ${ }^{13}$}

Estudos empíricos têm indicado que as séries econômicas apresentam comportamento nã̃o-estacionário com freqüência, o que requer estudo prévio das séries de preços consideradas na especificação do modelo econométrico de formação de preços no mercado de açúcar, para que a relação entre essas variáveis não seja uma relação espúria. Com a finalidade de testar a existência de tendência estocástica (raiz unitária) das variáveis, foram ajustados modelos com o número de defasagens determinado pelos critérios de informação de Akaike e Schwarz com o máximo de 12 defasagens, exceção feita aos casos em que apenas a variável contemporânea apresentou-se significativa. Nesses casos foi utilizada pelo menos uma defasagem para realização dos testes.

Nas Tabelas 4.2 a 4.4, apresentam-se os resultados de estacionariedade das variáveis em nível, segundo as estatísticas $\tau_{\tau}, \tau_{\mu}$ e $\tau$, as quais consideram os modelos para análise de estacionariedade com constante e tendência, apenas com constante e sem constante e tendência, respectivamente.

Na Tabela 4.2 foi utilizada, ainda, a estatística $\tau_{\beta \tau}$, para avaliar a significância da tendência no modelo, sendo não-significativa, em nível de $1 \%$, em todas as variáveis analisadas. Passou-se, então, para a Tabela 4.3, na qual as estatísticas $\tau_{\alpha \mu}$ e $\tau_{\mu}$ são

\footnotetext{
${ }^{13}$ Os testes de raiz unitária são realizados, comparando-se o valor da estatística t com os valores críticos de Fuller (1976), que se encontram na Tabela 1A.1, do Apêndice 1.
} 
apresentadas, tendo sido utilizadas para avaliar a significância do termo constante e a estacionariedade no modelo com constante, respectivamente.

Exceto na série de preço internacional (lpni), a qual foi estacionária em nível, num modelo com constante, todas as demais variáveis apresentaram o termo constante não-significativo a $1 \%$ e $5 \%$ de significância. Assim, não se utilizaram as estatísticas $\tau_{\tau} \mathrm{e}$ $\tau_{\mu}$ nas Tabelas 4.2 e 4.3 , pois a estacionariedade dessas variáveis em nível deveria ser verificada no modelo sem constante e sem tendência pela estatística $\tau$ (Tabela 4.4).

Tabela 4.2 - Teste de estacionariedade em modelo com constante $(\alpha)$ e tendência $(T)$, estatística $\tau_{\tau}$

\begin{tabular}{|c|c|c|c|c|}
\hline \multirow{2}{*}{$\begin{array}{l}\text { Modelo } 1 \\
\text { Variáveis }\end{array}$} & \multicolumn{3}{|c|}{$\Delta x_{t}=\alpha+\theta T+\gamma_{1} x_{t-1}+\sum_{j=1}^{n} \gamma_{j} \Delta x_{t-j}+e_{t}$} & \multirow{2}{*}{$\begin{array}{c}\mathrm{H}_{0}: \gamma_{1}=\mathbf{0} \\
\begin{array}{c}\text { Nível de significância } \\
\text { da estatística "Q" }\end{array}\end{array}$} \\
\hline & $\begin{array}{l}\text { Defasagens } \\
\quad(\mathrm{n})\end{array}$ & $\begin{array}{l}\text { Valor da Estatística t } \\
\qquad \mathrm{H}_{0}: \theta=0\end{array}$ & $\begin{array}{c}\text { Valor da Estatística } \mathrm{t} \\
\mathrm{H}_{0}: \gamma_{1}=\mathbf{0}\end{array}$ & \\
\hline Ippac & 1 & 0.18 & -2.01 & 0,39 \\
\hline Ipaac & 1 & 0.27 & -2.21 & 0,81 \\
\hline Ipvac & 1 & 0.51 & -2.06 & 0,33 \\
\hline lppar & 1 & 0.36 & -2.02 & 0,13 \\
\hline lpvar & 1 & 0.48 & -1.95 & 0,70 \\
\hline lpni & 1 & -1.37 & $-3.55^{* *}$ & 0,42 \\
\hline lpph & 1 & 1.13 & -1.6 & 0.68 \\
\hline lppi & 1 & 0.89 & -1.62 & 0.26 \\
\hline lpb & 1 & 1.83 & -2.04 & 0.95 \\
\hline lptr & 1 & 1.58 & -1.60 & 0,60 \\
\hline
\end{tabular}

**Significativo ao nível de significância de $\overline{5 \%}$. 
Tabela 4.3 - Teste de estacionariedade em modelo com constante ( $\alpha$ ), estatística $\tau_{\mu}$

\begin{tabular}{|c|c|c|c|c|}
\hline \multirow{2}{*}{$\begin{array}{l}\text { Modelo } 2 \\
\text { Variáveis }\end{array}$} & \multicolumn{3}{|c|}{$\Delta x_{t}=\alpha+\gamma_{1} x_{t-1}+\sum_{j=1}^{n} \gamma_{j} \Delta x_{t-j}+e_{t}$} & \multirow{2}{*}{$\begin{array}{c}\mathrm{H}_{0}: \gamma_{1}=0 \\
\begin{array}{c}\text { Nível de significância } \\
\text { da estatística "Q" }\end{array}\end{array}$} \\
\hline & $\begin{array}{l}\text { Defasagens } \\
\quad(\mathbf{n})\end{array}$ & $\begin{array}{l}\text { Valor da Estatística } \mathrm{t} \\
\qquad \mathrm{H}_{0}: \alpha=0\end{array}$ & $\begin{array}{l}\text { Valor da Estatística } \mathrm{t} \\
\qquad \mathrm{H}_{0}: \gamma_{1}=0\end{array}$ & \\
\hline lppac & 1 & -1.98 & -2.04 & 0,38 \\
\hline Ipaac & 1 & -2.14 & -2.23 & 0,80 \\
\hline Ipvac & 1 & -1.89 & -2.05 & 0,34 \\
\hline Ippar & 1 & -1.94 & -2.07 & 0,14 \\
\hline Ipvar & 1 & -1.86 & -2.02 & 0,67 \\
\hline Ipni & 1 & $-3.27^{* *}$ & $-3.30^{* *}$ & 0,45 \\
\hline lpph & 1 & -1.23 & -1.38 & 0.76 \\
\hline Ippi & 1 & -1.49 & -1.58 & 0.28 \\
\hline $\mathrm{lpb}$ & 1 & 1.02 & -1.001 & 0,82 \\
\hline lptr & 1 & 1.93 & -0.26 & 0,78 \\
\hline
\end{tabular}

**Significativo ao nível de significância de $5 \%$.

Na Tabela 4.4 foi observado estacionariedade no nível de $5 \%$ de significância apenas para a variável lpb. Na série de preços do produtor de açúcar refinado, foi observada a presença de autocorrelação de resíduos no nível de significância abaixo de 10\%. Dessa forma, esses resultados devem ser analisados com a devida cautela. 
Tabela 4.4 - Teste de estacionariedade em modelo sem constante e tendência, estatística $\tau$

\begin{tabular}{lccc}
\hline Modelo 3 : & $\Delta \boldsymbol{x}_{\boldsymbol{t}}=\gamma_{\boldsymbol{1}} \boldsymbol{x}_{\boldsymbol{t}-\boldsymbol{1}}+\sum_{j=1}^{n} \gamma_{j} \Delta \boldsymbol{x}_{\boldsymbol{t}-\boldsymbol{j}}+\boldsymbol{e}_{\boldsymbol{t}}$ & $\mathrm{H}_{0}: \gamma_{\boldsymbol{l}}=\mathbf{0}$ \\
\hline Variáveis & Defasagens (n) & $\begin{array}{r}\text { Valor da Estatística } \\
\mathrm{H}_{0}: \gamma_{\boldsymbol{1}}=\boldsymbol{0}\end{array}$ & $\begin{array}{c}\text { Nível de significância da } \\
\text { estatística "Q" }\end{array}$ \\
\hline lppac & 1 & -0.47 & 0,45 \\
lpaac & 1 & -0.66 & 0,80 \\
lpvac & 1 & -0.93 & 0,30 \\
lppar & 1 & -0.83 & 0,07 \\
lpvar & 1 & -0.99 & 0,75 \\
lpni & 1 & -0.44 & 0,17 \\
lpph & 1 & -0.77 & 0.66 \\
lppi & 1 & -0.63 & 0.21 \\
lpb & 1 & $2.23^{* *}$ & 0.79 \\
lptr & 1 & 1.61 & 0,52 \\
\hline
\end{tabular}

**Significativo ao nível de significância de 5\%.

A fim de verificar a presença de raiz unitária nas séries de preços, passou-se, então, à análise da Tabela 4.5, na qual se apresentam os resultados relativos à estacionariedade das séries de preços na primeira diferença, segundo a estatística $\tau$.

Os resultados indicam a presença de raiz unitária no nível de significância de $1 \%$, na maioria das variáveis consideradas no estudo, uma vez que foram aceitas as hipóteses de estacionariedade nos modelos na primeira diferença dessas variáveis. Os altos níveis de significância da estatística "Q" do teste de Box-Pierce, conforme descrito na última coluna da Tabela 4.5, assim como nas tabelas anteriores, rejeitam a hipótese de nulidade desse teste, que considera a existência de autocorrelação entre os resíduos. 
Uma vez que as variáveis descritas anteriormente foram analisadas conjuntamente, os testes de co-integração podem também auxiliar na definição da ordem de integração dessas variáveis. Assim, se duas ou mais séries forem co-integradas e se uma delas for integrada de primeira ordem - I (1), a outra também é I (1). Tal observação é válida para a série de preços internacionais de açúcar (lpni) e de bebida não-alcoólica (lpb), os quais foram estacionários também em nível, apenas com constante e sem tendência e constante, respectivamente.

Tabela 4.5 - Teste de raiz unitária ${ }^{14}$ em modelo sem constante e tendência, estatística $\tau$

\begin{tabular}{|c|c|c|c|}
\hline \multirow{2}{*}{$\begin{array}{l}\text { Modelo } 6 \\
\text { Variáveis }\end{array}$} & \multicolumn{2}{|c|}{$\Delta \Delta x_{t}=\sigma_{1} \Delta x_{t-1}+\sum_{j=1}^{n} \sigma_{j} \Delta \Delta x_{t-j}+e_{t}$} & \multirow{2}{*}{$\begin{array}{c}\mathrm{H}_{0}: \sigma_{1}=\boldsymbol{0} \\
\begin{array}{c}\text { Nível de significância da } \\
\text { estatística "Q" }\end{array}\end{array}$} \\
\hline & Defasagens ( $n$ ) & $\begin{array}{c}\text { Valor da Estatística t } \\
\mathrm{H}_{0}: \sigma_{1}=\boldsymbol{0}\end{array}$ & \\
\hline$\overline{\Delta l p p a c}$ & 1 & $-3.55^{*}$ & 0,41 \\
\hline$\Delta$ lpaac & 1 & $-3.41^{*}$ & 0,65 \\
\hline$\Delta$ lpvac & 1 & $-2.98^{*}$ & 0,85 \\
\hline$\Delta$ lppar & 1 & $-3.40^{*}$ & 0,94 \\
\hline$\Delta$ lpvar & 1 & $-2.74^{*}$ & 0,87 \\
\hline$\Delta$ Ipni & 1 & $-5.02^{*}$ & 0,34 \\
\hline$\Delta \mathrm{lpph}$ & 1 & $-2.98^{*}$ & 0.55 \\
\hline$\Delta$ lppi & 1 & $-4.66^{*}$ & 0.56 \\
\hline$\Delta \mathrm{lpb}$ & 1 & $-3.98^{*}$ & 0.61 \\
\hline$\Delta$ lptr & 1 & $-2.41 * *$ & 0,46 \\
\hline
\end{tabular}

*Significativo ao nível de significância de 1\%

**Significativo ao nível de significância de $5 \%$.

${ }^{14} \mathrm{O}$ símbolo " $\Delta$ " precedendo as descrições das variáveis simboliza o uso das mesmas na primeira diferença. 


\subsubsection{Testes de co-integração}

Os testes de co-integração foram realizados, primeiramente, entre as variáveis duas a duas, para obter os termos de correção de erro para os testes de causalidade que se seguem. Esses resultados têm a finalidade de testar as relações entre as variáveis que poderiam estar envolvidas no modelo econômico, verificando-se as pressuposições feitas neste modelo.

Conforme descrito na metodologia do teste de co-integração, as variáveis são consideradas co-integradas quando o resíduo de suas regressões é estacionário. Assim, foram realizadas regressões auxiliares, e as estatísticas de Dickey-Fuller (DF) e o número de defasagens (n) descritos nas regressões abaixo correspondem à análise da estacionariedade daqueles resíduos. Os resíduos foram estacionários quando o valor descrito da estatística DF foi maior do que o valor crítico apresentado na Tabela 1A.2, do Apêndice 1. As variáveis que apresentaram co-integradas são descritas a seguir ${ }^{15}$ :

\begin{tabular}{|c|c|c|c|}
\hline $\begin{array}{c}\text { Ipaac }=0,067+0,895 \text { lppac } \\
(0,26) \quad(0,00)\end{array}$ & $\mathrm{R}^{2}=0,91$ & $\mathrm{DF}=6.56$ & $\mathrm{n}=3$ \\
\hline $\begin{array}{c}\text { Ippac }=-0,17+1,025 \text { lpaac } \\
(0,00) \quad(0,00)\end{array}$ & $\mathrm{R}^{2}=0,91$ & $\mathrm{DF}=11.43$ & $\mathrm{n}=10$ \\
\hline $\begin{array}{c}\text { lpaac }=-0,157+1,26 \text { lpvac } \\
(0,009)(0,00)\end{array}$ & $\mathrm{R}^{2}=0,88$ & $\mathrm{DF}=8.13$ & $\mathrm{n}=11$ \\
\hline $\begin{array}{c}\text { lppac }=-0,5879+0,63 \text { lpph } \\
(0,00) \quad(0,00)\end{array}$ & $\mathrm{R}^{2}=0,70$ & $\mathrm{DF}=4.57$ & $\mathrm{n}=9$ \\
\hline $\begin{array}{c}\text { lpph }=0,3136+1,10 \text { lppac } \\
(0,05) \quad(0,00)\end{array}$ & $\mathrm{R}^{2}=0,70$ & $\mathrm{DF}=6.43$ & $\mathrm{n}=11$ \\
\hline $\begin{array}{c}\text { lppac }=-0,21+1,02 \text { lppi } \\
(0,03) \quad(0,00)\end{array}$ & $\mathrm{R}^{2}=0,78$ & $\mathrm{DF}=12.0$ & $\mathrm{n}=11$ \\
\hline Ippi $=-0,07+0,76 \mathrm{lppac}$ & $\mathrm{R}^{2}=0,78$ & $\mathrm{DF}=15.2$ & $\mathrm{n}=11$ \\
\hline
\end{tabular}
$(0,42) \quad(0,00)$

${ }^{15}$ Os valores entre parênteses abaixo dos coeficientes das regressões correspondem ao valor do nível de significância da estatística " $t$ ", que considera como hipótese de nulidade os coeficientes iguais a zero. 


\begin{tabular}{|c|c|c|c|}
\hline $\begin{aligned} \text { lpvac }= & 0,027+0,701 \text { lpaac } \\
& (0,56) \quad(0,00)\end{aligned}$ & $\mathrm{R}^{2}=0,88$ & $\mathrm{DF}=7.97$ & $n=9$ \\
\hline $\begin{array}{c}\text { Ippar }=0,125+0,794 \text { lppac } \\
(0,136)(0,00)\end{array}$ & $\mathrm{R}^{2}=0,82$ & $\mathrm{DF}=7.61$ & $\mathrm{n}=11$ \\
\hline $\begin{array}{c}\text { lppac }=-0,358+1,03 \text { lppar } \\
(0,00) \quad(0,00)\end{array}$ & $\mathrm{R}^{2}=0,82$ & $\mathrm{DF}=9.23$ & $\mathrm{n}=11$ \\
\hline $\begin{array}{c}\text { lppac }=-0,375+1,24 \text { lpvac } \\
(0,00) \quad(0,00)\end{array}$ & $\mathrm{R}^{2}=0,75$ & $\mathrm{DF}=6.79$ & $n=10$ \\
\hline $\begin{array}{c}\text { lpvac }=0,041+0,602 \text { lppac } \\
(0,59) \quad(0,00)\end{array}$ & $\mathrm{R}^{2}=0,75$ & $\mathrm{DF}=8.36$ & $\mathrm{n}=10$ \\
\hline $\begin{array}{c}\text { Ippac }=-0,54+1,32 \text { lpvar } \\
(0,00)(0,00)\end{array}$ & $\mathrm{R}^{2}=0,65$ & $\mathrm{DF}=4.41$ & $\mathrm{n}=10$ \\
\hline $\begin{array}{c}\text { lpvar }=0,061+0,498 \text { lppac } \\
(0,45) \quad(0,00)\end{array}$ & $\mathrm{R}^{2}=0,65$ & $\mathrm{DF}=6.22$ & $\mathrm{n}=9$ \\
\hline $\begin{aligned} \text { lpvar }= & 0,027+0,701 \text { lppar } \\
& (0,56) \quad(0,00)\end{aligned}$ & $\mathrm{R}^{2}=0,88$ & $\mathrm{DF}=7.97$ & $\mathrm{n}=9$ \\
\hline $\begin{array}{c}\text { Ipni }=-1,16+0,14 \text { lppac } \\
(0,00)(0,12)\end{array}$ & $\mathrm{R}^{2}=0,063$ & $\mathrm{DF}=4.45$ & $\mathrm{n}=9$ \\
\hline
\end{tabular}

Os sinais dos coeficientes estimados acima indicam que todas as variáveis relacionadas duas a duas são positivamente relacionadas.

A seguir foi testada a existência de co-integração entre as variáveis envolvidas nas equações especificadas segundo os modelos de formação de preços nos diversos níveis de mercado, conforme definido nas equações (3), (8), (12) e (16) do item 3.2.1. Como explicado anteriormente, o valor do teste de Dickey-Fuller e o número de defasagens (n) utilizados são referentes ao teste de estacionariedade do resíduo da equação estimada. Os seguintes resultados foram obtidos com as regressões:

$$
\begin{aligned}
& \text { Ippac }=1,2+1,35 \text { lpaác }-0,55 \text { lppar }+0,27 \text { lpni }-0,19 \text { lpb }+ \\
& \begin{array}{llll}
(0,44) & (0,00) \quad(0,01) \quad(0,00) \quad(0,53)
\end{array} \\
& +0,09 \text { lpph }+0,04 \text { lppi } \\
& (0,35) \quad(0,79) \\
& \mathrm{R}^{2}=0,95 \quad \mathrm{DF}=30.0 \quad \mathrm{n}=11
\end{aligned}
$$




$$
\text { lpaac }=\underset{(0,25)}{0,0424}+\underset{(0,00)}{0,532} \text { lppac }+\underset{(0,00)}{0,603 \text { lpvac }}
$$

$$
\begin{gathered}
\text { Ippar }=\underset{(0,105)}{0,072}+0,375 \text { lppac }+0,8567 \text { lpvar } \\
(0,00)
\end{gathered}
$$

$$
\text { Ipvac }=\underset{(0,63)}{0,025+0,7008 \mathrm{lpaac}+}+\underset{(0,00)}{0,0002} \mathrm{lptr}
$$$$
\text { lpvar }=-0,01+0,65 \text { lppar }+0,007 \text { lptr }
$$

$$
\begin{array}{lll}
\mathrm{R}^{2}=0,97 & \mathrm{DF}=17.0 & \mathrm{n}=10 \\
\mathrm{R}^{2}=0,95 & \mathrm{DF}=5.21 & \mathrm{n}=11 \\
\mathrm{R}^{2}=0,88 & \mathrm{DF}=7.91 & \mathrm{n}=9 \\
\mathrm{R}^{2}=0,90 & \mathrm{DF}=7.76 & \mathrm{n}=11
\end{array}
$$

Portanto, tem-se a presença de um vetor de co-integração entre as variáveis utilizadas em todos os modelos propostos. $\mathrm{Na}$ equação referente ao produtor de açúcar cristal, verificou-se que os sinais estavam de acordo com o esperado para as variáveis preço de bebida não-alcóolica (lpb) e preço de açúcar refinado no produtor (lppar). Entretanto, nesse mesmo modelo, a variável preço de açúcar cristal no atacado (lpaac), assim como as variáveis preço de açúcar cristal no varejo (lpvac) e de açúcar refinado no varejo (lpvar) nos modelos de preço de cristal no atacado e no produtor de refinado, respectivamente, apresentou sinais positivos, sendo esperada para essas variáveis uma relação negativa no modelo econômico. Tais resultados podem ser explicados pelo fato de que o teste foi realizado para as variáveis contemporâneas e os sinais esperados eram referentes àquelas variáveis defasadas de um período.

Uma vez que essas variáveis possuem raiz unitária, elas foram analisadas na primeira diferença ${ }^{16}$. Foi utilizado o modelo de causalidade de Granger, com termo de correção de erro entre as variáveis que se apresentaram co-integradas. O termo de correção de erro recuperou informações de longo prazo perdidas nas diferenças das variáveis em estudo.

\footnotetext{
${ }^{16}$ As variáveis lpni e lpb, uma vez sendo co-integradas com as demais variáveis, foram também consideradas I (1).
} 


\subsubsection{Testes de causalidade de Granger}

$\mathrm{O}$ número de defasagens da variável dependente utilizada no teste de causalidade de Granger corresponde ao resultado do critério de Akaike e Schwarz, que determina o número de defasagens $(\boldsymbol{p})$, o qual minimiza a soma dos quadrados dos resíduos estimados no processo auto-regressivo de ordem $\boldsymbol{p}$. No caso da variável explicativa, utilizaram-se as defasagens significativas do teste de correlação cruzada entre as variáveis relacionadas ou, pelo menos, uma defasagem no caso de não haver nenhuma significativa, tendo em vista atender aos procedimentos básicos do teste.

A fim de verificar o grau de associação linear entre a defasagem de uma variável em relação a outra, foram realizados testes de correlação cruzada. Os resultados dos testes de correlação estão apresentados na Tabela 4.6.

Os resultados indicaram que, na maior parte das relações estabelecidas, a relação contemporânea foi a mais significativa. Entretanto, o teste de causalidade de Granger utilizou as variáveis defasadas da variável explicativa.

Os resultados da Tabela 4.6 podem fornecer algumas informações a respeito do grau de correlação entre as variáveis ${ }^{17}$. Assim, tem-se uma relação linear significativa no sentido do preço internacional ( $\Delta$ lpni) e do preço do produtor de hidratado $(\Delta \operatorname{lpph})$ defasados para o preço do produtor de açúcar cristal $(\Delta \mathrm{lppac})$. Um alto grau de relação linear foi também verificado entre uma defasagem do preço de açúcar cristal no produtor com as variáveis contemporâneas do preço de álcool anidro no produtor ( $\Delta \mathrm{lppi})$, do preço de açúcar cristal no atacado ( $\Delta$ lpaac) e do preço de açúcar refinado no produtor ( $\Delta$ lppar). No caso da variável preço de bebida não-alcoólica $(\Delta \mathrm{lpb})$, apesar de somente a

\footnotetext{
${ }^{17}$ Todas as referências às variáveis "preços" descritas a seguir até o término do item 4.1 na verdade estão relacionadas à taxa de crescimento daqueles preços, pois as variáveis estão na primeira diferença do logaritmo desses preços. Tal denominação é utilizada para haver maior fluidez do texto.
} 
terceira defasagem em relação ao preço de açúcar cristal do produtor ser significativa, utilizaram-se as defasagens de 1 a 3 para o teste de causalidade, desde que os valores obtidos foram próximos do nível significativo.

Tabela 4.6 - Correlações cruzadas entre as variáveis utilizando 12 defasagens para as variáveis ${ }^{18}$

\begin{tabular}{|c|c|c|c|c|c|c|}
\hline \multirow[t]{2}{*}{ defasagens } & \multicolumn{6}{|c|}{ Correlações cruzadas } \\
\hline & \multicolumn{6}{|c|}{$\Delta$ lppac e $\Delta$ lpni } \\
\hline$-12 \mathrm{a}-5$ & -0.3902148 & -0.1295312 & 0.2912122 & 0.3743865 & 0.1485736 & 0.1883629 \\
\hline$-6 a-1:$ & 0.0520364 & -0.1972506 & -0.2032576 & -0.1640827 & -0.1955964 & -0.1362337 \\
\hline 0 a $5:$ & 0.1498078 & $0.3391728^{*}$ & -0.0146310 & 0.0155184 & 0.2206460 & -0.1353332 \\
\hline 6 a 11: & -0.0538223 & 0.1760720 & 0.1480044 & -0.1142838 & 0.0141613 & -0.0000573 \\
\hline \multirow[t]{2}{*}{ 12: } & -0.1485033 & & & & & \\
\hline & \multicolumn{6}{|c|}{$\Delta$ lppac e $\Delta l p p a r$} \\
\hline-12 a -5: & -0.0405864 & -0.0395321 & -0.0481093 & -0.0499554 & 0.0258864 & 0.1155883 \\
\hline$-6 a-1:$ & 0.0322373 & -0.0680309 & -0.1393248 & 0.1001103 & $0.3617246^{*}$ & $0.5835798^{*}$ \\
\hline 0 a $5:$ & $0.6086379^{*}$ & 0.2770112 & 0.1389428 & -0.0310606 & -0.0399264 & -0.0514145 \\
\hline 6 a 11: & -0.0456642 & -0.2099772 & -0.2430338 & -0.2202026 & -0.0626049 & 0.0160073 \\
\hline \multirow[t]{2}{*}{ 12: } & -0.0065197 & & & & & \\
\hline & \multicolumn{6}{|c|}{$\Delta$ lppac e $\Delta l p a a c$} \\
\hline-12 a $-5:$ & 0.0337349 & -0.0123284 & 0.0488138 & -0.0866992 & -0.1387436 & -0.0339165 \\
\hline$-6 a-1:$ & -0.1198610 & -0.2317030 & -0.0960250 & 0.1093273 & 0.3109988 & $0.6985385 *$ \\
\hline 0 a 5: & $0.7751186^{*}$ & 0.1734979 & 0.0589574 & 0.0388955 & -0.1839295 & -0.1633809 \\
\hline 6 a 11: & -0.0882869 & -0.1975493 & -0.2261757 & 0.0493140 & 0.0545492 & -0.0029469 \\
\hline \multirow[t]{2}{*}{ 12: } & 0.0217697 & & & & & \\
\hline & \multicolumn{6}{|c|}{$\Delta$ lppac e $\Delta \mathrm{lpb}$} \\
\hline-12 a $-5:$ & 0.1206056 & 0.1517457 & 0.0605362 & -0.1559534 & -0.1620679 & 0.0379934 \\
\hline$-6 a-1:$ & 0.1366738 & 0.0594269 & 0.0203771 & 0.3110899 & -0.1025162 & -0.2191764 \\
\hline 0 a $5:$ & -0.0308180 & -0.1486445 & -0.2804451 & $-0.3346402 *$ & 0.0981201 & -0.0071687 \\
\hline \multirow[t]{2}{*}{$\begin{array}{l}6 \text { a } 11: \\
12:\end{array}$} & $\begin{array}{l}0.1396140 \\
-0.1341537\end{array}$ & 0.2488842 & -0.1313822 & -0.2329569 & 0.0352305 & 0.1657342 \\
\hline & \multicolumn{6}{|c|}{$\Delta$ lppac e $\Delta$ lppi } \\
\hline-12 a $-5:$ & -0.2354091 & 0.0580973 & 0.2425737 & 0.0873376 & -0.1717457 & -0.0759755 \\
\hline$-6 a-1:$ & -0.0841470 & 0.0440802 & 0.1968699 & 0.0066728 & 0.0373425 & $0.3382873^{*}$ \\
\hline 0 a $5:$ & $0.4403891^{*}$ & 0.2305517 & 0.1844666 & 0.2135685 & -0.2183030 & -0.1189028 \\
\hline 6 a 11: & 0.0537798 & -0.1069231 & -0.0099495 & -0.0696507 & -0.2702149 & -0.2243695 \\
\hline \multirow[t]{2}{*}{ 12: } & 0.0705374 & & & & & \\
\hline & \multicolumn{6}{|c|}{$\Delta$ lppac e $\Delta$ lpph } \\
\hline-12 a -5 & -0.1908544 & 0.0010542 & 0.2624368 & 0.2190063 & -0.0673688 & -0.0507864 \\
\hline-6 a $-1:$ & -0.0424933 & -0.1001945 & 0.0265490 & 0.0484864 & 0.1696866 & 0.2624118 \\
\hline 0 a $5:$ & $0.5433348^{*}$ & $0.3318121^{*}$ & 0.1374571 & 0.3423948 & -0.0418799 & -0.1894054 \\
\hline 6 a 11: & -0.1655249 & -0.1855695 & -0.2779746 & -0.1253298 & -0.1646864 & -0.1435231 \\
\hline 12: & 0.0772285 & & & & & \\
\hline
\end{tabular}

\footnotetext{
${ }^{18}$ As defasagens negativas correspondem ao preço defasado da primeira variável descrita em relação ao preço da segunda variável, assim como as defasagens positivas referem-se ao preço defasado da segunda variável em relação à primeira.
} 
Tabela 4.6, cont... ${ }^{19}$

\begin{tabular}{|c|c|c|c|c|c|c|}
\hline defasagens & & & Correlaç & $s$ cruzadas & & \\
\hline & & & $\Delta$ lppa & $\Delta$ lpvar & & \\
\hline-12 a -5 & 0.0102110 & -0.0080694 & -0.0108196 & -0.0080235 & 0.0688874 & 0.0497235 \\
\hline$-6 a-1:$ & 0.1237804 & 0.0172668 & -0.0052136 & 0.2944712 & $0.4819488^{*}$ & $0.4668769^{*}$ \\
\hline 0 a $5:$ & $0.4705872 *$ & $0.3050845^{*}$ & 0.0239310 & -0.1968129 & -0.1290095 & -0.1511648 \\
\hline $\begin{array}{l}6 \text { a 11: } \\
12:\end{array}$ & $\begin{array}{l}-0.2089193 \\
0.0129476\end{array}$ & -0.1307520 & -0.1893263 & -0.1732075 & -0.1156817 & 0.0500511 \\
\hline & & & $\Delta \mathrm{lppa}$ & $\Delta$ lpvac & & \\
\hline-12 a -5: & 0.0502344 & 0.0010055 & -0.0519730 & -0.0221872 & 0.0461393 & -0.0041516 \\
\hline$-6 a-1:$ & 0.0420382 & 0.0527453 & -0.0324257 & 0.2072818 & $0.5144507^{*}$ & $0.5460803 *$ \\
\hline 0 a $5:$ & $0.5291481^{*}$ & $0.3284599 *$ & 0.0889477 & -0.1468062 & -0.1835588 & -0.1174574 \\
\hline $\begin{array}{l}6 \text { a } 11: \\
12:\end{array}$ & $\begin{array}{c}-0.1485166 \\
0.0969644\end{array}$ & -0.1188596 & -0.2810960 & -0.1697477 & -0.0516276 & 0.0155368 \\
\hline & & & Alpaa & $\Delta$ lpvac & & \\
\hline-12 a $-5:$ & -0.0997897 & 0.0015320 & -0.0553341 & -0.1154659 & -0.0695921 & 0.0171912 \\
\hline$-6 a-1:$ & 0.0811824 & 0.1102131 & 0.0381183 & 0.1392476 & $0.4328475 *$ & $0.6403530^{*}$ \\
\hline 0 a $5:$ & $0.7130482 *$ & $0.5813511 *$ & 0.2791378 & -0.0443109 & -0.1909163 & -0.1803121 \\
\hline $\begin{array}{l}\text { 6 a 11: } \\
12:\end{array}$ & $\begin{array}{l}-0.1602049 \\
0.0103582\end{array}$ & -0.0992075 & -0.2024573 & -0.2455022 & -0.1419315 & -0.0708684 \\
\hline & & & $\Delta \mathrm{lppa}$ & $\Delta$ lpvar & & \\
\hline-12 a -5: & -0.1654847 & -0.2199369 & -0.2242181 & -0.2009850 & -0.0711109 & 0.0487169 \\
\hline$-6 a-1:$ & 0.2016663 & 0.1864675 & 0.1519318 & 0.2303193 & $0.4824117^{*}$ & $0.7640497 *$ \\
\hline 0 a $5:$ & $0.8402500^{*}$ & $0.5536658^{*}$ & 0.1846490 & -0.0851405 & -0.1950163 & -0.0749554 \\
\hline 6 a 11: & 0.0264227 & -0.0326228 & -0.2437423 & -0.3269965 & -0.2692714 & -0.1243211 \\
\hline 12: & -0.0573316 & & & & & \\
\hline & & & $\Delta \mathrm{lpv}$ & e $\Delta \operatorname{lptr}$ & & \\
\hline-12 a $-5:$ & 0.0732076 & 0.0416519 & 0.0769527 & 0.1322141 & 0.0488340 & -0.1270022 \\
\hline$-6 a-1:$ & -0.2525284 & -0.3821313 & -0.3964295 & -0.2410759 & -0.0329935 & 0.1060923 \\
\hline 0 a $5:$ & 0.2018543 & 0.2987057 & 0.2260625 & 0.0329636 & -0.0997808 & -0.0568735 \\
\hline 6 a 11: & 0.0384677 & 0.0249986 & -0.0229995 & -0.1392835 & -0.3614536 & -0.4882798 \\
\hline & & & $\Delta \mathrm{lpv}$ & e $\Delta l p t r$ & & \\
\hline-12 a -5: & 0.0785457 & 0.0668385 & 0.0798351 & 0.1067658 & 0.0857840 & -0.0785403 \\
\hline$-6 a-1:$ & -0.3216282 & -0.4182539 & -0.3688382 & -0.2844380 & -0.1371548 & 0.0733844 \\
\hline 0 a $5:$ & 0.2054987 & 0.2620208 & 0.2021363 & 0.0474445 & -0.0658106 & -0.0180406 \\
\hline 6 a 11: & 0.1223483 & 0.1345235 & 0.0466420 & -0.0945056 & -0.3050266 & -0.4425398 \\
\hline & 27 & & Alnna & & & \\
\hline-12 a $-5:$ & -0.0194577 & -0.0455789 & -0.1801442 & -02766670 & $-0,1926341$ & -011748426 \\
\hline$-6 a-1:$ & -0.0534165 & -0.0810902 & -0.0542095 & 0.0837484 & 0.2871714 & $0.5700479 *$ \\
\hline 0 a $5:$ & $0.8311317^{*}$ & $0.6094763^{*}$ & 0.1852331 & -0.0299568 & -0.0500618 & 0.0860190 \\
\hline 6 a 11: & 0.0857295 & -0.0020376 & -0.0836546 & -0.1088796 & -0.0937565 & -0.0702385 \\
\hline 12: & -0.0774069 & & & & & \\
\hline
\end{tabular}

* Correlação significativa (valor crítico para o teste de correlação $=0,32$, que é da fórmula $2 / \sqrt{n}$ ).

\footnotetext{
${ }^{19}$ As defasagens negativas correspondem ao preço defasado da primeira variável descrita em relação ao preço da segunda variável, assim como as defasagens positivas referem-se ao preço defasado da segunda variável em relação à primeira.
} 
Os resultados de correlação cruzada não indicam a existência de relação de causalidade entre aquelas variáveis. Entretanto, de acordo com os modelos econômicos descritos no item 3.2 onde as equações são apresentadas na forma linear, espera-se uma relação forte entre as variáveis relacionadas quando expressas na forma linear. De fato, foi constatado relação linear significativa na maioria das relações estabelecidas. Apenas as variáveis $\Delta$ lppar e $\Delta$ lpaac defasadas não apresentaram correlação significativa com a variável contemporânea do preço de açúcar cristal no produtor ( $\Delta \mathrm{lppac})$.

Os resultados das equações definidas no teste de causalidade são apresentados na Tabela 4.7. As relações de causalidade fornecem uma indicação das relações comportamentais do mercado de açúcar. Os resultados indicam que o sentido de causalidade esperado entre as variáveis é da seguinte forma. O conjunto de variáveis composto por: preço de bebida não-alcoólica $(\Delta \mathrm{lpb})$; preço de açúcar no mercado internacional ( $\Delta$ lpni); preço de açúcar refinado no produtor ( $\Delta$ lppar); preço de álcool hidratado no produtor $(\Delta \mathrm{lpph})$ e preço de álcool anidro no produtor ( $\Delta \mathrm{lppi})$, causam o preço do açúcar cristal no produtor $(\Delta \mathrm{lppac})$. O preço de açúcar cristal no varejo $(\Delta \mathrm{lpvac})$ e o preço de açúcar refinado no varejo ( $\Delta$ lpvar), foram causados pelo preço de transporte $(\Delta \mathrm{lptr})$.

Outras relações observadas consideraram a possibilidade de $\Delta$ lppac também causar $\Delta$ lpni e $\Delta \mathrm{lppi}$, indicando a importância do preço doméstico de açúcar na determinação dos preços no mercado externo. Verificou-se relação causal da variável $\Delta$ lpvac para o preço de açúcar cristal no atacado ( $\Delta$ lpaac). Já no mercado de refinado, a relação foi no sentido de que $\Delta$ lppar causa $\Delta$ lpvar.

As relações de causalidade envolvendo $\Delta$ lpph e $\Delta$ lppi foram observadas apenas para longo prazo, sendo, portanto, diagnosticadas no termo de correção de erro dos modelos. 
Tabela 4.7 - Resultado do teste de causalidade de Granger com termo de correção de erro, ao nível de signicância de $10 \%$

\begin{tabular}{|c|c|c|c|c|}
\hline Variável dependente & Variável explicativa & Teste $\mathrm{F}^{*}$ & Teste $t^{*}$ & Teste $Q^{*}$ \\
\hline$\Delta$ lpni & $\Delta$ lppac & - & 0.05 & 0.54 \\
\hline$\Delta$ lppac & $\Delta$ lpni & 0.06 & - & 0.59 \\
\hline$\Delta$ lppac & $\Delta$ lppar & - & 0.08 & 0.42 \\
\hline$\Delta$ lppac & $\Delta \mathrm{lpb}$ & 0.07 & - & 0.79 \\
\hline$\Delta \mathrm{lppi}$ & $\Delta$ lppac & - & 0.03 & 0.33 \\
\hline$\Delta \mathrm{lppac}$ & $\Delta$ lppi & - & 0.03 & 0.37 \\
\hline$\Delta$ lppac & $\Delta \mathrm{lpph}$ & - & 0.06 & 0.26 \\
\hline$\Delta$ lpaac & $\Delta$ lpvac & 0.013 & - & 0.90 \\
\hline$\Delta$ lpvac & $\Delta$ lptr & 0.08 & - & 0.96 \\
\hline$\Delta$ lpvar & $\Delta$ lppar & 0.06 & - & 0.82 \\
\hline$\Delta$ lpvar & $\Delta \mathrm{lptr}$ & 0.06 & - & 0.76 \\
\hline
\end{tabular}

* Os valores indicados para os testes estatísticos $\mathrm{F}, \mathrm{t}$ e $\mathrm{Q}$ representam os níveis de significância desses testes. $\mathrm{O}$ teste $\mathrm{F}$ tem como hipótese nula que os coeficientes da variável explicativa são iguais a zero. $\mathrm{O}$ teste $\mathbf{t}$ considera o termo de correção de erro (quando presente) igual a zero, e o teste $Q$ tem como hipótese de nulidade a ausência de autocorrelação de resíduos.

Entretanto, no modelo proposto de formação desses preços, foram adotadas algumas outras relações, além das observadas no teste anterior, em função dos pressupostos quanto à forma de funcionamento previsto pelo modelo econômico, as quais, muitas vezes, não são captadas nos testes estatísticos.

\subsubsection{Equações de formação de preços com termo de correção de erro}

Os modelos desenvolvidos no item 3.2.1 descrevem as variáveis envolvidas nos modelos de formação de preços nos níveis de mercado considerados no presente estudo. Tais modelos foram descritos para as variáveis em nível. No entanto, uma vez que as séries possuem raiz unitária, foram utilizadas na primeira diferença. As novas equações desenvolvidas diferenciam-se pelo fato de que as variáveis representam a taxa de crescimento dos preços e não os preços propriamente ditos. Foi incluído também o termo de correção de erro nos modelos, uma vez que as variáveis se apresentaram 
relações de co-integração, recuperando, assim, as informações de longo prazo perdidas nas diferenças das variáveis em estudo.

As equações foram estimadas pelo modelo de equações simultâneas, uma vez que o modelo econômico subjacente sustenta a proposição de que os preços em questão formam simultaneamente, por excesso de demanda, nos níveis de produtor de açúcar cristal, de produtor de açúcar refinado e atacado do açúcar cristal. Os resultados são descritos nas Tabelas 4.8 e 4.9, para os mercados de açúcar cristal e açúcar refinado, respectivamente ${ }^{20}$.

Os valores entre parênteses abaixo dos coeficientes estimados são os respectivos níveis de significância do teste $t$, de Student, o qual considera como hipótese nula o valor do coeficiente igual a zero.

Nas colunas da Tabela 4.8, têm-se estimados os coeficientes das equações (3), (8) e (12) equivalente ao modelo apresentado no tópico 3. Exceto para a equação referente ao produtor de açúcar cristal (segunda coluna da Tabela 4.8 ), os valores de $\mathrm{R}^{2}$ obtidos foram razoáveis, indicando bom ajustamento das regressões. Os altos níveis de significância da estatística "Q", de Box e Pierce, evidenciaram não haver problemas de autocorrelação de resíduos naquelas equações.

Os sinais dos coeficientes estimados da equação de formação do preço do produtor de açúcar cristal apresentaram-se de acordo com o proposto pelo modelo econômico para as variáveis que representam, do lado da demanda, o atacado desse mercado ( $\Delta$ lpaac) e o produto industrial que utiliza o açúcar cristal como insumo de produção $(\Delta \mathrm{lpb})$ sendo ambos com sinal negativo, conforme proposto na equação (9). Pelo lado da oferta, o próprio preço do produtor $(\Delta \mathrm{lppac})$ defasado, o preço do produtor

${ }^{20}$ Embora as equações de formação de preço de açúcar cristal e de açúcar refinado estejam sendo apresentadas em tabelas diferentes, as cinco equações foram estimadas simultaneamente. 
de hidratado $(\Delta \mathrm{lpph})$ e o preço do açúcar no mercado internacional ( $\Delta \mathrm{lpni})$ defasado, apresentam sinal positivo, conforme proposto na equação (10), descritas no tópico 3 (item 3.2.1). Entretanto, a baixa qualidade do ajustamento observado na estimação dessa equação pode justificar os sinais contrários às expectativas do modelo para as variáveis $\Delta$ lppar (do lado da demanda) e $\Delta \operatorname{lppi}$ (do lado da oferta). Uma possível explicação para o problema de especificação desse modelo é o grande número de variáveis explicativas incluídas associado ao número limitado de observações disponíveis para realizar a análise econométrica. $\mathrm{O}$ curto período dos dados é uma restrição à utilização de muitas variáveis, podendo resultar em problemas de multicolinearidade ao se relacionar grande número de variáveis.

Gujarati (1995) e Hoffmann (1998) descreveram que o problema de multicolinearidade pode ter como uma de suas conseqüências variâncias das estimativas dos parâmetros elevadas. Gujarati (1995) indicou, ainda, alguns testes para detectar a presença de multicolinearidade: altos valores dos coeficientes de correlação simples entre as variáveis do modelo duas a duas e $\mathrm{R}^{2}$ de regressões auxiliares de cada uma das variáveis exógenas contra as demais variáveis utilizadas no modelo, maior do que o $\mathrm{R}^{2}$ estimado pelo modelo ${ }^{21}$.

Na Tabela 2A.1, do Apêndice 2, são apresentados os resultados das variâncias dos coeficientes estimados para os modelos de todos os níveis de mercado considerados para o açúcar cristal e o refinado. Verificam-se, nessa tabela, altos valores das variâncias dos coeficientes estimados apenas para a equação referente ao produtor de açúcar cristal. Os coeficientes de correlação simples para as variáveis duas a duas nesse modelo, assim como nos demais modelos incluídos no mercado de açúcar, são apresentados nas Tabelas 2A.2 a 2A.6 do Apêndice 2. Os resultados das Tabelas 2A.2 a 2A.6 indicam baixos coeficientes de correlação simples entre as variáveis. Entretanto esse resultado não é suficiente para determinar ausência de multicolinearidade. Assim, regressões

\footnotetext{
${ }^{21}$ Maiores detalhes podem ser obtidos em Gujarati (1998).
} 
auxiliares foram desenvolvidas com algumas das variáveis explicativas contra as demais. Esse teste mostrou que, conforme pressuposto, a presença de multicolinearidade na equação ao produtor de açúcar cristal. Ao relacionar $\Delta$ lpaac contra as demais variáveis, obteve-se $\mathrm{R}^{2}$ igual a $69 \%$. Utilizando a variável $\Delta$ lppar como dependente, o valor de $\mathrm{R}^{2}$ foi de $56 \%$; para as regressões com as variáveis $\Delta$ lpph e $\Delta$ lppi como dependentes, obteve-se $\mathrm{R}^{2}$ de $72 \%$ e $71 \%$, respectivamente.

$\mathrm{Na}$ equação de formação do preço de açúcar cristal no atacado, descrita pelo modelo econômico na equação (8), têm-se os sinais dos coeficientes positivos, de acordo com o previsto, para as variáveis que representam o produtor de açúcar cristal ( $\Delta$ lppac) e o próprio atacado ( $\Delta \mathrm{lpaac})$ defasado. O sinal positivo da variável que representa o nível do varejo de açúcar cristal ( $\triangle \mathrm{lpvac}$ ), contrário ao esperado na descrição dos sinais das equações (4) e (6), no tópico 3, pode ser justificado pelo fato de que o açúcar cristal é mais acessível em termos de preço do que o açúcar refinado. Assim, mesmo havendo variação positiva do preço de açúcar cristal no varejo, não se tem, de maneira geral, preço superior ao preço do açúcar refinado em valor absoluto. Portanto, acredita-se que o aumento na demanda de açúcar cristal influencia seu preço (e não o inverso), sendo, então, transferido ao atacado, condição que não foi pressuposta no modelo econômico.

Os sinais dos coeficientes na equação referentes à formação do preço de açúcar cristal no varejo foram positivos, conforme previsto, para o preço de açúcar cristal no atacado ( $\Delta \mathrm{lpaac})$, preço de transporte $(\Delta \mathrm{lptr})$ e o preço de açúcar cristal no varejo ( $\Delta$ lpvac) defasado. No entanto, aparentemente, o insumo de comercialização do varejo não foi bem representado pelo preço de transporte ( $\Delta$ lptr), apesar de influenciar positivamente o preço do varejo, o que foi indicado pelo baixo valor do coeficiente estimado para essa variável. 
Tabela 4.8 - Estimativas de formação dos preços nos níveis de produtor, atacado e varejo do mercado de açúcar cristal no Estado de São Paulo de acordo com um sistema de equações simultâneas; período: abril de 1997 a maio de $2000^{22}$

\begin{tabular}{|c|c|c|c|}
\hline \multirow{2}{*}{$\begin{array}{l}\text { Variáveis exógenas } \\
\text { e Estatísticas }\end{array}$} & \multicolumn{3}{|c|}{ Variáveis endógenas } \\
\hline & $\Delta \mathrm{lppac}_{\mathrm{t}}$ & $\Delta \mathrm{lpaac}_{\mathrm{t}}$ & $\Delta \operatorname{lpvac}_{\mathrm{t}}$ \\
\hline$\Delta \operatorname{lppac}_{\mathrm{t}}$ & - & $\begin{array}{c}0.482 \\
(0.00)\end{array}$ & - \\
\hline$\Delta \mathrm{lppac}$ t-1 & $\begin{array}{l}0.929 \\
(0.01)\end{array}$ & - & - \\
\hline$\Delta$ lpaac $_{\mathrm{t}}$ & - & - & $\begin{array}{l}0.259 \\
(0.00)\end{array}$ \\
\hline$\Delta \mathrm{lpaac}_{\mathrm{t}-1}$ & $\begin{array}{l}-0.946 \\
(0.05)\end{array}$ & $\begin{array}{c}0.364 \\
(0.00)\end{array}$ & - \\
\hline$\Delta \operatorname{lppar}_{t-1}$ & $\begin{array}{c}0.366 \\
(0.45)\end{array}$ & - & - \\
\hline$\Delta \operatorname{lpvac}_{\mathrm{t}-1}$ & - & $\begin{array}{l}0.177 \\
(0.23)\end{array}$ & $\begin{array}{l}0.389 \\
(0.00)\end{array}$ \\
\hline$\Delta l p b_{t-1}$ & $\begin{array}{l}-1.63 \\
(0.33)\end{array}$ & - & - \\
\hline$\Delta l p n i_{t-1}$ & $\begin{array}{c}0.100 \\
(0.59)\end{array}$ & - & - \\
\hline$\Delta l p p h_{t}$ & $\begin{array}{c}0.556 \\
(0.03)\end{array}$ & - & - \\
\hline$\Delta \mathrm{lppi}_{\mathrm{t}}$ & $\begin{array}{l}-0.296 \\
(0.35)\end{array}$ & - & - \\
\hline$\Delta \operatorname{lptr}_{\mathrm{t}}$ & - & - & $\begin{array}{l}0.0071= \\
(0.72)\end{array}$ \\
\hline$e_{t-1}$ & $\begin{array}{l}-0.718 \\
(0.13)\end{array}$ & - & - \\
\hline$e a_{t-1}$ & - & $\begin{array}{l}-0.68 \\
(0.00)\end{array}$ & - \\
\hline$e c_{t-1}$ & - & - & $\begin{array}{l}-0.272 \\
(0.00)\end{array}$ \\
\hline $\mathrm{R}^{2}$ & 0.46 & 0.88 & 0.71 \\
\hline$Q(\%)$ & $4.59(0.87)$ & $14.57(0.10)$ & $5.20(0.81)$ \\
\hline
\end{tabular}

${ }^{22}$ As variáveis $\mathbf{e p}_{t-1}$, ea ${ }_{t-1}$ e evc t-1 $_{1}$ representam os termos de correção de erro referente aos modelos ao produtor, atacado e varejo, respectivamente. 
Para o mercado de açúcar cristal, a multicolinearidade foi verificada apenas no nível do produtor, corroborando a possível explicação dos sinais não coincidentes com o esperado. Algumas alternativas para a solução desse problema, segundo Gujarati (1995), é a transformação das variáveis na primeira diferença ou a eliminação de variáveis. Entretanto, as séries primárias dos preços já estão diferenciadas e a eliminação de variáveis pode causar problemas de especificação no modelo. Portanto, o problema de multicolinearidade é apenas descrito como uma forma de advertência para a interpretação dos resultados desse modelo.

Na Tabela 4.9, têm-se as estimativas dos coeficientes dos modelos de formação de preços no produtor e no varejo do açúcar refinado, respectivamente na segunda e terceira colunas, como descritos nas equações (16) e (3), desenvolvidas no item 3.2.1.

Os coeficientes apresentaram os sinais de acordo com o previsto no modelo econômico. Dessa forma, as variáveis preço de açúcar cristal do produtor ( $\Delta \mathrm{lppac}$ ) e preço de açúcar refinado no produtor ( $\Delta$ lppar) defasado são positivamente relacionadas na formação do preço do produtor de açúcar refinado. Os resultados indicam que o preço do açúcar refinado no varejo ( $\Delta$ lpvar) apresenta relação negativa na formação desse preço, também conforme o proposto. Dessa forma, os ajustamentos no mercado de açúcar refinado diferem daquele no mercado de açúcar cristal, tendo-se identificado maior influência dos preços ao varejo sobre a demanda do consumidor. Isso porque a variável do preço de açúcar cristal no varejo apresentou sinal positivo na formação do preço de açúcar cristal no nível de mercado imediatamente anterior (atacado).

Observou-se também, comparando as Tabelas 4.8 e 4.9, que o preço do açúcar cristal no atacado ( $\Delta \mathrm{lpaac})$ é formado, predominantemente, pela variável correspondente ao preço do açúcar cristal no produtor ( $\Delta \mathrm{lppac}$ ), com grau de ajustamento de $88 \%$, e o preço do açúcar refinado no produtor ( $\Delta$ lppar) é formado, predominantemente, por sua própria série defasada, com menor participação do preço no produtor do açúcar cristal 
( $\triangle$ Ippac), e apresenta menor grau de ajustamento (66\%). A provável razão desse resultado é o fato de que os serviços incluídos no nível de atacado do cristal são bem menores do que aqueles incluídos no produtor de refinado, ambos a partir do produtor de cristal.

Tabela 4.9 - Estimativas de formação dos preços nos níveis de produtor e varejo do mercado de açúcar refinado no Estado de São Paulo de acordo com um sistema de equações simultâneas; período: abril de 1997 a maio de $2000^{23}$

\begin{tabular}{|c|c|c|}
\hline \multirow{2}{*}{$\begin{array}{l}\text { Variáveis exógenas e } \\
\text { Estatísticas }\end{array}$} & \multicolumn{2}{|c|}{ Variáveis endógenas } \\
\hline & $\begin{array}{c}\text { Taxa de crescimento do preço no } \\
\text { produtor }-\Delta \text { lppar }_{t}\end{array}$ & $\begin{array}{c}\text { Taxa de crescimento do preços no } \\
\text { varejo - } \Delta \text { lpvar }_{t}\end{array}$ \\
\hline$\Delta \mathrm{lppac}_{\mathrm{t}}$ & $\begin{array}{l}0.411 \\
(0.00)\end{array}$ & - \\
\hline$\Delta \operatorname{lppar}_{\mathrm{t}}$ & - & $\begin{array}{l}0.3379 \\
(0.00)\end{array}$ \\
\hline$\Delta \operatorname{lppar}_{t-1}$ & $\begin{array}{l}0.725 \\
(0.00)\end{array}$ & $\begin{array}{c}0.04 \\
(0.76)\end{array}$ \\
\hline$\Delta \operatorname{lpvar}_{\mathrm{t}-1}$ & $\begin{array}{l}-0.306 \\
(0.27)\end{array}$ & $\begin{array}{c}0.26 \\
(0.06)\end{array}$ \\
\hline$\Delta \operatorname{lptr}_{\mathrm{t}-1}$ & - & $\begin{array}{l}0.0076 \\
(0.60)\end{array}$ \\
\hline $\operatorname{epr}_{t-1}$ & $\begin{array}{l}-0.359 \\
(0.03)\end{array}$ & - \\
\hline$e r_{t-1}$ & - & $\begin{array}{l}-0.245 \\
(0.03)\end{array}$ \\
\hline $\mathrm{R}^{2}$ & 0.66 & 0.82 \\
\hline$Q(\%)$ & $6.34(0.70)$ & $4.09(0.90)$ \\
\hline
\end{tabular}

O preço ao varejo de açúcar refinado, ao contrário do que ocorreu com o açúcar cristal, indicou maior influência do nível de mercado anterior ao do próprio preço defasado. Os sinais dos coeficientes estimados na equação referente à formação do preço nesse nível do mercado apresentaram-se positivos para preço do açúcar refinado no

${ }^{23}$ As variáveis epr $_{\mathrm{t}-1}$ e evr $\mathrm{t}_{\mathrm{t}-1}$ representam os termos de correção de erro referente aos modelos ao produtor e varejo, respectivamente. 
produtor e preço de transporte e do próprio nível de varejo defasados, o que corrobora o modelo econômico proposto no item 3.2.1.

As equações referentes ao mercado de açúcar refinado não apresentaram problemas de multicolinearidade entre as variáveis explicativas, conforme pode ser verificado nas Tabelas 2A.5 e 2A.6, no Apêndice 2, e pelas regressões auxiliares nãosignificativas.

\subsection{Mercado de álcool combustível anidro}

\subsubsection{Testes de raiz unitária ${ }^{24}$}

As variáveis incluídas no estudo do mercado de álcool anidro são os logaritmos naturais de: preço ao produtor de açúcar cristal (lppac), preço ao produtor de álcool hidratado (lpph) e de álcool anidro (lppi), preço de petróleo (lppetro) e preço ao varejo (na bomba) de álcool anidro (lpvi), no qual foi utilizado o preço no varejo da gasolina como "proxy", conforme descrito na fonte de dados (item 3.3.2). O período a ser considerado, conforme o período inicial de desregulamentação, foi de maio de 1998 a julho de 2000 .

Como definido para o mercado de açúcar, foi realizado um estudo prévio das séries de preços consideradas, para verificar a presença de tendência estocástica (raiz unitária) naquelas variáveis. Foram ajustados modelos com o número de defasagens determinado pelos critérios de informação de Akaike e Schwarz, utilizando-se o máximo de sete defasagens nesse teste. A maior limitação no número de defasagens está relacionada ao menor número de observações das séries consideradas. Quando apenas a

\footnotetext{
${ }^{24}$ Os testes de raiz unitária foram realizados, comparando-se o valor da estatística $\mathbf{t}$, de Student, com os valores críticos de Fuller (1976), que se encontram na Tabela 1A.1, do Apêndice 1.
} 
variável contemporânea se apresentou significativa foi utilizada pelo menos uma defasagem para realizar os testes.

Pela estatística $\tau_{\beta \tau}$, da Tabela 4.10 , avaliou-se a significância da tendência no modelo, sendo não significativa no nível de $1 \%$, nas variáveis analisadas. Na Tabela 4.11, a estatística $\tau_{\alpha \mu}$ foi utilizada para avaliar a significância do termo constante, sendo significativo a $5 \%$ de probabilidade apenas para a variável preço de petróleo.

A estacionariedade dessas variáveis em nível deve, então, ser verificada no modelo sem constante e sem tendência pela estatística $\tau$ da Tabela 4.12, não sendo observado estacionariedade no nível de $1 \%$ de significância.

Tabela 4.10 - Teste de estacionariedade em modelo com constante $(\alpha)$ e tendência $(\boldsymbol{T})$, estatística $\tau_{\tau}$

\begin{tabular}{|c|c|c|c|c|}
\hline \multirow{2}{*}{$\begin{array}{l}\text { Modelo } 1 \\
\text { Variáveis }\end{array}$} & \multicolumn{3}{|c|}{$\Delta x_{t}=\alpha+\theta T+\gamma_{1} x_{t-1}+\sum_{j=1}^{n} \gamma_{j} \Delta x_{t-j}+e_{t}$} & \multirow{2}{*}{$\begin{array}{c}\mathrm{H}_{0}: \gamma_{1}=0 \\
\begin{array}{c}\text { Nível de significância } \\
\text { da estatística "Q" }\end{array}\end{array}$} \\
\hline & $\begin{array}{l}\text { Defasagens } \\
\quad(n)\end{array}$ & $\begin{array}{l}\text { Valor da Estatística } \mathrm{t} \\
\mathrm{H}_{0}: \theta=0\end{array}$ & $\begin{array}{c}\text { Valor da Estatística } t \\
\mathrm{H}_{0}: \gamma_{1}=0\end{array}$ & \\
\hline lppetro & 1 & 1.17 & -1.74 & 0,19 \\
\hline lppac & 1 & 2.23 & -2.10 & 0,52 \\
\hline Ippi & 1 & 2.470 & -1.679 & 0,44 \\
\hline Ipvi & 1 & 2.232 & -2.203 & 0,38 \\
\hline lpph & 1 & 2.065 & -1.80 & 0,33 \\
\hline
\end{tabular}


Tabela 4.11 - Teste de estacionariedade em modelo com constante $(\alpha)$, estatística $\tau_{\mu}$

\begin{tabular}{|c|c|c|c|c|}
\hline Modelo 2 & \multicolumn{3}{|c|}{$\Delta x_{t}=\alpha+\gamma_{1} x_{t-1}+\sum_{j=1}^{n} \gamma_{j} \Delta x_{t-j}+e_{t}$} & $\mathrm{H}_{0}: \gamma_{1}=0$ \\
\hline Variáveis & $\begin{array}{l}\text { Defasagens } \\
\quad(\mathrm{n})\end{array}$ & $\begin{array}{l}\text { Valor da Estatística t } \\
\qquad \mathrm{H}_{0}: \alpha=0\end{array}$ & $\begin{array}{l}\text { Valor da Estatística } \mathrm{t} \\
\mathrm{H}_{0}: \gamma_{1}=0\end{array}$ & $\begin{array}{l}\text { Nível de significância } \\
\text { da estatística "Q" }\end{array}$ \\
\hline lppetro & 1 & $3.61 * *$ & $-3.16^{* *}$ & 0,37 \\
\hline lppac & 1 & -0.55 & -0.71 & 0,55 \\
\hline lppi & 1 & -0.087 & -0.264 & 0,77 \\
\hline Ipvi & 1 & 1.624 & -0.214 & 0,43 \\
\hline Ipph & 1 & -0.114 & -0.398 & 0,73 \\
\hline
\end{tabular}

**Significativo ao nível de significância de 5\%.

Tabela 4.12 - Teste de estacionariedade em modelo sem constante e tendência, estatística $\tau$

\begin{tabular}{lccc}
\hline Modelo 3 : & $\Delta x_{t}=\gamma_{1} x_{t-1}+\sum_{j=1}^{n} \gamma_{j} \Delta x_{t-j}+e_{t}$ & $\mathrm{H}_{0}: \gamma_{1}=0$ \\
\hline Variáveis & Defasagens (n) & $\begin{array}{c}\text { Valor da Estatística } \\
\mathrm{H}_{0}: \gamma_{1}=\boldsymbol{0}\end{array}$ & $\begin{array}{c}\text { Nível de significância da } \\
\text { estatística "Q" }\end{array}$ \\
\hline Ippetro & 1 & 1.74 & 0,45 \\
lppac & 1 & -0.930 & 0,45 \\
lppi & 1 & -0.859 & 0,76 \\
lpvi & 1 & 0.979 & 0,40 \\
lpph & 1 & -0.941 & 0,70 \\
\hline
\end{tabular}

Não sendo observada a estacionariedade das séries, passou-se, então, à análise da Tabela 4.13, na qual se encontram os resultados relativos a estacionariedade na primeira diferença daqueles preços, segundo a estatística $\tau$. 
Tabela 4.13 - Teste de raiz unitária em modelo sem constante e tendência, estatística $\tau$

\begin{tabular}{lccc}
\hline Modelo 6 & $\Delta \Delta x_{t}=\sigma_{1} \Delta x_{t-1}+\sum_{j=1}^{n} \sigma_{j} \Delta \Delta x_{t-j}+e_{t}$ & $\mathrm{H}_{0}: \sigma_{1}=0$ \\
\hline Variáveis & Defasagens (n) & $\begin{array}{c}\text { Valor da Estatística t } \\
\mathrm{H}_{0}: \sigma_{1}=0\end{array}$ & $\begin{array}{c}\text { Nível de significância da } \\
\text { estatística "Q" }\end{array}$ \\
\hline$\Delta$ lppetro & 1 & $-3.02^{*}$ & 0,82 \\
$\Delta$ lppac & 1 & $-3.05^{*}$ & 0,56 \\
$\Delta$ lppi & 1 & $-3.216^{*}$ & 0,94 \\
$\Delta$ lpvi & 1 & $-1.978^{* *}$ & 0,06 \\
$\Delta$ lpph & 1 & $-2.232^{* *}$ & 0,57 \\
\hline
\end{tabular}

*Significativo ao nível de significância de $1 \%$

**Significativo ao nível de significância de $5 \%$.

Os resultados indicam a presença de raiz unitária no nível de significância de $1 \%$ para as variáveis lppetro, lppac e lppi e, no nível de 5\% de probabilidade, para as variáveis lpvi e lpph. Os altos níveis de significância da estatística "Q", do teste de BoxPierce, descritos na última coluna da Tabela 4.13, rejeitaram a hipótese de nulidade desse teste, que considerou a existência de autocorrelação entre os resíduos.

\subsubsection{Testes de co-integração}

Da mesma maneira que foi realizado para o açúcar, os testes de co-integração foram executados primeiramente entre as variáveis duas a duas, a fim de se terem os termos de correção de erro dos testes de causalidade.

A seguir, têm-se os resultados das variáveis que se apresentam co-integradas e os respectivos valores das estatísticas de Dickey-Fuller, bem como o número de defasagens ( $\mathrm{n}$ ) dos resíduos dessas equações. Os resíduos foram estacionários, indicando co-integração, quando o valor descrito da estatística DF foi maior do que o valor crítico apresentado na Tabela 1A.2, do Apêndice 1: 


$$
\begin{aligned}
& \text { lppi }=-0,36+0,644 \text { lpph } \\
& (0,00) \quad(0,00)
\end{aligned}
$$

$$
\begin{gathered}
\text { lpph }=0,419+1,42 \text { lppi } \\
(0,00) \quad(0,00)
\end{gathered}
$$

$$
\begin{aligned}
& \text { lppac }=-0,315+0,955 \text { lppi } \\
& (0,00) \quad(0,00)
\end{aligned}
$$

$$
\text { lppi }=0,12+0,889 \mathrm{lppac}
$$$$
(0,23)(0,00)
$$

$$
\text { lpvi }=-1,05+0,3834 \text { lppetro }
$$$$
(0,00)(0,00)
$$

$\begin{array}{lll}\mathrm{R}^{2}=0,91 & \mathrm{DF}=10.29 & \mathrm{n}=8 \\ \mathrm{R}^{2}=0,91 & \mathrm{DF}=13.66 & \mathrm{n}=10 \\ \mathrm{R}^{2}=0,84 & \mathrm{DF}=8.83 & \mathrm{n}=9 \\ \mathrm{R}^{2}=0,84 & \mathrm{DF}=3.79 & \mathrm{n}=5 \\ \mathrm{R}^{2}=0,94 & \mathrm{DF}=6.40 & \mathrm{n}=5\end{array}$

$\mathrm{R}^{2}=0,94 \quad \mathrm{DF}=6.40 \quad \mathrm{n}=5$

Os sinais dos coeficientes estimados acima indicaram que todas as variáveis relacionadas duas a duas, as quais se apresentaram co-integradas, foram positivamente relacionadas no período estudado. A variável preço de álcool anidro no varejo (lpvi) não se apresentou co-integrada com o preço de álcool anidro no nível do produtor, mas foi co-integrada com o preço do petróleo. Esse resultado era esperado, porque, sendo o preço do varejo apresentado pelo preço da gasolina na bomba e como o álcool anidro é utilizado em pequena quantidade na mistura com esse combustível, a relação esperada do preço do produtor de álcool anidro com o preço da gasolina é também pequena.

A seguir foi testada a co-integração para o conjunto de variáveis envolvidas na formação de preço no nível do produtor e do varejo, conforme definido no item 3.2.2. O seguinte resultado foi obtido com a regressão, indicando a presença de um vetor de cointegração entre aquelas variáveis:

$$
\begin{aligned}
& \text { lppi }=-0,31+0,50 \mathrm{lpph}+0,092 \mathrm{lpvi}+0,164 \mathrm{lppac} \quad \mathrm{R}^{2}=0,92 \quad \mathrm{DF}=7.37 \quad \mathrm{n}=6 \\
& \begin{array}{llll}
(0,04) & (0,00) \quad(0,40) & (0,33)
\end{array} \\
& \text { lpvi }=-0,739+0,153 \text { lppi }+0,336 \text { lppetro } \quad R^{2}=0,96 \quad \mathrm{DF}=28.38 \quad \mathrm{n}=6 \\
& (0,00) \quad(0,00) \quad(0,00)
\end{aligned}
$$


Verificou-se, então, que os sinais estavam de acordo com o esperado, exceto para a variável preço de álcool anidro no varejo (lpvi), no modelo de formação de preço ao produtor. $\mathrm{O}$ esperado para essa variável é uma relação negativa na formação desse preço, mas observou-se sinal positivo. A explicação para tal resultado é similar à descrita para os sinais não-coerentes nas equações de co-integração do mercado de açúcar, qual seja de que o sinal negativo era esperado para aquela variável defasada e não contemporânea, conforme o procedimento do teste de co-integração.

\subsubsection{Testes de causalidade de Granger}

O modelo de causalidade de Granger utilizou as variáveis na primeira diferença e com termo de correção de erro naqueles modelos, em que as variáveis se apresentaram co-integradas. O número de defasagens foi utilizado segundo o critério de Akaike e Schwarz, com máximo de sete defasagens para a variável dependente; para a variável explicativa, utilizaram-se as defasagens significativas do teste de correlação cruzada entre as variáveis relacionadas ou, pelo menos, uma defasagem no caso de não haver defasagem significativa. Os resultados do teste de correlação cruzada estão descritos na Tabela 4.14.

Verificou-se que o grau de associação linear entre as variáveis ${ }^{25}$ foi significativo quando relacionado, contemporaneamente, o preço de álcool anidro no produtor $(\Delta \mathrm{lppi})$ com o preço de açúcar cristal no produtor $(\Delta \mathrm{lppac})$ e com o preço de álcool hidratado no produtor ( $\Delta \mathrm{lpph})$. Com uma defasagem de $\Delta$ lppac, tem-se correlação significativa com a contemporânea de $\Delta$ lppi. Alto grau de relação linear foi verificado entre uma defasagem de $\Delta$ lppi com as variáveis contemporâneas de $\Delta l p p h$ e do preço de álcool anidro no varejo ( $\Delta$ lpvi), embora esta última variável não tenha sido significativa.

\footnotetext{
${ }^{25}$ Todas as referências às variáveis "preços" descritas a seguir até o término do item 4.2 na verdade estão relacionadas à taxa de crescimento daqueles preços, pois as variáveis estão na primeira diferença do logaritmo desses preços. Tal denominação é utilizada para haver maior fluidez ao texto.
} 
Tabela 4.14 - Correlações cruzadas entre as variáveis utilizando 7 defasagens para as variáveis ${ }^{26}$

\begin{tabular}{|c|c|c|c|c|c|c|}
\hline \multirow[t]{2}{*}{ Defasagens } & \multicolumn{6}{|c|}{ Correlações cruzadas } \\
\hline & \multicolumn{6}{|c|}{$\Delta$ lppac e $\Delta$ lppi } \\
\hline-7 a $-2:$ & 0.1260404 & -0.0573826 & 0.0241485 & 0.1027667 & -0.0280957 & -0.1261445 \\
\hline-1 a $4:$ & $0.4198977^{*}$ & $0.4982417^{*}$ & 0.1820024 & 0.1539543 & 0.1831281 & -0.2622799 \\
\hline \multirow[t]{2}{*}{5 a $7:$} & -0.1436712 & 0.1111463 & 0.0058384 & & & \\
\hline & \multicolumn{6}{|c|}{$\Delta$ lppi e $\Delta$ lpph } \\
\hline$-7 \mathrm{a}-2:$ & -0.2040306 & -0.0892217 & 0.0185255 & 0.0447460 & -0.0622630 & -0.0853741 \\
\hline-1 a $4:$ & $0.4047262^{*}$ & $0.7941961^{*}$ & 0.1239603 & 0.0758777 & 0.1918213 & 0.0670409 \\
\hline \multirow[t]{2}{*}{5 a $7:$} & 0.1624270 & -0.1060110 & -0.1725548 & & & \\
\hline & \multicolumn{6}{|c|}{$\Delta$ lppi e $\Delta$ lpvi } \\
\hline$-7 \mathrm{a}-2:$ & -0.1952869 & -0.1284665 & -0.0927943 & -0.0536172 & -0.2041553 & -0.1668069 \\
\hline-1 a $4:$ & 0.2910440 & $0.4119408^{*}$ & 0.0630759 & 0.1385393 & 0.1960451 & 0.2799524 \\
\hline \multirow[t]{2}{*}{5 a $7:$} & -0.0185991 & 0.1737906 & 0.0926300 & & & \\
\hline & \multicolumn{6}{|c|}{$\Delta$ lpvi e $\Delta$ lppetro } \\
\hline-7 a $-2:$ & -0.0633926 & -0.1027541 & -0.2708696 & -0.0078380 & 0.1384676 & 0.2654460 \\
\hline-1 a 4: & 0.1163316 & 0.1925960 & 0.2499992 & 0.3092937 & 0.0300677 & 0.1797216 \\
\hline 5 a $7:$ & 0.0470973 & 0.0956760 & -0.1406902 & & & \\
\hline
\end{tabular}

* Correlação significativa (valor crítico para o teste de correlação $=0,38$, que é da fórmula $2 / \sqrt{n}$ ).

Conforme descrito no item 4.1, os resultados de correlação cruzada não correspondem a uma relação de causalidade entre aquelas variáveis, entretanto era esperada uma relação linear elevada entre as variáveis relacionadas no modelo econômico proposto em 3.2.1. Entretanto, não foi verificado correlação significativa entre o preço de álcool anidro no varejo ( $\Delta$ lpvi) defasado com o preço ao produtor ( $\Delta$ lppi), assim como as variáveis $\Delta$ lpvi e preço do petróleo ( $\Delta$ lppetro) não apresentaram correlação significativa.

Os resultados do teste de causalidade de Granger, descritos na Tabela 4.15, indicam apenas as relações causais nas quais a estatística referente à variável explicativa, ou termo de correção de erro, obteve baixo nível de significância, ou seja, a relação causal foi significativa.

\footnotetext{
${ }^{26}$ As defasagens negativas correspondem ao preço defasado da primeira variável descrita em relação ao preço da segunda variável, assim como as defasagens positivas referem-se ao preço defasado da segunda variável em relação à primeira.
} 
Observou-se que o preço de álcool anidro no produtor ( $\Delta \mathrm{lppi}$ ) causou o preço no varejo ( $\Delta$ lpvi) em um nível de significância de $12 \%$, no curto prazo, e a variável preço de petróleo ( $\Delta$ lppetro) causou $\Delta$ lpvi em um nível de 5\% de significância, no longo prazo. Tal resultado corrobora a hipótese de que a variação do preço ao varejo deve ser explicada de forma mais expressiva por variáveis que explicam o preço da gasolina, uma vez que o álcool anidro é utilizado apenas como aditivo naquele combustível. Foi também observado relação causal do $\Delta$ lppi para $\Delta$ lppac, no longo prazo.

Tabela 4.15 - Resultado do teste de causalidade de Granger com termo de correção de erro

\begin{tabular}{llccc}
\hline Variável dependente & Variável explicativa & Teste $\mathrm{F}^{*}$ & Teste ${ }^{*}$ & Teste $\mathrm{Q}^{*}$ \\
\hline$\Delta \mathrm{lpvi}$ & $\Delta \mathrm{lppi}$ & 0.12 & - & 0.42 \\
$\Delta \mathrm{lpvi}$ & $\Delta$ lppetro & - & 0.05 & 0.62 \\
$\Delta \mathrm{lppac}$ & $\Delta \mathrm{lppi}$ & - & 0.09 & 0.56
\end{tabular}

* Os valores indicados para os testes estatísticos $\mathrm{F}, \mathrm{t}$ e $\mathrm{Q}$ representam os níveis de significância desses testes. $\mathrm{O}$ teste $\mathrm{F}$ tem como hipótese nula que os coeficientes da variável explicativa são iguais a zero. $\mathrm{O}$ teste $\mathbf{t}$ considera o termo de correção de erro (quando presente) igual a zero, e o teste $\mathrm{Q}$ tem como hipótese de nulidade a ausência de autocorrelação de resíduos.

\subsubsection{Equações de formação de preços com termo de correção de erro}

Assim como no item 4.1, as séries de preços utilizadas determinar as elasticidades de transmissão de preços possuem raiz unitária, sendo utilizadas na primeira diferença, e representando a taxa de crescimento dos preços e não os preços propriamente ditos. O termo de correção de erro foi utilizado quando as variáveis utilizadas nas equações se apresentaram co-integradas, recuperando, assim, as informações de longo prazo perdidas nas diferenças das variáveis em estudo.

Os coeficientes das equações de formação de preços com as variáveis na primeira diferença foram estimados pelo método de equações simultâneas, e os resultados estão descritos na Tabela 4.16. O modelo econômico proposto para o produtor e o varejo de álcool anidro está descrito no item 3.2.2. 
Tabela 4.16 - Estimativas de formação dos preços nos níveis de produtor e varejo do mercado de álcool anidro no Estado de São Paulo de acordo com um sistema de equações simultâneas; período: maio de 1998 a julho de $2000^{27}$

\begin{tabular}{|c|c|c|}
\hline \multirow{3}{*}{$\begin{array}{l}\text { Variáveis exógenas e } \\
\text { Estatísticas }\end{array}$} & \multicolumn{2}{|c|}{ Variáveis endógenas } \\
\hline & $\begin{array}{c}\text { Taxa de crescimento do preço no } \\
\text { produtor }\end{array}$ & $\begin{array}{c}\text { Taxa de crescimento do preços no } \\
\text { varejo }\end{array}$ \\
\hline & $\Delta \mathrm{lppi}_{\mathbf{t}}$ & $\Delta \operatorname{lpvi}_{\mathrm{t}}$ \\
\hline$\Delta \operatorname{lppi}_{\mathrm{t}}$ & - & $\begin{array}{l}0.172 \\
(0,01)\end{array}$ \\
\hline$\Delta l p p i_{t-1}$ & $\begin{array}{l}0.281 \\
(0,04)\end{array}$ & - \\
\hline$\Delta \mathrm{lppac}$ & $\begin{array}{l}-0.018 \\
(0.89)\end{array}$ & - \\
\hline$\Delta \operatorname{lpph}_{\mathrm{t}}$ & $\begin{array}{l}0.619 \\
(0,00)\end{array}$ & - \\
\hline$\Delta l p v i_{t-1}$ & $\begin{array}{l}-0.02 \\
(0,94)\end{array}$ & $\begin{array}{c}0.332 \\
(0,07)\end{array}$ \\
\hline$\Delta$ lppetro $_{\mathrm{t}}$ & - & $\begin{array}{l}0.115 \\
(0,04)\end{array}$ \\
\hline epi $i_{t-1}$ & $\begin{array}{l}-0.57 \\
(0,0)\end{array}$ & - \\
\hline$e v i_{t-1}$ & - & $\begin{array}{c}-0.64 \\
(0,00)\end{array}$ \\
\hline $\mathrm{R}^{2}$ & 0.78 & 0.56 \\
\hline$Q(\%)$ & $2.95(0.81)$ & $3.33(0.76)$ \\
\hline
\end{tabular}

Os coeficientes estimados para a equação (20) proposta no tópico 3 (item 3.2.2) para a formação do preço do produtor de álcool anidro são descritos na segunda coluna da Tabela 4.16. Exceto para a variável preço de açúcar cristal no produtor ( $\Delta \mathrm{lppac})$, os demais coeficientes estimados apresentaram os sinais de acordo com a teoria estabelecida. O baixo nível de significância do coeficiente dessa variável pode ser indicação da fraca influência das variações dos preços de açúcar no produtor sobre o preço de álcool anidro no produtor ( $\Delta$ lppi), no período analisado. A baixa relação entre

${ }^{27}$ As variáveis epi $\mathbf{i}_{t-1}$ e evi $\mathbf{i}_{\text {t-1 }}$ representam os termos de correção de erro referente aos modelos ao produtor 
as variáveis $\Delta \mathrm{lppac}$ e $\Delta \mathrm{lppi}$ foi também verificada no modelo referente ao produtor de açúcar cristal no item 4.1. Por sua vez, o preço de álcool hidratado no produtor ( $\Delta \mathrm{lpph})$ possui expressivo peso na explicação da variável dependente. Tal fato pode estar relacionado à condição de que ambos os produtos são utilizados com a mesma finalidade (como combustível).

$\mathrm{Na}$ equação de formação do preço de álcool anidro no varejo, descrita na terceira coluna da Tabela 4.16, os sinais também se apresentaram de acordo com o esperado, ou seja, é positivamente influenciada pelos preços de álcool anidro no produtor $(\Delta \mathrm{lppi})$, pelo preço de petróleo ( $\Delta$ lppetro) e pelo próprio preço de álcool anidro no varejo defasado. Tem-se maior influência desta última variável no curto prazo, estimada em 33,2\%. Entretanto, tal equação apresenta baixo grau de ajustamento (baixo valor de $\mathrm{R}^{2}$ ), ressaltando-se duas possíveis explicações em relação a esse resultado. Primeiro, porque a participação do álcool anidro na gasolina é pequena (variando de $20 \mathrm{a}$ $25 \%$ ), esperando-se igual influência do preço do produtor de álcool anidro na formação desse preço varejista. Tal fato foi observado na Tabela 4.16, pelo baixo valor do coeficiente da variável preço de álcool anidro no produtor ( $\Delta \mathrm{lppi}$ ), estimado em 0,17 . Segundo, tem-se que o preço da gasolina, considerada como indicadora do preço de varejo de álcool anidro, não oscila em perfeito acordo com o comportamento do mercado. O preço é controlado no setor atacadista desse mercado (refinarias de petróleo) pelo pagamento da Parcela de Preço Específico (PPE). A PPE é uma contribuição usada para custear subsídios em outros combustíveis, sendo representada pela diferença entre o preço dos derivados importados pela Petrobrás e o preço desses produtos vendidos pela estatal no mercado interno. Assim, a arrecadação da PPE diminui quando os preços internacionais aumentam, e o preço de venda da gasolina ao consumidor não acompanha o mesmo ritmo. Dessa maneira, observou-se o baixo valor do coeficiente da variável preço de petróleo considerada na formação do preço de varejo desse mercado, estimado em 0,115 . Entretanto, há emenda constitucional à espera de aprovação no Congresso 
Nacional que cria um imposto seletivo sobre os combustíveis. Esse imposto permitirá a desregulamentação do mercado, com os preços da gasolina também oscilando de acordo com o comportamento do mercado.

Foram realizados testes para detectar a presença de multicolinearidade entre as variáveis utilizadas nas equações da Tabela 4.16, não sendo observada pelos testes de correlação simples entre as variáveis explicativas ${ }^{28}$ e pelas regressões auxiliares, conforme descrito no item anterior, para o mercado de açúcar.

\subsection{Mercado de álcool hidratado}

O estudo do mercado do álcool hidratado teve forte limitação referente ao número de dados, uma vez que este foi o último a ser desregulamentado pelo governo, o que ocorreu em fevereiro de 1999 , sendo julho de 2000 o último mês considerado no presente estudo. Procurou-se estabelecer uma indicação da formação dos preços ao produtor e ao varejo de álcool hidratado num contexto de livre mercado, entretanto, se devem ressaltar tais restrições.

\subsubsection{Testes de raiz unitária ${ }^{29}$}

Utilizaram-se neste estudo os preços ao produtor (lpph) e ao varejo, na bomba, de álcool hidratado (lpvh), preço de açúcar cristal do produtor (lppac) e do produtor de álcool anidro (lppi). O período a ser considerado, conforme o período inicial de desregulamentação, foi de fevereiro de 1999 a julho de 2000.

\footnotetext{
${ }^{28}$ Nas Tabelas 2A.7 a 2A.9, do Apêndice 2, são apresentados os resultados da variância dos coeficientes estimados, assim como dos testes de correlação simples. Os baixos valores de ambos indicam não haver multicolinearidade, entretanto não são condições suficientes para essa afirmativa, devendo ser também realizadas regressões auxiliares com as variáveis explicativas e verificando os valores de $R^{2}$ resultantes.

${ }^{29}$ Os testes de raiz unitária são realizados, comparando-se o valor da estatística t, de Student, com os valores críticos de Fuller (1976), que se encontram na Tabela 1A.1, do Apêndice 1.
} 
Com a finalidade de testar a existência de tendência estocástica (raiz unitária) das variáveis, foram ajustados modelos econométricos para verificar a estacionariedade das séries de preços. O número de defasagens foi determinado pelos critérios de informação de Akaike e Schwarz, utilizando o máximo de seis defasagens, em razão da limitação de dados para o teste. Quando apenas a variável contemporânea apresentou-se significativa, foi utilizada, pelo menos, uma defasagem para realizar os testes.

Nas Tabelas 4.17 a 4.19 , apresentam-se os resultados de estacionariedade das variáveis em nível, segundo as estatísticas $\tau_{\tau}, \tau_{\mu}$ e $\tau$, as quais consideram os modelos para análise de estacionariedade com constante e tendência, apenas com constante e sem constante e tendência, respectivamente.

A estatística $\tau_{\beta \tau}$ utilizada na Tabela 4.17 avaliou a significância da tendência no modelo, sendo significativa no nível de 5\% apenas na variável lpvh; entretanto, a estatística $\tau_{\tau}$ não indicou estacionariedade daquela variável. Na Tabela 4.18 a estatística $\tau_{\alpha \mu}$ é utilizada para avaliar a significância do termo constante, sendo não-significativo, a $1 \%$ de probabilidade, naquelas variáveis.

Tabela 4.17 - Teste de estacionariedade em modelo com constante $(\alpha)$ e tendência $(T)$, estatística $\tau_{\tau}$

\begin{tabular}{|c|c|c|c|c|}
\hline \multirow{2}{*}{$\begin{array}{l}\text { Modelo } 1 \\
\text { Variáveis }\end{array}$} & \multicolumn{3}{|c|}{$\Delta x_{t}=\alpha+\theta T+\gamma_{1} x_{t-1}+\sum_{j=1}^{n} \gamma_{j} \Delta x_{t-j}+e_{t}$} & \multirow{2}{*}{$\begin{array}{c}\mathrm{H}_{0}: \gamma_{1}=0 \\
\begin{array}{c}\text { Nível de significância } \\
\text { da estatística "Q" }\end{array}\end{array}$} \\
\hline & $\begin{array}{l}\text { Defasagens } \\
\quad(\mathrm{n})\end{array}$ & $\begin{array}{l}\text { Valor da Estatística t } \\
\qquad \mathrm{H}_{0}: \theta=0\end{array}$ & $\begin{array}{l}\text { Valor da Estatística } \mathrm{t} \\
\mathrm{H}_{0}: \gamma_{1}=0\end{array}$ & \\
\hline lpph & 2 & 1.69 & -1.98 & 0,80 \\
\hline Ipvh & 1 & $2.92 * *$ & -2.96 & 0,59 \\
\hline lppac & 1 & 2.64 & -2.70 & 0.83 \\
\hline lppi & 3 & 1.510 & -1.842 & 0.63 \\
\hline
\end{tabular}

**Significativo ao nível de significância de 5\%. 
Tabela 4.18 - Teste de estacionariedade em modelo com constante $(\alpha)$, estatística $\tau_{\mu}$

\begin{tabular}{|c|c|c|c|c|}
\hline \multirow{2}{*}{$\begin{array}{l}\text { Modelo } 2 \\
\text { Variáveis }\end{array}$} & \multicolumn{3}{|c|}{$\Delta x_{t}=\alpha+\gamma_{1} x_{t-1}+\sum_{j=1}^{n} \gamma_{j} \Delta x_{t-j}+e_{t}$} & \multirow{2}{*}{$\begin{array}{c}\mathrm{H}_{0}: \gamma_{1}=0 \\
\begin{array}{c}\text { Nível de significância } \\
\text { da estatística "Q" }\end{array}\end{array}$} \\
\hline & $\begin{array}{l}\text { Defasagens } \\
\quad(\mathrm{n})\end{array}$ & $\begin{array}{l}\text { Valor da Estatística } \mathrm{t} \\
\qquad \mathrm{H}_{0}: \alpha=0\end{array}$ & $\begin{array}{c}\text { Valor da Estatística } \mathrm{t} \\
\mathrm{H}_{0}: \gamma_{1}=0\end{array}$ & \\
\hline lpph & 2 & -0.15 & -1.05 & 0,82 \\
\hline Ipvh & 1 & -0.21 & -0.65 & 0,51 \\
\hline lppac & 1 & -0.498 & -0.711 & 0.95 \\
\hline Ippi & 3 & -0.361 & -1.395 & 0.80 \\
\hline
\end{tabular}

A estacionariedade dessas variáveis em nível deve, então, ser verificada no modelo sem constante e sem tendência pela estatística $\tau$ na Tabela 4.19. As variáveis lpph e lppi apresentaram estacionariedade nos níveis de significância de 5\% e 1\%, respectivamente. Entretanto, as variáveis lpvh e lppac não tiveram o mesmo resultado, devendo-se, então, verificar a estacionariedade dessas séries de preços na primeira diferença.

Tabela 4.19 - Teste de estacionariedade em modelo sem constante e tendência, estatística $\tau$

\begin{tabular}{lccc}
\hline Modelo 3 : & $\Delta \boldsymbol{x}_{\boldsymbol{t}}=\gamma_{\boldsymbol{1}} \boldsymbol{x}_{\boldsymbol{t}-\boldsymbol{1}}+\sum_{\boldsymbol{j}=\mathbf{1}}^{n} \gamma_{\boldsymbol{j}} \Delta \boldsymbol{x}_{\boldsymbol{t}-\boldsymbol{j}}+\boldsymbol{e}_{\boldsymbol{t}}$ & $\mathrm{H}_{0}: \gamma_{\boldsymbol{1}}=\mathbf{0}$ \\
\hline Variáveis & Defasagens (n) & $\begin{array}{c}\text { Valor da Estatística } \\
\mathrm{H}_{0}: \gamma_{\boldsymbol{1}}=\mathbf{0}\end{array}$ & $\begin{array}{c}\text { Nível de significância da } \\
\text { estatística "Q" }\end{array}$ \\
\hline lpph & 2 & $-2.35^{* *}$ & 0,83 \\
lpvh & 1 & -1.22 & 0,52 \\
lppac & 1 & -1.041 & 0.94 \\
lppi & 3 & $-3.980^{*}$ & 0.83
\end{tabular}

*Significativo ao nível de significância de 1\%.

**Significativo ao nível de significância de $5 \%$. 
Para verificar a presença de raiz unitária nas séries de preços, passou-se, então, à análise da Tabela 4.20, que apresenta os resultados relativos à estacionariedade das séries de preços na primeira diferença, segundo a estatística $\tau$.

Tabela 4.20 - Teste de raiz unitária em modelo sem constante e tendência, estatística $\tau$

\begin{tabular}{lccc}
\hline Modelo $6:$ & $\Delta \Delta x_{t}=\sigma_{1} \Delta x_{t-1}+\sum_{j=1}^{n} \sigma_{j} \Delta \Delta x_{t-j}+e_{t}$ & $H_{0}: \sigma_{1}=0$ \\
\hline Variáveis & Defasagens (n) & $\begin{array}{c}\text { Valor da Estatística t } \\
\mathrm{H}_{0}: \sigma_{1}=0\end{array}$ & $\begin{array}{c}\text { Nível de significância da } \\
\text { estatística "Q" }\end{array}$ \\
\hline $\begin{array}{l}\text { lpph } \\
\text { llpvh }\end{array}$ & 1 & $-2.01^{* *}$ & 0,87 \\
$\Delta$ lppac & 1 & $-2.03^{* *}$ & 0,67 \\
$\Delta$ lppi & 1 & $-2.11^{* *}$ & 0.73 \\
\hline
\end{tabular}

**Significativo ao nível de significância de 5\%.

Os resultados indicaram a presença de raiz unitária no nível de significância de $5 \%$ para as variáveis $1 \mathrm{pph}$, lpvh e lppac. A variável lppi não se apresentou estacionária na primeira diferença. Os altos níveis de significância da estatística "Q", do teste de Box-Pierce, descritos na última coluna da tabela, rejeitam a hipótese de nulidade desse teste, que considera a existência de autocorrelação entre os resíduos.

\subsubsection{Testes de co-integração}

Os testes de co-integração podem auxiliar na definição da ordem de integração das variáveis da seguinte maneira: se duas séries forem co-integradas e se uma delas for I (1), a outra deverá ser também I (1). Então, os testes de co-integração entre as séries que se apresentaram estacionárias em nível e as que se apresentaram estacionárias nas diferenças podem ajudar na definição da ordem de integração das variáveis. 
Verificou-se que as variáveis se apresentaram co-integradas quando os resíduos das equações estimadas entre elas foram estacionários. Nesse caso, o valor descrito da estatística DF foi maior do que o valor crítico apresentado na Tabela 1A.2, do Apêndice 1. As seguintes variáveis foram co-integradas:

\begin{tabular}{|c|c|c|c|}
\hline $\begin{array}{c}\mathrm{lpph}=0,87+1,507 \mathrm{lppac} \\
(0,00) \quad(0,00)\end{array}$ & $\mathrm{R}^{2}=0,94$ & $\mathrm{DF}=11.74$ & $\mathrm{n}=5$ \\
\hline 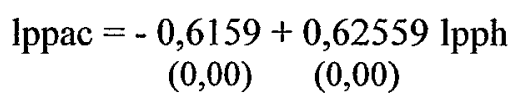 & $\mathrm{R}^{2}=0,94$ & $\mathrm{DF}=7.36$ & $n=6$ \\
\hline $\begin{aligned} & \mathrm{lpph}= 0,519+1,5287 \mathrm{lppi} \\
&(0,00) \\
&(0,00)\end{aligned}$ & $\mathrm{R}^{2}=0,95$ & $\mathrm{DF}=3.603$ & $\mathrm{n}=6$ \\
\hline 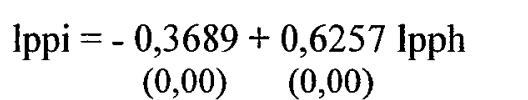 & $\mathrm{R}^{2}=0,95$ & $\mathrm{DF}=5.12$ & $\mathrm{n}=5$ \\
\hline 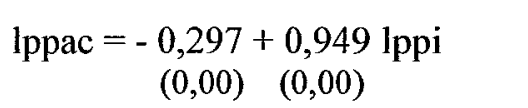 & $\mathrm{R}^{2}=0,88$ & $\mathrm{DF}=9.4$ & $\mathrm{n}=4$ \\
\hline $\mathrm{lppi}=\underset{(0,13)}{0,166}+\underset{(0.00)}{0,9359} \mathrm{lppac}$ & $\mathrm{R}^{2}=0,88$ & $\mathrm{DF}=5.348$ & $\mathrm{n}=6$ \\
\hline
\end{tabular}

Pelo fato de lppi e lpph serem co-integradas com séries I (1), pode-se inferir que as séries de preços ao produtor de álcool anidro e de álcool hidratado são também I (1), da mesma maneira que o preço ao varejo de hidratado e ao produtor de açúcar cristal.

A seguir foi testada a co-integração para o conjunto de variáveis envolvidas na formação de preço no nível do produtor, conforme definido na equação (24) do item 3.2.3. O seguinte resultado foi obtido com a regressão, indicando a presença de um vetor de co-integração entre aquelas variáveis:

$$
\begin{aligned}
& \text { lpph }=0,556+0,6468 \text { lppi }+0,514 \text { lppac }+0,469 \text { lpvh } \quad R^{2}=0,98 \quad \text { DF }=4.56 \quad n=5 \\
& \begin{array}{llll}
(0,00) & (0,00) \quad(0,01) \quad(0,04)
\end{array}
\end{aligned}
$$


Verificou-se, então, que os sinais estavam de acordo com o esperado para as variáveis preço de álcool anidro no produtor (lppi) e preço de açúcar cristal no produtor (lppac). Entretanto, o preço de álcool hidratado no varejo (lpvh) apresentou sinal positivo, sendo o esperado para essa variável uma relação negativa na formação desse preço. Conforme descrito para os mercados de açúcar e álcool anidro anteriormente, tal resultado pode estar relacionado ao fato de que foi a variável contemporânea do preço de álcool hidratado no varejo (lpvh) utilizada na equação, e o sinal negativo era esperado para a variável defasada.

Para a equação referente à formação de preço de álcool hidratado no varejo, não foi verificada a presença de co-integração entre o preço no varejo (lpvh) e o preço no produtor (lpph).

\subsubsection{Testes de causalidade de Granger}

Foi utilizado o modelo de causalidade de Granger com as variáveis na primeira diferença e com o termo de correção de erro naqueles modelos, cujas variáveis utilizadas se apresentaram co-integradas. $\mathrm{O}$ número de defasagens foi utilizado segundo o critério de Akaike e Schwarz (com máximo de sete defasagens) para a variável dependente; para a variável explicativa, adotaram-se as defasagens significativas do teste de correlação cruzada entre as variáveis relacionadas ou, pelo menos, uma defasagem no caso de não haver defasagem significativa. Os resultados do teste de correlação cruzada estão descritos na Tabela 4.21 . 
Tabela 4.21 - Correlações cruzadas entre as variáveis utilizando 4 defasagens para as variáveis ${ }^{30}$

\begin{tabular}{|c|c|c|c|c|c|c|}
\hline \multirow[t]{2}{*}{ defasagens } & \multicolumn{6}{|c|}{ Correlações cruzadas } \\
\hline & \multicolumn{6}{|c|}{$\Delta \mathrm{lpph}$ e $\Delta \mathrm{lpvh}$} \\
\hline-4 a 1: & 0.0373457 & -0.1170159 & 0.2554889 & $0.5972304^{*}$ & $0.7455802^{*}$ & 0.0094451 \\
\hline \multirow[t]{2}{*}{2 a $4:$} & -0.0241179 & -0.1623862 & -0.1790751 & & & \\
\hline & \multicolumn{6}{|c|}{$\Delta \mathrm{lpph}$ e $\Delta \mathrm{lppac}$} \\
\hline-4 a 1: & -0.2102796 & 0.2442042 & 0.0060270 & 0.3657008 & $0.6771416^{*}$ & 0.3346878 \\
\hline \multirow[t]{2}{*}{2 a $4:$} & 0.0290078 & -0.0024886 & -0.1923995 & & & \\
\hline & \multicolumn{6}{|c|}{$\Delta$ lpph e $\Delta$ lppi } \\
\hline-4 a $1:$ & -0.0411216 & -0.2508240 & -0.1915308 & 0.3960705 & $0.8146253^{*}$ & 0.0343962 \\
\hline 2 a 4: & -0.0235485 & 0.1580069 & -0.0553904 & & & \\
\hline
\end{tabular}

* Correlação significativa (valor crítico para o teste de correlação $=0,47$, que é da fórmula $2 / \sqrt{n}$ ).

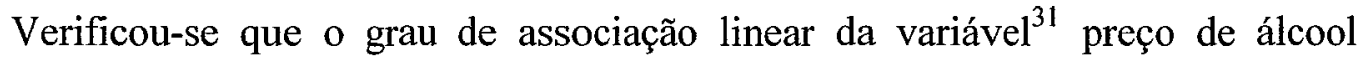
hidratado do produtor $(\Delta \mathrm{lpph})$ com as demais variáveis foi significativo quando relacionadas contemporaneamente. Com uma defasagem de $\Delta \mathrm{lpph}$, tem-se também o valor da correlação significativa com a contemporânea do preço de álcool hidratado no varejo $(\Delta \mathrm{lpvh})$. Houve também alto grau de relação linear, porém não-significativa, com uma defasagem da variável $\Delta \mathrm{lpph}$ com as contemporâneas do preço de açúcar cristal no produtor ( $\Delta \mathrm{lppac})$ e do preço de álcool anidro no produtor $(\Delta \mathrm{lppi})$.

É esperado uma relação linear forte entre as variáveis relacionadas no modelo econômico proposto em 3.2.3, entretanto o resultado de correlação cruzada não foi significativo entre o preço de álcool hidratado no varejo $(\Delta \mathrm{lpvh})$ defasado com o preço do produtor $(\Delta \mathrm{lpph})$.

\footnotetext{
${ }^{30}$ As defasagens negativas correspondem ao preço defasado da primeira variável descrita em relação ao preço da segunda variável, assim como as defasagens positivas referem-se ao preço defasado da segunda variável em relação à primeira.

${ }^{31}$ Todas as referências às variáveis "preços" descritas a seguir até o término do item 4.3 na verdade estão relacionadas à taxa de crescimento daqueles preços, pois as variáveis estão na primeira diferença do logaritmo daqueles preços. Tal denominação foi utilizada para haver maior fluidez ao texto.
} 
Foi realizado o teste de causalidade, cujos resultados estão descritos na Tabela 4.22. Observa-se, nessa tabela, o sentido causal do preço de álcool hidratado no produtor $(\Delta \mathrm{lpph})$ para o preço de hidratado no varejo ( $\Delta \mathrm{lpvh})$, no nível de significância abaixo de $5 \%$, no curto prazo.

Tabela 4.22 - Resultado do teste de causalidade de Granger com termo de correção de erro

\begin{tabular}{llccc}
\hline Variável dependente & Variável explicativa & Teste $\mathrm{F}^{*}$ & Teste $\mathbf{t}^{*}$ & Teste $\mathrm{Q}^{*}$ \\
\hline$\Delta \mathrm{lpvh}$ & $\Delta \mathrm{lpph}$ & 0.02 & - & 0.59 \\
$\Delta \mathrm{lpph}$ & $\Delta \mathrm{lppi}$ & 0.04 & - & 0.17 \\
$\Delta \mathrm{lppac}$ & $\Delta \mathrm{lpph}$ & - & 0.02 & 0.63 \\
\hline
\end{tabular}

* Os valores indicados para os testes estatísticos $\mathrm{F}, \mathrm{t}$ e $\mathrm{Q}$ representam os níveis de significância desses testes. O teste $\mathrm{F}$ tem como hipótese nula que os coeficientes da variável explicativa são iguais a zero. $\mathrm{O}$ teste $t$ considera o termo de correção de erro (quando presente) igual a zero, e o teste $Q$ tem como hipótese de nulidade a ausência de autocorrelação de resíduos.

Outras relações indicaram um sentido causal unidirecional, no nível do produtor, da seguinte maneira: preço de álcool anidro ( $\Delta$ lppi) causa preço de hidratado ( $\Delta$ lpph) no curto prazo e preço de hidratado $(\Delta l p p h)$ causa preço de açúcar cristal ( $\triangle$ lppac) no longo prazo.

Os resultados do teste de causalidade se aproximaram do resultado esperado pelo modelo proposto, sendo a seguir estimados os coeficientes desse modelo.

\subsubsection{Equações de formação de preços com termo de correção de erro}

As séries de preços utilizadas para determinar as elasticidades de transmissão de preços foram utilizadas na primeira diferença (possuem raiz unitária), representando a taxa de crescimento dos preços e não os preços propriamente ditos. O termo de correção de erro foi, então, utilizado quando as variáveis descritas nas equações se apresentaram co-integradas, recuperando, assim, as informações de longo prazo perdidas nas diferenças das variáveis em estudo. 
Os coeficientes foram estimados para o modelo de formação de preços descrito no tópico 3 (item 3.2.3), pelo método de equações simultâneas. Os resultados, referentes ao período analisado, são descritos na Tabela 4.23.

Tabela 4.23 - Estimativas de formação dos preços nos níveis de produtor e varejo do mercado de álcool hidratado no Estado de São Paulo de acordo com um sistema de equações simultâneas; período: fevereiro de 1999 a julho de $2000^{32}$

\begin{tabular}{|c|c|c|}
\hline \multirow[b]{2}{*}{$\begin{array}{l}\text { Variáveis exógenas e } \\
\text { Estatísticas }\end{array}$} & \multicolumn{2}{|c|}{$\begin{array}{ll} & \text { Variáveis endógenas }\end{array}$} \\
\hline & $\begin{array}{c}\text { Taxa de crescimento do preço no } \\
\text { produtor } \\
\Delta \mathrm{lpph}_{\mathrm{t}}\end{array}$ & $\begin{array}{c}\text { Taxa de crescimento do preços no } \\
\text { varejo } \\
\Delta \operatorname{lpvh}_{\mathrm{t}}\end{array}$ \\
\hline$\Delta \operatorname{lpph}_{\mathrm{t}}$ & - & $\begin{array}{l}0,425 \\
(0.00)\end{array}$ \\
\hline$\Delta \operatorname{lppi}_{\mathrm{t}}$ & $\begin{array}{c}0.98 \\
(0.00)\end{array}$ & - \\
\hline$\Delta$ lppac $_{\mathrm{t}}$ & $\begin{array}{l}0.496 \\
(0.02)\end{array}$ & - \\
\hline$\Delta \mathrm{lpph}_{\mathrm{t}-1}$ & $\begin{array}{c}0.089 \\
(0.77)\end{array}$ & - \\
\hline$\Delta \mathrm{lpvh}_{\mathrm{t}-\mathrm{I}}$ & $\begin{array}{c}0.05 \\
(0.88)\end{array}$ & $\begin{array}{c}0,36 \\
(0.03)\end{array}$ \\
\hline$e p h_{t-1}$ & $\begin{array}{c}-1.02 \\
(0.13)\end{array}$ & - \\
\hline $\mathrm{R}^{2}$ & 0.82 & 0.72 \\
\hline$Q(\%)$ & $0.57(0.96)$ & $9.24(0.05)$ \\
\hline
\end{tabular}

$\mathrm{O}$ valor de $\mathrm{R}^{2}$ indicou um bom grau de ajustamento linear desses modelos, apesar da ausência da variável no nível de atacado. Os coeficientes estimados na Tabela 4.29 apresentam, exceto para o preço de álcool hidratado no varejo $(\Delta \mathrm{lpvh})$, sinais de acordo com o esperado pelo modelo econômico. O sinal contrário de $\Delta$ lpvh pode ser o resultado do problema causado pela ausência do preço atacadista. 
$\mathrm{Na}$ estimação da equação (24) referente à formação do preço de álcool hidratado no produtor, o preço de álcool anidro no produtor ( $\Delta$ lppi) exerceu forte influência na informação de curto prazo do preço de hidratado ( $\Delta \mathrm{lpph})$. A relação inversa, qual seja, da influência do preço de álcool hidratado no preço de anidro descrita no item 4.2, foi também alta, e, conforme explicado naquela ocasião, tal resultado pode ser explicado pelo fato de os mercados de álcool anidro e hidratado estarem mais relacionados, uma vez que ambos são utilizados como combustível. Contemporaneamente, não apenas a variável $\Delta$ lppi, como também o preço de açúcar cristal do produtor $(\Delta \mathrm{lppac})$, exerce forte influência sobre $\Delta$ lpph. Os sinais das variáveis $\Delta$ lppi e $\Delta$ lppac apresentaram-se de acordo com o esperado pelo modelo econômico proposto no tópico 3, descrito nas equações (22) e (24).

Realizados testes de multicolinearidade entre as variáveis explicativas das equações descritas na Tabela $4.23^{33}$, concluiu-se que não houve presença de multicolinearidade naquelas equações.

\footnotetext{
${ }^{32} \mathrm{~A}$ variável $\mathbf{e p h} \mathbf{h}_{\mathbf{t}-1}$ representa o termo de correção de erro referente ao modelo ao produtor.

${ }^{33}$ Valores altos da variância dos coeficientes estimados e das correlações simples entre as variáveis explicativas indicam a presença de multicolinearidade. Tais resultados se encontram na Tabela 2.7 (variâncias) e nas Tabelas 2.10 e 2.11 (correlaçôes), do Apêndice 2. Regressões auxiliares com as variáveis explicativas utilizadas como dependentes também não detectaram multicolinearidade.
} 


\section{CONCLUSÕES}

Este trabalho analisou o comportamento dos preços dos principais produtos do setor sucroalcooleiro - açúcar, álcool anidro e álcool hidratado - no mercado do Estado de São Paulo, compreendendo o período posterior à desregulamentação de preços desses produtos.

Os resultados obtidos permitiram concluir que, de maneira geral, a formação de preços dos produtos finais nesse setor, pode ser explicada, ao longo do período analisado, utilizando-se um modelo de desequilíbrio no curto prazo, segundo o qual, choques de oferta e demanda causam alterações iniciais nos preços ao produtor e ao atacado, simultaneamente.

Os testes de causalidade de Granger confirmaram muitas das relações entre variáveis estabelecidas pelo modelo econômico, assim como a hipótese geral da relação de causalidade, qual seja, do nível de mercado mais concentrado para o menos concentrado. Assim, observou-se que, no mercado de açúcar, o preço ${ }^{34}$ de açúcar refinado no produtor causa o preço desse mesmo açúcar no varejo. De forma semelhante, nos mercados de álcool combustível, os preços do produtor causavam os preços de varejo. Entretanto, no mercado de açúcar cristal, o preço no varejo causou o preço no atacado contrariando a hipótese inicial.

\footnotetext{
${ }^{34}$ Aqui também, todas as referências a preços indicam, na verdade, à taxa de crescimento desses preços.
} 
$\mathrm{Na}$ equação referente à formação de preço do produtor de açúcar cristal, evidenciaram-se problemas em relação aos sinais e, mesmo, de magnitude dos coeficientes estimados naquela equação, o que pode estar associado a problemas de multicolinearidade e ao curto período de tempo utilizado na pesquisa.

A estimativa da equação de formação do preço de açúcar cristal no atacado apresentou resultado contrário ao esperado somente em relação ao sinal da variável referente à demanda do atacado, contrariando a hipótese previamente estabelecida. Temse uma indicação de que o açúcar cristal possui uma baixa sensibilidade da demanda aos preços de varejo. A equação de formação do preço do produtor de açúcar refinado foi coerente com a teoria estabelecida no modelo econômico, qual seja, apresentou sinal positivo para o preço do produtor de açúcar cristal e de açúcar refinado defasado e negativo para o preço no varejo de açúcar refinado. Os coeficientes estimados para a equação de formação do preço de açúcares cristal e refinado no varejo foram positivos para o próprio preço no varejo defasado e para o preço de transporte (variável utilizada como "proxy" para insumos de varejo), conforme previsto no modelo econômico.

Os preços no atacado do mercado de álcool combustível, nível representado principalmente pelas grandes distribuidoras, não foram utilizados nesse estudo em função de restrições no acesso a séries de dados que possibilitam avaliar esse nível. A princípio, no entanto, esse mercado possui um setor atacadista muito concentrado e desvinculado do nível de produção, ao contrário do que se verifica no mercado de açúcar. Dessa forma, acredita-se que alterações nos preços dos combustíveis, sejam essas causadas por choques de oferta do produtor ou de demanda do varejo teriam seus efeitos evidenciados, a princípio, a esse nível de mercado.

Com relação à estimativa da equação proposta para o mercado de álcool anidro na formação do preço do produtor, tem-se que os sinais foram positivos para as variáveis preço de álcool anidro no produtor defasado e preço de álcool hidratado e negativos para 
o preço de álcool anidro no varejo. Apenas a variável referente ao preço de açúcar cristal do produtor apresentou sinal contrário ao proposto no modelo. Tais resultados indicaram que existe baixa influência entre o preço do produtor de açúcar cristal e o preço de álcool anidro no período estudado. Esse resultado foi corroborado pelas estimativas da equação referente à formação do preço de açúcar cristal no produtor. Observou-se forte relação entre os preços do produtor de álcool anidro e de álcool hidratado, provavelmente pelo fato de ambos serem utilizados como combustível.

Os resultados referentes à estimação da equação de formação do preço de álcool anidro no varejo podem ser úteis aos formuladores de política no que se relaciona a alterações de preço da gasolina, em razão da regulamentação ainda existente nesse nível de mercado. O teste de causalidade sugere que o preço de álcool anidro causa o de gasolina, ao longo do período estudado, ainda que de maneira pouco expressiva.

No mercado de álcool hidratado, a variação tanto dos preços de açúcar quanto de álcool anidro apresentou sinal positivo, influenciando fortemente essa variável, no período analisado, o que está de acordo com a hipótese estabelecida. O sinal não coincidente com a teoria da variável de demanda (preço de hidratado no varejo) pode ser atribuído à ausência de informações relativas a preços do atacadista desse mercado. No nível de varejo, os sinais dos coeficientes estimados foram positivos para as variáveis preço de álcool hidratado ao produtor e do próprio preço ao varejo defasado, conforme proposto no modelo econômico.

A redução do preço no varejo de álcool hidratado, como incentivo ao aumento de demanda por esse combustível em substituição à gasolina, por ser menos poluente do que este último, pode ser realizada pelos formuladores de política, controlando os preços ao produtor de álcool hidratado. $\mathrm{O}$ impacto causado pela variação no preço ao produtor sobre a variação do preço ao varejo foi estimada em $42,5 \%$ no período analisado. 
Os resultados indicaram alta relação entre os preços no nível do produtor de álcool hidratado com os preços do produtor de açúcar cristal e de álcool anidro na explicação da formação desșes três preços, ao longo do período estudado. Dessa maneira, havendo interesse por parte dos formuladores de política desses setores em realizar alteração da taxa de crescimento do preço em alguns desses mercados, os resultados da pesquisa indicaram que esta terá como efeito resultante mudanças positivas nas taxas de crescimento daqueles preços relacionados.

Sugere-se, entretanto, que se realizem novas estimativas dos modelos econômicos formulados para estudo desses mercados, compreendendo dados relativos a períodos mais extensos quando estes estiverem disponíveis, uma vez que o curto período deste estudo se constituiu em uma das restrições à análise dos resultados obtidos. Além disso, é importante se destacar que no período inicial da desregulamentação de um mercado, os preços podem se comportar de forma não representativa quanto à forma de reestruturação que se estabelece nesse mercado. Da mesma maneira, mediante a perspectiva de concretizar a proposta de se criar um imposto seletivo sobre os combustíveis, desregulamentando o preço da gasolina, sugere-se que estas estimativas sejam reavaliadas, pois o comportamento dos preços no mercado de álcool combustível pode vir a sofrer alterações em relação àquele preço. 


\section{REFERÊNCIAS BIBLIOGRÁFICAS}

AGUIAR, D. R. D. A Questão da transmissão de preços agrícolas. Revista de Economia e Sociologia Rural, v.31, n.4, p.291-308, out./dez. 1993.

AGUIAR, D. R. D. Formação de preços na indústria Brasileira de soja: 1982-1989. Piracicaba, 1990. 140p. Dissertação (Mestrado) - Escola Superior de Agricultura Luiz de Queiroz, Universidade de São Paulo.

AGUIAR, D. R. D. Transmissão de preços mensais entre os mercados externo e interno: uma adaptação do modelo de Mundlak-Larson. Revista de Economia e Sociologia Rural, v.33, n.4, p.43-50, out./dez. 1995.

ALMEIDA, C. O.; MESQUITA, T. C. Causalidade entre preços externos e quantidades exportadas de café do Brasil no mercado internacional - 1965/89. Pesquisa e Planejamento Econômico, v.25, n.3, p.527-540, dez. 1995.

ALVES, J. M. Transmissão de preços e margens de comercialização de abacaxi, banana e laranja em Minas Gerais. Viçosa, 1996. 74p. Dissertação (Mestrado) Universidade Federal de Viçosa.

BACCHI, M. R. P. Causalidade entre preços no mercado de carnes do Estado de São Paulo. Revista de Economia e Sociologia Rural, v.34, n.2, p.51-60, nov./dez. 1995.

BACCHI, M. R. P. Transmissão de preços entre os segmentos produtivos da pecuária de corte brasileira. In: XXXVII CONGRESSO BRASILEIRO DE ECONOMIA E SOCIOLOGIA RURAL, Foz do Iguaçu, 1999. (compact disc). Viçosa: Agromídia Software, 1999.

BACCHI, M. R. P.; MARJOTTA-MAISTRO, M. C. Comportamento do preço do açúcar no Estado de São Paulo. Preços Agrícolas, v. XIV, n.158, p.11-13, dez. 1999. 
BARROS, A. R. Uma avaliação das políticas públicas para o setor sucroalcooleiro no Brasil. Revista Econômica do Nordeste, v.27, n.3, p.321-362, jul./set. 1996.

BARROS, G. S. C. Transmissão de preços pela central de abastecimento de São Paulo, Brasil. Revista Brasileira de Economia, v.44, n.1, p.5-20, jan./mar. 1990.

BARROS, G. S. C.; MAFIOLETTI, R. L. Formação de preços na cadeia agro-industrial da soja na década de 90. In: XXXVII CONGRESSO BRASILEIRO DE ECONOMIA E SOCIOLOGIA RURAL, Foz do Iguaçu, 1999. (compact disc). Viçosa: Agromídia Software, 1999.

BITTENCOURT, M. V. L. Formação de preços e caracterização do mercado de frango em São Paulo. Piracicaba, 1995. 161p. Dissertação (Mestrado) - Escola Superior de Agricultura Luiz de Queiroz, Universidade de São Paulo.

BLISKA, F. M. M. Transmissão de preços de carne bovina entre níveis de mercado: uma aplicação do modelo de auto-regressão vetorial. Piracicaba, 1989. 209p. Dissertação (Mestrado) - Escola Superior de Agricultura Luiz de Queiroz, Universidade de São Paulo.

BURNQUIST, H. L. A questão da causalidade entre preços a diferentes níveis de mercados agrícolas. Piracicaba: ESALQ, 1986. 83p. Dissertação (Mestrado) - Escola Superior de Agricultura Luiz de Queiroz, Universidade de São Paulo.

BURNQUIST, H. L. Panorama da safra sucroalcooleira na Região Centro-Sul. Preços Agrícolas, v. XIV, n.158, p.7-10, dez. 1999.

- CARVAlHO, J. C. C. Pesos diferentes. Agroanalysis, v.20, n.3, p.41-45. mar. 2000.

CARVALHO, F. C; ; et al. Preços de algodão nos mercados interno e externo: uma análise de causalidade. Revista de Economia e Sociologia Rural, v.21, n.2, p.241249, abr./jun. 1983.

CENTRO DE ESTUDOS AVANÇADOS EM ECONOMIA APLICADA (CEPEA). Indicadores. Açúcar. Álcool. http://www.ciagri.usp.br/ cepea (julho de 2000)

CONJUNTURA ECONÔMICA. Fundação Getúlio Vargas, v.51 a 54, 1997 a 2000.

CONSELHO DOS PRODUTORES DE CANA-DE-AÇÚCAR, AÇÚCAR E ÁLCOOL DO ESTADO DE SÃO PAULO. Manual de Instruções. Piracicaba, 1999. 92p.

COOPERATIVA DE PRODUTORES DE CANA, AÇÚCAR E ÁLCOOL DO ESTADO DE SÃO PAULO Ltda. - Copersucar. http://www.copersucar.com.br/ (maio de 2000). 
CORREIA, E. L. Proálcool - do sucesso à polêmica. Agroanalysis, v.16, n.8, p.12-16, ago. 1996.

DIAS J.; SORDI, J. C. A importância da curva da demanda e o comportamento do setor para uma política de determinação de preços: o caso do álcool hidratado no Brasil. Revista Econômica do Nordeste, v.30, n.4, p.978-998, out/dez. 1999.

DICKEY, D.A.; FULLER, W. A. Likelihood ratio statistics for auto-regressive time series with a unit root. Econometrica, Illinois, v.49, n.4, p.1057-72, 1981.

EID, F. Progresso técnico na agroindústria sucroalcooleira. Informações Econômicas, v.26, n.5, p.29-35, maio 1996.

EID, F., CHAN, K., PINTO, S. S. Tecnologia e co-geração de energia na indústria sucroalcooleira paulista: uma análise da experiência e dificuldades de difusão. Informações Econômicas, v.28, n.5, p.7-11, maio 1998.

ENGLE, R. F. \& GRANGER, C. W. J. Cointegration and error correction: representation, estimation and testing. Econometrica, v.55, p.251-276, 1987.

ENGLE, R. F. \& YOO, S. Forecasting and testing in cointegrated systems. Journal of Econometrics, v.35, p.143-159, 1987.

FELIPPI, E. E.; WAQUIL, P. D. Transmissão de preços entre os níveis de mercado de atacado e de varejo: metodologia e estudo de caso na região metropolitana de Porto Alegre. In: XXXVII CONGRESSO BRASILEIRO DE ECONOMIA E SOCIOLOGIA RURAL, Foz do Iguaçu, 1999. (compact disc). Viçosa: Agromídia Software, 1999.

FNP CONSULTORIA \& COMÉRCIO. Agrianual: Anuário de Agricultura Brasileira. São Paulo, 2000. p.249-267: cana-de-açúcar.

FULLER, W. A. Introduction to statistical time series. New York, John Wiler. 1976.

GARDNER, B. L. The farm-retail price spread in a competitive food industry. American Journal of Agricultural Economics, v.57, p.399-409. 1975.

GUJARATI, D.N. 1995. Basic Econometrics. 3. ed. Singapore: McGraw-Hill,Inc., 1995. 838p.

HEIEN, D. M. Markup pricing in a dynamic model of food industry. Americam Journal of Agricultural Economics, v.62, p.10-18. 1980. 
HOFFMANN, R.; VIEIRA, S. Análise de regressão: Uma Introdução à Econometria. São Paulo: Hucitec, 1998. 379p.

ÍNDICE de Preços ao Consumidor. São Paulo: FIPE, n.701 a 739, 1997 a 2000.

INSTITUTO BRASILEIRO DE GEOGRAFIA E ESTATÍSTICA. Anuário Estatístico do Brasil. Rio de Janeiro, v.56, p.2-14, 1996.

INSTITUTO DE PESQUISA ECONÔMICA APLICADA. Ipeadata. Tema: Preços. http://www.ipeadata.gov.br/ipeaweb.dll (agosto de 2000).

KHALAFALLA, K. Y.; WEBB, A. J. Exports and economic growth under structural change: a co-integration analysis of evidence from Malaysia. Universiti Putra Malaysia. International Agricultural Trade Research Consortium, April 2000. 23p. (wording paper, 00-1).

LAMOUNIER, W. M.; BRESSAN, A. A. Causalidade entre preços agrícolas e inflação no Brasil pós-plano real. In: XXXVII CONGRESSO BRASILEIRO DE ECONOMIA E SOCIOLOGIA RURAL, Foz do Iguaçu, 1999. (compact disc). Viçosa: Agromídia Software, 1999.

LIMA, R. C.; SAMPAIO, Y. Estimação de função de transferência para o preço do açúcar: uma aplicação do modelo armax. Revista Econômica do Nordeste, v.28, n.especial, p.461-467, jul. 1997.

LÜTKEPOHL, H. Introduction to multiple time series. 2. ed. Berlin: Springer-Verlag, 1993. 545p.

MAIA, S. F.; ROCHA, E. C.; LIMA, R. C. Elasticidade de transmissão de preços usando função de transferência e defasagens distribuídas: metodologias comparadas. In: XXXVII CONGRESSO BRASILEIRO DE ECONOMIA E SOCIOLOGIA RURAL, Foz do Iguaçu, 1999. (compact disc). Viçosa: Agromídia Software , 1999.

MARGARIDO, M. A. Transmissão de preços internacionais de suco de laranja para preços ao nível de produtor de laranja no Estado de São Paulo. São Paulo, 1994. 96p. Dissertação (Mestrado) - Fundação Getúlio Vargas.

MARGARIDO, V. A.; et al. Transmissão de preços no mercado internacional do grão de soja: uma aplicação da metodologia de séries temporais. In: XXXVII CONGRESSO BRASILEIRO DE ECONOMIA E SOCIOLOGIA RURAL, Foz do Iguaçu, 1999. (compact disc). Viçosa: Agromídia Software, 1999.

MELLO, R. O. S. Desafios claros. Agroanalysis, v. 20, n.3, p.25-26, mar. 2000. 
-MORAES, M. A. F. D. Alterações nas relações contratuais da cadeia sucroalcooleira, decorrentes da desregulamentação, analisadas sob a ótica da nova economia das instituições. Revista de Economia e Sociologia Rural, v.36, n.3, p.55-77, jul./set. 1998.

PESONEN, H. Assessing causal linkages between the emerging stock markets of Asia and Russia. Russian and East European Finance and Trade, v.35, n.2, p.73-82, Mar/April 1999.

PILON J. Duro aprendizado. Agroanalysis, v.20, n.3, p.35-36, mar. 2000.

PINAZZA, L. A.; ALIMANDRO, R. Via crucis. Agroanalysis, v.20, n.3, p.35-36, mar. 2000 .

RODRIGUES, V. L. G. S. O associativismo em questão: os empresários dos complexos sucro-alcooleiro e citrícola. Informações Econômicas, v.28, n.9, p.11-24, set. 1998.

SAATCIOGLU, K.; STARKS, L. T. The stock price - volume relationship in emerging stock markets: the case of Latin America. International Journal of Forecasting, v.14, p.215-225, 1998.

SANTOS, E. V.; FETT, M. S. Causalidade e elasticidade na transmissão de preços de maçã entre produtor, atacado e varejo no Rio Grande do Sul. In: XXXVII CONGRESSO BRASILEIRO DE ECONOMIA E SOCIOLOGIA RURAL, Foz do Iguaçu, 1999. (compact disc). Viçosa: Agromídia Software , 1999.

SHIKIDA, P. F. A.; BACHA, C. J. C. Evolução da agroindústria canavieira brasileira de 1975 a 1995. Revista Brasileira de Economia, v.53, n.1, p.69-89, jan./mar. 1999.

SIMS, C. A.; STOCK, J. H.; WATSON, M. W. Inference in linear time series models with some unit roots. Econometrica, v.58, n.1, p.113-44, Jan/1990.

- STALDER, S. H. G. M.; BURNQUIST, H. L. A importância dos subprodutos da canade-açucar no desempenho do setor agroindustrial. Revista de Economia e Sociologia Rural, v.34, n.3 e 4, p.103-119, jul./dez. 1996.

STRAUSS, J. Productivity differentials, the relative price of non-tradables and exchange rates. Journal of International Money and Finance, v.18, p.383-409, 1999.

UNIÃO DA AGROINDÚSTRIA CANAVIEIRA DO ESTADO DE SÃO PAULO. Acompanhamento de Safra. http://www.unica.com.br/unica.htm (junho de 2000a). 
UNIÃO DA AGROINDÚSTRIA CANAVIEIRA DO ESTADO DE SÃO PAULO. $\mathbf{O}$ Açúcar e o Álcool no Estado de São Paulo. http://www.unica.com.br/unica.htm (junho de 2000b).

URI, N. D. Energy and the use of conservation tillage in US agriculture. Journal of Energy Policy, v.27, p.299-306, 1999.

VIAN, C. E. F.; et al. Estratégias de crescimento em destilarias de álcool e usinas açucareiras: estudos de caso em nove empresas paulistas. Informações Econômicas, v.27, n.9, p.7-25, set. 1997.

WILLETT, L. S.; HANSMIRE, M. R.; BERNARD, J. C. Asymmetric price response behavior of red delicious apples. Agribusiness, v.13, n.6, p.649-658, 1997.

ZEN, S. Integração entre os mercados de boi gordo e de carne bovina nas regiões centrooeste e sudeste do Brasil. Piracicaba, 1997. 81p. Dissertação (Mestrado) - Escola Superior de Agricultura Luiz de Queiroz, Universidade de São Paulo. 


\section{APÊNDICE 1}

\section{Estatísticas do teste de Raiz Unitária e de Co-integração}


Tabela 1A.1 - Valores críticos das estatísticas $\tau_{\tau}, \tau_{\mu}$ e $\tau$ para raiz unitária e estatísticas $\tau_{\beta \tau}$, e $\tau_{\alpha \tau}$

\begin{tabular}{lcc}
\hline $\begin{array}{l}\text { Tamanho da } \\
\text { amostra (n) }\end{array}$ & 1 & Probabilidade (\%) \\
\hline & $\tau_{\beta \tau}$ (testa significância do termo de tendência determinística no modelo) \\
50 & 3.60 & 2.81 \\
25 & 3.74 & 2.85 \\
\hline & $\tau_{\alpha \tau}$ (testa significância da constante no modelo) \\
50 & 3.87 & 3.14 \\
25 & 4.05 & 3.20 \\
\hline & $\tau_{\tau}$ (testa estacionariedade em modelo com constante e tendência) \\
50 & -4.15 & -3.50 \\
25 & -4.38 & -3.60 \\
\hline & $\tau_{\mu}($ testa estacionariedade em modelo com constante) \\
50 & -3.58 & -2.93 \\
25 & -3.75 & -3.00 \\
\hline & $\tau($ testa estacionariedade em modelo sem constante e sem tendência) \\
50 & -2.62 & -1.95 \\
\hline & -2.65 & -1.95 \\
\hline
\end{tabular}

Fonte: Fuller (1976) - estatísticas $\tau_{\mu}, \tau$ e $\tau_{\tau}$

Dickey e Fuller (1981) - estatísticas $\tau_{\alpha}, \tau$ e $\tau_{\beta \tau}$. 
Tabela 1A.2 - Valores críticos dos testes de co-integração para 50 observações

\begin{tabular}{ccc}
\hline $\begin{array}{c}\text { Número de } \\
\text { variáveis }\end{array}$ & 1 & Nível de significância (\%) \\
\hline 1 & 3.58 & 5 \\
2 & 4.32 & 2.93 \\
3 & 4.84 & 3.67 \\
5 & 5.41 & 4.11 \\
& & 4.76 \\
\hline
\end{tabular}

Fonte: Engle e Yoo (1987). 


\section{APÊNDICE 2}

Resultados da análise de multicolinearidade 
Tabela 2A.1 - Valores da variância dos coeficientes estimados das regressões no mercado de açúcar cristal e refinado

\begin{tabular}{|c|c|c|c|c|c|}
\hline \multirow{2}{*}{$\begin{array}{l}\text { Variáveis } \\
\text { explicativas }\end{array}$} & \multicolumn{5}{|c|}{ Variáveis dependentes } \\
\hline & $\Delta$ lppac & $\Delta$ lpaac & $\Delta l p v a c$ & $\Delta$ lppar & $\Delta$ lpvar \\
\hline$\Delta \mathrm{lppac}_{\mathrm{t}}$ & - & 0.00488 & - & 0.008301 & - \\
\hline$\Delta \mathrm{lppac}_{\mathrm{t}-1}$ & 0.11639 & - & - & - & - \\
\hline$\Delta$ lpaac $_{t}$ & - & - & 0.006713 & - & - \\
\hline$\Delta \mathrm{lpaac}_{\mathrm{t}-1}$ & 0.21079 & 0.00719 & - & - & - \\
\hline$\Delta \operatorname{lpvac}_{t-1}$ & - & 0.021806 & 0.01503 & - & - \\
\hline$\Delta$ lppar $_{t}$ & - & - & - & - & 0.009508 \\
\hline$\Delta$ lppar $_{t-1}$ & 0.23283 & - & - & 0.034969 & 0.01618 \\
\hline$\Delta l p v a r_{t-1}$ & - & - & - & 0.07502 & 0.01907 \\
\hline$\Delta \mathrm{lpb}_{\mathrm{t}-1}$ & 2.78450 & - & - & - & - \\
\hline$\Delta \operatorname{lptr}_{\mathrm{t}-1}$ & - & - & 0.00041 & - & 0.000215 \\
\hline$\Delta$ lpni $_{\mathrm{t}}$ & 0.03435 & - & - & - & - \\
\hline$\Delta \mathrm{lpph}_{\mathrm{t}}$ & 0.06371 & - & - & - & - \\
\hline$\Delta \mathrm{lppi}_{\mathrm{f}}$ & 0.09942 & - & - & - & - \\
\hline
\end{tabular}


Tabela 2A.2 - Valores dos coeficientes de correlação simples entre as variáveis da regressão no mercado de açúcar cristal ao produtor

\begin{tabular}{lccccccc}
\hline & $\Delta \mathrm{lppac}_{\mathrm{t}-1}$ & $\Delta \mathrm{lpaac}_{\mathrm{t}-\mathrm{l}}$ & $\Delta \mathrm{lppar}_{\mathrm{t}-1}$ & $\Delta \mathrm{lpni}_{\mathrm{t}}$ & $\Delta \mathrm{lpb}_{\mathrm{t}-1}$ & $\Delta \mathrm{lpph}_{\mathrm{t}}$ & $\Delta \mathrm{lppi}_{\mathrm{t}}$ \\
\hline$\Delta \mathrm{lppac}_{\mathrm{t}-1}$ & 0.393459 & 0.238247 & 0.158162 & -0.04824 & -0.00098 & 0.113189 & 0.11370 \\
$\Delta \mathrm{lpaac}_{\mathrm{t}-\mathrm{l}}$ & & 0.242056 & 0.16629 & -0.03997 & -0.00513 & 0.102850 & 0.056058 \\
$\Delta$ lppar $_{\mathrm{t}-1}$ & & & 0.162155 & -0.02490 & -0.000424 & 0.1248617 & 0.048239 \\
$\Delta \mathrm{lpni}_{\mathrm{t}}$ & & & 0.30804 & -0.008028 & 0.097490 & 0.07751 \\
$\Delta \mathrm{lpb}_{\mathrm{t}-1}$ & & & & 0.003492 & -0.00434 & -0.00448 \\
$\Delta \mathrm{lpph}_{\mathrm{t}}$ & & & & & 0.436892 & 0.259837 \\
$\Delta \mathrm{lppi}_{\mathrm{t}}$ & & & & & & 0.268129 \\
\hline
\end{tabular}

OBS: A matriz não foi completamente preenchida porque é simétrica.

Tabela 2A.3 - Valores dos coeficientes de correlação simples entre as variáveis da regressão no mercado de açúcar cristal ao atacado

\begin{tabular}{lccc}
\hline & $\Delta$ lpaac $_{\mathrm{t}-1}$ & $\Delta$ lppac $_{\mathrm{t}}$ & $\Delta \mathrm{lpvac}_{\mathrm{t}-1}$ \\
\hline$\Delta$ lpaac $_{\mathrm{t}-1}$ & 0.242056 & 0.055951 & 0.10895 \\
$\Delta$ lppac $_{\mathrm{t}}$ & & 0.398396 & 0.06556 \\
$\Delta$ lpvac $_{\mathrm{t}-1}$ & & 0.09477 \\
\hline
\end{tabular}

OBS: A matriz não foi completamente preenchida porque é simétrica.

Tabela 2A.4 - Valores dos coeficientes de correlação simples entre as variáveis da regressão no mercado de açúcar cristal ao varejo

\begin{tabular}{lccc}
\hline & $\Delta$ lpvac $_{\mathrm{t}-1}$ & $\Delta$ lpaac $_{\mathrm{t}}$ & $\Delta \mathrm{ptr}_{\mathrm{t}-1}$ \\
\hline$\Delta \operatorname{lpvac}_{\mathrm{t}-1}$ & 0.094779 & 0.089351 & 0.045009 \\
$\Delta \operatorname{lpaac}_{\mathrm{t}}$ & & 0.235900 & 0.079206 \\
$\Delta \operatorname{lptr}_{\mathrm{t}-1}$ & & & 1.959765 \\
\hline
\end{tabular}

OBS: A matriz não foi completamente preenchida porque é simétrica. 
Tabela 2A.5 - Valores dos coeficientes de correlação simples entre as variáveis da regressão no mercado de açúcar refinado ao produtor

\begin{tabular}{lccc}
\hline & $\Delta$ lppar $_{\mathrm{t}-1}$ & $\Delta$ lppac $_{\mathrm{t}}$ & $\Delta$ lpvar $_{\mathrm{t}-1}$ \\
\hline$\Delta$ lppar $_{\mathrm{t}-1}$ & 0.16215 & 0.072382 & 0.094069 \\
$\Delta \mathrm{lppac}_{\mathrm{t}}$ & & 0.398396 & 0.055035 \\
$\Delta$ lpvar $_{\mathrm{t}-1}$ & & & 0.077056 \\
\hline
\end{tabular}

OBS: A matriz não foi completamente preenchida porque é simétrica.

Tabela 2A.6 - Valores dos coeficientes de correlação simples entre as variáveis da regressão no mercado de açúcar refinado ao varejo

\begin{tabular}{lcccc}
\hline & $\Delta$ lpvar $_{\mathrm{t}-1}$ & $\Delta$ lppar $_{\mathrm{t}}$ & $\Delta \mathrm{lppar}_{\mathrm{t}-1}$ & $\Delta \mathrm{lptr}_{\mathrm{t}-1}$ \\
\hline$\Delta$ lpvar $_{\mathrm{t}-1}$ & 0.077056 & 0.062536 & 0.094069 & 0.042853 \\
$\Delta \operatorname{lppar}_{\mathrm{t}}$ & & 0.15681658 & 0.1098306 & 0.072917 \\
$\Delta \operatorname{lppar}_{\mathrm{t}-1}$ & & 0.162155 & 0.057474 \\
$\Delta \operatorname{lptr}_{\mathrm{t}-1}$ & & & 1.959765 \\
\hline
\end{tabular}

OBS: A matriz não foi completamente preenchida porque é simétrica. 
Tabela 2A.7 - Valores da variância dos coeficientes estimados das regressões no mercado de álcool combustível anidro e hidratado

\begin{tabular}{|c|c|c|c|c|}
\hline \multirow{2}{*}{$\begin{array}{l}\text { Variáveis } \\
\text { explicativas }\end{array}$} & \multicolumn{4}{|c|}{ Variáveis dependentes } \\
\hline & $\Delta \mathrm{lppi}$ & $\Delta$ lpvi & $\Delta \mathrm{lpph}$ & $\Delta \mathrm{lpvh}$ \\
\hline$\Delta \operatorname{lppac}_{t}$ & 0.019349 & - & 0.039439 & - \\
\hline$\Delta \operatorname{lppi}_{\mathrm{t}}$ & - & 0.004225 & 0.051133 & - \\
\hline$\Delta l p p i_{t-1}$ & 0.01721 & - & - & - \\
\hline$\Delta \operatorname{lpph}_{\mathrm{t}}$ & 0.01241 & - & - & 0.008748 \\
\hline$\Delta \operatorname{lpph}_{\mathrm{t}-1}$ & - & - & 0.094354 & - \\
\hline$\Delta l p v \dot{i}_{t-1}$ & 0.11976 & 0.031376 & - & - \\
\hline$\Delta \mathrm{lpvh}_{\mathrm{t}-1}$ & - & - & 0.127471 & 0.023374 \\
\hline$\Delta$ lppetro & - & 0.00295 & - & - \\
\hline
\end{tabular}

Tabela 2A.8 - Valores dos coeficientes de correlação simples entre as variáveis da regressão no mercado de álcool anidro ao produtor

\begin{tabular}{lcccc}
\hline & $\Delta \mathrm{lpph}_{\mathrm{t}}$ & $\Delta \mathrm{lppac}_{\mathrm{t}}$ & $\Delta \mathrm{lpvi}_{\mathrm{t}-\mathrm{I}}$ & $\Delta \mathrm{lppi}_{\mathrm{t}-1}$ \\
\hline$\Delta \mathrm{lpph}_{\mathrm{t}}$ & 0.515982 & 0.2684259 & 0.01873 & 0.058585 \\
$\Delta \mathrm{Jppac}_{\mathrm{t}}$ & 0.344203 & 0.020138 & 0.072180 \\
$\Delta \mathrm{lpvi}_{\mathrm{t}-\mathrm{I}}$ & & 0.034570 & 0.024233 \\
$\Delta \mathrm{lppi}_{\mathrm{t}-1}$ & & & 0.257940 \\
\hline
\end{tabular}

OBS: A matriz não foi completamente preenchida porque é simétrica. 
Tabela 2A.9 - Valores dos coeficientes de correlação simples entre as variáveis da regressão no mercado de álcool anidro ao varejo

\begin{tabular}{lccc}
\hline & $\Delta \mathrm{lppi}_{\mathrm{t}}$ & $\Delta \mathrm{lpvi}_{\mathrm{t}-1}$ & $\Delta \mathrm{lppetro}_{\mathrm{t}}$ \\
\hline$\Delta \mathrm{lppi}_{\mathrm{t}}$ & 0.345195 & 0.0169364 & 0.087310 \\
$\Delta \mathrm{lpvi}_{\mathrm{t}-1}$ & & 0.034570 & 0.0376754 \\
$\Delta \mathrm{lppetro}$ & & 0.4026506 \\
\hline
\end{tabular}

OBS: A matriz não foi completamente preenchida porque é simétrica.

Tabela 2A.10 - Valores dos coeficientes de correlação simples entre as variáveis da regressão no mercado de álcool hidratado ao produtor

\begin{tabular}{lcccc}
\hline & $\Delta \mathrm{lpph}_{\mathrm{t}-1}$ & $\Delta \mathrm{lppac}_{\mathrm{t}}$ & $\Delta \mathrm{lppi}_{\mathrm{t}}$ & $\Delta \mathrm{lpvh}_{\mathrm{t}-1}$ \\
\hline$\Delta \mathrm{lpph}_{\mathrm{t}-1}$ & 0.403147 & 0.153683 & 0.1711687 & 0.180186 \\
$\Delta \mathrm{lppac}_{\mathrm{t}}$ & & 0.2951114 & 0.1652582 & 0.049860 \\
$\Delta \mathrm{lppi}_{\mathrm{t}}$ & & 0.2838929 & 0.032223 \\
$\Delta \mathrm{lpvh}_{\mathrm{t}-1}$ & & & & 0.148517 \\
\hline
\end{tabular}

OBS: A matriz não foi completamente preenchida porque é simétrica.

Tabela 2A.11 - Valores dos coeficientes de correlação simples entre as variáveis da regressão no mercado de álcool hidratado ao varejo

\begin{tabular}{lcc}
\hline & $\Delta \operatorname{lpph}_{\mathrm{t}}$ & $\Delta \mathrm{lpvh}_{\mathrm{t}-1}$ \\
\hline$\Delta \operatorname{lpph}_{\mathrm{t}}$ & 0.478286 & 0.032598 \\
$\Delta \operatorname{lpvh}_{\mathrm{t}-1}$ & & 0.1485176 \\
\hline
\end{tabular}

OBS: A matriz não foi completamente preenchida porque é simétrica. 